Illinois State University

ISU ReD: Research and eData

Theses and Dissertations

10-11-2021

\title{
Perceptions of Masculinity and Femininity in Online Dating Profiles of Men: Intersections With Race
}

Luke Alexander Ploessl

Illinois State University, Iploess@ilstu.edu

Follow this and additional works at: https://ir.library.illinoisstate.edu/etd

\section{Recommended Citation}

Ploessl, Luke Alexander, "Perceptions of Masculinity and Femininity in Online Dating Profiles of Men: Intersections With Race" (2021). Theses and Dissertations. 1501.

https://ir.library.illinoisstate.edu/etd/1501

This Thesis is brought to you for free and open access by ISU ReD: Research and eData. It has been accepted for inclusion in Theses and Dissertations by an authorized administrator of ISU ReD: Research and eData. For more information, please contact ISUReD@ilstu.edu. 


\section{PERCEPTIONS OF MASCULINITY AND FEMININITY IN ONLINE DATING PROFILES \\ OF MEN: INTERSECTIONS WITH RACE}

\section{LUKE PLOESSL}

79 Pages

Many people currently find a dating partner online, which at many websites involves viewing the profiles of several users and deciding which to pursue. Considerable social scientific research has studied this new way of seeking dating partners. The purpose of this thesis study was to examine how people believe online dating site users would perceive a man on these sites based on the profile characteristics mentioned regarding femininity and masculinity in combination with a race-based filter (Black or white). These variables were manipulated within a Qualtrics survey with four vignette hypothetical profiles (a white man with a masculine profile, a Black man with a masculine profile, a white man with a feminine profile, and a Black man with a feminine profile). The participants were obtained from three major sources: students in certain sociology classes at a Midwestern public university who were offered extra credit to take the survey, a post made on my social media page, and MTurk, a survey sharing site through Amazon. Each participant was shown one profile at random and told to imagine that the profile they received was posted on a dating website and to answer the questions that followed by thinking of how both heterosexual women and gay men would perceive the profile (one at a time). A final section included questions to measure how the participants would respond to the target. I analyzed those data with multiple Independent t-tests, two ANOVA tests, and one repeated measures-mixed ANOVA. Participants perceived masculine targets as being more 
sexually attractive and as desired more for a short-term relationship than feminine targets, whereas the feminine target was perceived as having higher friendship attraction than the masculine target. The research also showed that the masculine and Black target was seen as more trustworthy, more likely to be contacted by the users, and more desirable for long-term relationships than the feminine and Black target, whereas the feminine and white target was perceived as more trustworthy, more likely to be contacted by the users, and more desirable for long-term relationships than the masculine and white target. This study will help us understand how people expect online dating site users would judge male users based on the male user's levels of femininity/masculinity co-constructed alongside race.

KEYWORDS: online dating, men, attraction, race, masculinity, femininity 


\section{PERCEPTIONS OF MASCULINITY AND FEMININITY IN ONLINE DATING PROFILES}

OF MEN: INTERSECTIONS WITH RACE

LUKE PLOESSL

A Thesis Submitted in Partial

Fulfillment of the Requirements

for the Degree of

\section{MASTER OF SCIENCE}

Department of Sociology \& Anthropology

ILLINOIS STATE UNIVERSITY

2021 
(C) 2021 Luke Ploessl 


\section{PERCEPTIONS OF MASCULINITY AND FEMININITY IN ONLINE DATING PROFILES OF MEN: INTERSECTIONS WITH RACE}

LUKE PLOESSL

COMMITTEE MEMBERS:

Susan Sprecher, Chair

Jason Whitesel

Chris Wellin 


\section{ACKNOWLEDGMENTS}

I thank Dr. Susan Sprecher for helping me find the direction my research ended up going in and for the many times she reviewed my entire thesis paper to help improve it. Dr. Susan Sprecher also helped me find many pieces of useful literature for this topic to use in my literature review and helped create my independent and dependent variables. Dr. Susan Sprecher suggested that I use Qualtrics to construct my survey and also reviewed my survey to make sure it was properly formatted, had relevant questions, and flowed properly. Dr. Susan Sprecher found MTurk, which resulted in over half of the total respondents my survey received. Dr. Susan Sprecher helped the coding of my final datasheet, as well as suggesting the kind of statistical analysis I should run. Dr. Susan Sprecher gave me guides on how to write multiple sections of my thesis while also providing multiple different examples of previously written section of similar research paper (i.e., Results sections, Discussion sections, etc.). Dr. Jason Whitesel reviewed a previous version of my thesis and gave helpful insight on how to properly cite resources as well as giving helpful feedback on editing the paper to make sure only relevant information was used. I would also like to thank Dr. Jason Whitesel for his notes on my assessment of prior literature that immensely helped to improve my critical thinking and analysis of the material. This advice not only helped improve my literature review, but his notes also greatly improved my analysis of the data I collected. I would like to specifically thank Dr. Susan Sprecher, Dr. Jason Whitesel, and Dr. Chris Wellin for being members of my committee, for always being there to support me and expand my critical thinking, and all of the advice they gave me during my thesis proposal and editing suggestions that helped me create my final paper.

L. P. 


\section{CONTENTS}

Page

ACKNOWLEDGMENTS

CHAPTER I: INTRODUCTION 1

Online Dating for the LGBT+ Community 2

Studies of Online Dating $\quad 2$

Race and Masculinity/Femininity 3

$\begin{array}{ll}\text { Online Dating Attractiveness } & 6\end{array}$

Past Research Manipulating the Masculinity/Femininity of a Target Person $\quad 10$

Aims of My Thesis $\quad 12$

Research Questions 13

$\begin{array}{ll}\text { CHAPTER II: METHOD } & 15\end{array}$

$\begin{array}{ll}\text { Sample } & 15\end{array}$

Design and Procedure 16

$\begin{array}{ll}\text { Independent Variables } & 17\end{array}$

$\begin{array}{ll}\text { Dependent Variables } & 18\end{array}$

Manipulation checks of masculinity and femininity 19

Expectations of users' attraction to the target 20

Participants' ratings of friendship and attraction to the target 21

Open-ended reactions to the sections 22 
Overall Responses

Ratings of target characteristics

Independent $\mathrm{T}$ Tests Comparing Reactions to a White Target Versus a Black Target

Independent $\mathrm{T}$ Test Comparing the Masculine Versus the Feminine Target

Ratings of target characteristics

Expectations of users' attraction

Views of Gay Men versus Heterosexual Women

The Moderating Role of the Race of Target in Effects of Masculinity/Femininity of Target on Dependent Variables

Repeated Measures Analysis Assessing All of the Variables on a Composite Score on

Attraction

Open-ended Questions 
Strengths and Limitations of the Study

Future Directions of Research

General Conclusion

WORKS CITED

APPENDIX A: TABLES 


\section{CHAPTER I: INTRODUCTION}

Online dating has become commonplace in the modern world. Many people who say that they are dating currently or were in the recent past have used the internet to facilitate the formation of their relationship (Rosenfeld, Thomas, and Hausen 2019). While the exact history of online dating is not directly recorded, commercial matchmaking services appeared in the 1950s, which was almost as soon as computers started appearing (Sprecher, Schwartz, Harvey, and Hatfield 2008). As more and more relationships began to develop through the use of computer technology, so too did the commercial interest in online dating (Finkel, Eastwick, Karney, Reis, and Sprecher 2012). In the 1970s, businesses started to directly invest in computer match making, and as computers became smaller and cheaper, the public's access to online dating became more widespread (Finkel et al. 2012). Online dating sites, such as eHarmony.com and Chemistry.com, offered "matching assistance" where online users would fill out questionnaires so that the dating service could match them with other users who gave similar answers on their questionnaires (Sprecher et al. 2008). Online dating has grown into a diverse billion-dollar industry that has incredibly strong roots all around the world (Finkel et al. 2012). However, as online line dating has grown in prevalence, it has become more important to research how people interact within it and perceive it.

In this study, I examine how people perceive a hypothetical man who uses online dating sites based on this fictious user's perceived masculinity/femininity in combination with their race. Next, I provide a background to my study by reviewing literature on LGBT+ online dating, race, masculinity/femininity, and attraction in online dating. After this general literature review, I focus on the study done by Chappetta and Barth (2016), which involved manipulating the profile pictures and the wording in online dating profiles to examine how that would affect the 
participants' attraction to the target in the profile and explain how I built on their study for my research.

\section{Online Dating for the LGBT+ Community}

Online dating has a special purpose for the LGBT+ community, especially among gay men (Campbell 2014; Rosenfeld, Thomas, and Hausen 2019). In the past, it has been difficult for gay men to connect with one another as a very small percentage of people in the United States openly identify as gay, but with the aid of online resources, gay men are able to connect with and even date others (Jones 2021). The online setting has provided an alternative form of meeting to the gay bar (Branchik 2002). Gay bars used to represent one of the safest and most acceptable social environments for gay men to find romantic or sexual connection with other men (Branchik 2002). However, as technology changed, so too did gay men's ability to interact with and seek other gay men (Campbell 2014). While the prominence of LGBT+ people in online dating is historically important, the study of online dating is still growing.

\section{Studies of Online Dating}

Online dating has been studied in many ways, including the demographics of who uses online dating (Fiore et al. 2008; Ellison, Heino, and Gibbs 2006), attitudes about online dating (Anderson 2005; Darden and Koski 1988), what traits are emphasized in profiles for different groups (such as men and women) (Leonhardt 2006; Mathews 1965), and attractiveness and attitudes in dating (Hitsch et al. 2010). There have also been several studies focused on how people react to others in online dating sites, using hypothetical dating profiles (Anderson et al. 2014; Brand, Bonatsos, D’Orazio, and DeShong 2012; Chappetta and Barth 2016), and it is this research that I extend. That is, in this line of research, researchers have conducted experimental 
studies and created hypothetical dating profiles, randomly assigned participants to different versions, and then examined how the manipulations affected perceptions of and reactions to the target person (e.g., on attractiveness, desire to date). In these studies, a variety of variables have been manipulated, ranging from the physical attractiveness of the target person in the profile (Chappetta and Barth 2016; McGloin and Denes 2018) to the dominance and trustworthiness conveyed in faces (Doll et al. 2014; Fiore et al. 2008). When studying online dating, an important aspect to examine is how online dating is affected by an individual's race and masculinity/femininity; however, past research on these variables has been very limited.

\section{Race and Masculinity/Femininity}

Perceptions that gay men who use online dating resources have of other gay men online seem to be subject to forms of hegemonic masculinity. Hegemonic masculinity is a macro-level social perception that helps to inform the way people treat others based on said persons' perceived gender norm portrayal (Rodriguez, Huemmer, and Blumell 2016). Essentially, hegemonic masculinity can lead to gay men perceiving other gay men as having more, or less, value based on their levels of masculinity or femininity, usually with more masculine gay men having more value and feminine men having less (Rodriguez, Huemmer, and Blumell 2016). Furthermore, these perceived levels of femininity/masculinity can also affect how well gay men treat each other. Gay men who are feminine or do not appear to follow any gender roles are labeled as an "abject other" (Hale and Ojeda 2018:310). It is also important to mention that, according to past literature, "men show greater sexual desire than do women" (Peplau 2003:37). Thus, it would stand to reason that there exists a social stereotype that some gay men would want to interact with other men in online dating spaces with the intention of having sex more than 
obtaining a long-term relationship (Matsick et al. 2021; Peplau 2003). Though gay men have important relevance in online dating research, it is more important to my research to cover how race affects how people use online dating.

One factor that has not been very widely manipulated in studies presenting online dating profiles created by the researchers (to my knowledge) is the race of the target person in the profile. However, as online dating has become more prevalent, racial stereotyping may also be found in interactions in online dating and in reactions to online dating profiles (Alhabash et al. 2014). Racial stereotyping, which is defined as representation of a group of a certain ethnicity or race in a generalized manner and portraying all members to display certain typical characteristics, is commonplace in the United States (Alhabash et al. 2014). Therefore, it would follow that such stereotyping may occur in online dating (Alhabash et al. 2014; Farley 1997). Race is most certainly an important factor in online dating, and for men of color, it manifests in encountering negative preconceived notions about them held by whites. For example, Black men are stereotyped to be extremely masculine in the United States whereas Asian men are stereotyped as being more feminine when compared to white and Black men (Ferber 2007; Wade and Harper 2020). The stereotype about Black male masculinity in the United States is exemplified by the beliefs that Black men are viewed as hypermasculine and hypersexual "bucks" in need of taming due to white supremacy present in United States culture (Ferber 2007). This "sexual racism," also known as "Racialized Sexual Discrimination," is a phenomenon that has played a part in online dating for men of color (Wade and Harper 2020). The idea that Black men are phallicized bucks has existed in the United States since the Colonial Era, being normalized when Ronald Reagan told stories about working-class whites being upset 
by the "strapping young buck" buying T-bone steaks with food stamps during his 1976 presidential campaign to further normalize the idea of deviant hypermasculinity among freeloading Black men framed as “deadbeat dads" (Clayton, Moore, and Sharon 2021:392).

However, there appears to be an inconsistency here when it comes to the relationship between race and gender expression, as white men can appear as masculine or feminine without being stereotyped into either role as they hold more "erotic capital" (Daroya 2018). This phrase, sexual/erotic capital, originates from studies of racism within communities of gay men "to disrupt the narratives of homogeneity and veiled unity among gay white men" and to show white privilege in the LGBT+ community, essentially exposing the inherent racial structures behind many gay male interactions (Winder 2020:1029). The phrase "erotic capital" in this case refers to the idea that being white is worth more in a socio-sexual environment than being another race, most likely due to the social prestige that goes along with being white in United States society as well as the "role versatility" that is allowed to white people (Riggs 2018). The discrepancy in erotic capital and gender maneuverability between white people and most other races based on nothing more than race demonstrates a racial inequality in the way people can express femininity and masculinity in the sexual marketplace while online dating. I will now discuss a variable that has been examined in online dating that can affect first impressions - attractiveness. Although my study will not manipulate physical appearance, I will consider the role of the perception of attractiveness of the online dating profile. I will then examine whether determinants of attractiveness are tied to race and masculinity/femininity, the two variables I do manipulate. 


\section{Online Dating Attractiveness}

Attractiveness in online dating can come in many forms, including physical attractiveness, sexual attractiveness, and even seeing someone as trustworthy (Brand et al. 2012; Chopik and Johnson 2021; Kranz, Pröbstle, and Evidis 2017; McGloin and Denes 2018). A way to view attractiveness in online dating sites is through the "halo effect" of physical attractiveness, which essentially means that the more physically attractive a person is, the more positive characteristics and opinions are attributed to that person regardless of what that person may actually be like (Zebrowitz and Montepare 2008). Perceived physical attractiveness of men in online dating plays a large role in both their likelihood of being contacted and the traits attributed to them. Men who are seen as traditionally attractive are often viewed as also having "other attractive qualities" to their personalities even if there is no evidence of this in the man's profile (Brand et al. 2012:166). Essentially, attractive men are at first glance seen as having more desirable personalities, hobbies, and activities, when compared to unattractive men, regardless of any information present in their profiles (Brand et al. 2012). Physical attractiveness also acts as a strong influence on behavior in online dating in that it directly affects whether or not an online dating site user would be willing to be romantic with another person (Eastwick, Eagly, Finkel, and Johnson 2011).

However, when studying online dating attractiveness, it is important to look for studies that research how attractiveness is affected by the demographic information present in dating profiles. One study done by Fiore (2008) researched how demographic information affects attractiveness in online dating. Sixty-five participants were asked to rate on a five-point Likert scale 65 male and female profiles on these dimensions: attractiveness, masculinity, femininity, 
warmth, kindness, self-esteem, extraversion, and self-centeredness. The researchers manipulated these previously mentioned dimensions through the vignette profiles' demographic section, indepth section, and profile picture and included language that indicated how much the dimensions were indicated. The researchers found that when rating the whole profile, which included the information about the person in the profile as well as the profile picture, participants who rated the male profiles high in masculinity also rated the profile as being higher in overall attractiveness. However, male profiles that had a profile picture that was perceived as being feminine were rated as more attractive than profiles with profile pictures that were perceived as masculine. This contradiction essentially means that when a profile had only a photo and no text or demographic information, it was rated as more attractive when the photo was perceived as feminine. However, when a profile had a photo-and-text demographic information, it was rated as more attractive if the whole profile was perceived as masculine (Fiore et al. 2008). This study suggests that traditional gender roles of a person in an online dating profile may not be as important as they once were, as the participants attraction to the profiles was different based on the inclusion of a text demographic information. If adherence to traditional gender roles was still as important as in the past, then it likely would not have mattered if the text demographic information was included or not. The existence of this contradiction could open the idea that perhaps people could find online individuals more attractive the less they adhere to gender role stereotypes.

Demographic information in attractiveness research does not end there, as a study was conducted by Chopik and Johnson (2021) where they studied demographic information and personality traits in dating profiles. Chopik and Johnson (2021) manipulated the pictures used for 
their profiles with the Big Five-Inventory portrayed by Tinder users on their small bio with photo, alongside the attractiveness (re: how the researcher varied the attractiveness of the photo) and race of the target. Chopik and Johnson (2021) predicted how attractive the target was viewed by research participants when the participants made swiping decisions (swipe right = interest or left $=$ disinterest $)$. The two studies they conducted used images of faces for the target profiles to create hypothetical profiles, each selected to roughly match the age range of targets that students would pursue; the researchers ended up with a sample of 127 White faces (53\% women), 113 Black faces (54\% women), 74 Hispanic faces (61\% women), and 81 Asian faces (54\% women). The race of the photographs was not manipulated as the participants were all shown random profiles. Participants were told they would complete a task in which they would see photos of people of the opposite sex and decide whether they would like to start a conversation with that person that might lead to a date. Participants were then told to complete a task similar to actually using the dating app Tinder to choose potential targets they would like to talk to and to make their decisions quickly and based on their first impressions. The photos shown to the participants were randomized, as each participant was shown one face, and the face remained on screen until the participant expressed whether they liked or did not like the photo.

The results of the studies were that the male targets were rated as less attractive than female targets in both study 1a and study 1 b. Furthermore, participants were 4.8 times more likely to swipe right on attractive targets in Study 1a and 4.4 times more likely to swipe right on attractive targets in Study 1b regardless of the differences in potential demographic information in the target. Lastly, participants were 2.7 times more likely to choose targets who were the same race as them in Study 1a, and 1.8 times more likely to choose targets that were the same race as 
them in Study 1b. Participants, $72 \%$ of which were white, were less likely to swipe right for targets who were Black, Asian, and Hispanic than targets who were white. In study 1b, specifically, participants were far less likely to swipe right on Black targets than white targets. Participants were 2.3 times less likely to swipe right on Black versus White targets in Study 1a and 2.5 times less likely to swipe right on Black versus White targets in Study 1b. Therefore, even though Study 1a seems to be an outlier for participant swiping, the other studies in this research indicate that the participants were more likely to swipe right on same race targets than they were on targets of a different race. Chopik and Johnson's (2021) study is relevant to my research because it provides examples of attraction through similarity, and the potential bias it creates, even though it includes the study of how people respond to faces and my study does not study faces.

To continue the literature on race's influence in online dating, research conducted by Anderson, Goel, Huber, Malhotra, and Watts (2014) showed that most people are seeking samerace partners when using online dating sites. They conducted their research by reviewing the user activity logs of online dating site users to see how they spent their time and what they found preferable. They found that the users had a general preference for people in online dating sites who were similar to them, which meant that white people would often prefer other white people, Black people would often prefer other Black people, and so on. The idea that online dating site users would expect to be more likely to prefer people who are similar to them indicates that there is a likelihood that online dating site users would rate profiles with people of the same race as the user as more attractive than profiles with users of other races (Anderson et al. 2014). 
Now that I have summarized literatures that have relevance to my thesis study, I will discuss in more detail the past research that has most influenced my research.

\section{Past Research Manipulating the Masculinity/Femininity of a Target Person}

Although there were several studies cited above that referred to the researchers manipulating an aspect of the femininity/masculinity of the profile (Chappetta and Barth 2016; McGloin and Denes 2018) here I will cover one study and describe it in more detail. In ways that I will outline later, my thesis study extends this prior study. Chappetta and Barth (2016) examined the effects of gender role congruence and the physical attractiveness of a target in a hypothetical dating profile on the romantic interest expressed by college students toward that target. Their study presented participants with hypothetical profiles that varied in the physical attractiveness of the photo in the profile and in the adherence to gender role norms (e.g., by including masculine and feminine wording in the profile information and male and female profile pictures) and examined how these manipulated variables affected how the participants labeled how attractive they found the target (Chappetta and Barth 2016). Chappetta and Barth used 64 pictures of men and women that had previously been rated by 1000 people as either highly attractive or average in looks and they created four masculine profiles and four feminine profiles in total. Chappetta and Barth operationalized the masculinity and femininity of the targets by manipulating the content in the following sections of the profile: occupation, "about me" (a short paragraph to describe themselves), hobbies, "a typical Friday night for me," and “what I'm looking for in a partner" (Chappetta and Barth 2016). To create a profile that was gender congruent or incongruent, they manipulated the masculinity and femininity of the profile, which is especially relevant to my study. More specifically, a target presented as feminine was 
described with words like affectionate, intuitive, and kind in the profile information. A target presented as masculine had a profile that had masculine words like ambitious, analytical, and competitive in the profile information. Gender congruence versus gender incongruence came into play when a profile of a man was given feminine profile information and a profile of a woman was given masculine profile information. Thus, their design was $2 \times 2$ (participant gender: male/female x profile gender role: congruent/incongruent).

After the participants viewed the profile, they were asked to rate the target on several dimensions including general likeability (how friendly and knowledgeable the target is) and desirability as a dating partner (how attractive the target is and how much the participant would want to date the target). Each participant was shown four random profiles out of the total pool of eight: one with gender role congruence and high physical attractiveness, one with gender role congruence and average physical attractiveness, one with gender role incongruence and high physical attractiveness, and one with gender role incongruence and average physical attractiveness. Multiple hypothetical profiles were created, and the participants initially filled out a demographic questionnaire that would determine which kind of profiles they would see. For example, if a straight man were to fill out the demographic section, he would only see profiles of women. Chappetta and Barth found that the participants liked the profiles that included attractive profile pictures and incongruent gender norms more than profiles that included average profile pictures and congruent gender norms. Both men and women participants came to this conclusion, which is somewhat inconsistent with some previous literature for women. Essentially, Chappetta and Barth found that not only did men and women want their potential partners to be physically attractive, but if the partner not following traditional gender roles also made them more 
attractive. This conclusion would align with the data gathered from Fiore's (2008) study and would further lead me to believe that people are less concerned with gender role congruence when they find someone in an online dating attractive.

The gap in their research as it relates to my thesis study topic, however, is that they did not manipulate the race of the target in the vignette profile. Future research could benefit from how race intersects with information on masculinity/femininity in a dating profile. The Chappetta and Barth (2016) method will inform and guide my research, but my interest is in the effects of the masculinity/femininity of only one gender (men), and how the gender congruence (being presented as masculine in a dating profile) or gender incongruence (being presented as feminine in a dating profile) affects how men are perceived, and whether their race moderates this effect. Although Chappetta and Barth examined physical attractiveness, I will not manipulate physical attractiveness in my research. The purposes of my thesis study will be discussed further in the next section.

\section{Aims of My Thesis}

Research examining how people respond to a dating profile using the experimental method is not as advanced as other forms of sociological research. My thesis study will contribute to this new area of research and directly extend the Chappetta and Barth (2016) study by examining the intersection between femininity/masculinity and race of a target in a profile influencing how the target is perceived in regard to romantic desirability. Therefore, for my thesis, I propose to extend the Chappetta and Barth (2016) study by adapting their procedure for manipulating masculinity/femininity of a dating profile but extending their research by also manipulating the race of the target. This thesis study will explore how people believe online 
dating site users would judge male users based on the femininity/masculinity and race of the target in the profile. My research will use only male targets in dating profiles, as there is research suggesting that gender nonconformity can have greater effects on how men (vs. women) are perceived (Rodriguez, Huemmer, and Blumell 2016). My research will be studying how participants perceive a target's sexual and physical attraction, likelihood of being contacted, trustworthiness, short-term relationship desirability versus long-term relationship desirability, and other research participants' reactions based on the vignette profile's depictions of masculine/feminine characteristics (in combination with the profile's information on race). The profile characteristics included information on occupation and interests, and the exact content was manipulated and changed to include words and interests that are either traditionally masculine or traditionally feminine, adapted from the work of Chappetta and Barth (2016).

\section{Research Questions}

Below are my research questions, which are influenced by the literature review summarized above.

- What effect will the masculinity/femininity of the target in the profile have on the attraction (sexual attraction, desire for friendship, etc.) the participants expect users to express toward the target?

- In what ways will the race of the target moderate (i.e., interact with) the effect of the masculinity/femininity of the target on how participants will rate how users express attraction toward the target? 
- In addressing the above issues, will there be differences between how participants believe that the hypothetical profile will be viewed from the perspective of gay men versus heterosexual women?

- Will the participants be similarly as attracted to the profiles as they think the gay men and heterosexual women will be? 


\section{CHAPTER II: METHOD}

\section{Sample}

The sample consisted of adults of any race, gender and sexual orientation obtained in three ways. First, an extra credit option was given to students in one sociology class at a Midwestern public university, with the permission of the instructor, to complete the online survey. Second, the study was offered to the students of two other sociology classes at a Midwestern public university. Third, the study was posted on my social media page, which led to a snowball sample. Fourth, the study was posted on MTurk, a survey sharing site through Amazon, where participants were paid one dollar to participate in the survey. According to previous studies conducted on the quality of data collected through MTurk, the data are of good quality and at least as reliable as data obtained through traditional means, so long as proper attention checks are used when collecting that data (Buhrmester, Kwang, and Gosling 2016; Zhang and Gearhart 2020). Originally, 131 participants started the survey, but some did not complete it and thus those cases were eliminated. In total, 119 completed the survey, with $31.9 \%$ coming from a one particular sociology class at Illinois State University, 3.4\% coming from other classes at ISU, $5.9 \%$ coming from the link on my social media page, and $58.8 \%$ coming from MTurk. However, out of all of the MTurk participants, 2 participants missed the first attention check questions and 7 missed both attention check questions, which means that their data were eliminated. The mean age of the participants was $29.76(S D=9.19)$, with the mean age for the student participants being 23.57 and the mean age for MTurk participants being 33.54. Of the total sample, $79.8 \%$ were white participants, 9.2\% were African American or Black participants, 5\% were Latino/a/x participants, 3.4\% were Asian or Asian American participants, 
and $2.5 \%$ participants did not provide their race/ethnicity. For the gender of the participants, $72.3 \%$ were men, $23.5 \%$ were women, $3.4 \%$ were nonbinary, and $0.8 \%$ did not provide their preferred gender identity. For sexual orientation of the participants, $83.2 \%$ were heterosexual, $0.8 \%$ were gay, $10.9 \%$ were lesbian, $1.7 \%$ were bisexual, $0.8 \%$ was pansexual, $0.8 \%$ was asexual, and $1.7 \%$ did not provide their sexual orientation.

\section{Design and Procedure}

I created a vignette experiment embedded in a Qualtrics survey (Brand et al. 2012). It was a between-subject design, meaning that each participant received a different vignette and then I compare the participants in the different conditions. There were four vignette profiles in total: a white man with a masculine profile, a Black man with a masculine profile, a white man with a feminine profile, and a Black man with a feminine profile. The survey participant was initially told to imagine that the profile they received (within their Qualtrics survey) was posted on a dating website and to answer the questions that followed in the third person and by thinking of how others would perceive the profile and not how they as an individual would perceive it. It was stated in the survey that the man in the target profile will be in the age range that the people viewing said profile would be attracted to. This procedure was used to increase the sample size (it would be challenging to limit the study to only gay men, for example). However, there was also a final section of questions that measured how the participants themselves would react to the profile if they found the profile on a "Friend-finder site" and still a smaller set in this section that asked the specific group who are attracted to men to indicate how attracted they would be to the hypothetical profile. For this research, race was a moderator variable to help focus on how people interpret the level of attraction they feel towards a masculine or feminine profile. By this, 
I mean that I measured how attractive they thought users would view the masculine profile of a Black man versus how attractive they thought users would view the masculine profile of a white man even though the only difference between the two profiles was the race category. I did the same with feminine profile for each race as well.

\section{Independent Variables}

A 2 x 2 research design within a Qualtrics survey was used for this study. The first independent variable was race; the race of the man in the profile was either Black or white. The vignette profile was made to have the race description (in text; no photo) of the target near the top of the vignette, just below the name given (See Appendix B). The second independent variable was the degree to which the profile had feminine or masculine characteristics. The profile characteristics listed were occupations, "things I can't live without", "about me" sections or a short paragraph to describe the hypothetical user, their hobbies and activities, including a "typical Friday night" (See Appendix B). Some of the demographic information in each of the profiles was modified from Chappetta and Barth's (2016) vignette profiles to apply to my research.

Through the information presented in the profile, masculinity versus femininity was manipulated based on an approach adapted from Chappetta and Barth's (2016) research. The occupation presented was either traditionally masculine (engineering and business) or traditionally feminine (arts and nursing). In addition, the "about me" section had either masculine (ambitious and competitive) or feminine (intuitive and kind) characteristics; hobbies were presented to be either traditionally masculine (video games and sports) or traditionally feminine (cooking and shopping). Typical Friday night activities were described as either 
masculine (gaming and going to bars) or feminine (reading books and spending time with friends) characteristics. Finally, six things the target cannot live without included five neutral items but then either one traditionally masculine item (lifting weights) or one traditionally feminine item (crocheting). All of the characteristics were directly inspired from Chappetta and Barth's study, although the section on things they can't live without (with a masculine or feminine item included) were unique to this study.

\section{Dependent Variables}

I had several dependent variables that assessed how the participants believed that the target would be perceived by a user interacting with the dating website, with the choice of some of these items inspired by the research of Chappetta and Barth (2016) and other studies that have manipulated an online dating profile (e.g., Kogan and Volsche 2020). For example, Chappetta and Barth asked the participants about the likeability and physical attractiveness of their target. They measured these variables by having statements in their survey like "This person is friendly" and "This person is knowledgeable" and providing 7-point scales, where $1=$ very strongly disagree, 4 = neither agree nor disagree, and 7 = very strongly agree. In my survey, after the participants viewed their randomly assigned vignette profile, they were asked to complete several items from the perspective of a user at the dating site. Participants in my research were asked to respond to the items twice, from both the perspective of gay men and the perspective of heterosexual women, with some of the items in this section serving as a manipulation check on the effective manipulation of masculinity vs. femininity in the profile. After responding from the viewpoint of gay men and heterosexual women (order randomly assigned), there was a final section in which participants were asked how they would respond to the profile if they found it 
on an online site for friendship. Furthermore, each question section had a part in the instructions that informed the participants that they could go back and view the profile again if need be. Below, I describe the dependent variables in more detail.

\section{Manipulation checks of masculinity and femininity}

The participants were presented with a list of six traits and asked to rate how each group of users (heterosexual women and gay men) would respond to the target on the traits, with a response scale that ranges from $1=$ does not describe them at all; to $7=$ definitely describes them. The traits are "strong personality," "masculine," "dominant," "acts as a leader," "affectionate," "warm," "gentle," and "feminine." These traits are based on the Bem (2020) Sex

Role Inventory taken from a previous study done by Kogan and Volsche (2020). However, it should be mentioned that the Bem Sex Role Inventory has been criticized in the past by researchers such as Janet Spence (1984), who mentioned that the existence of male and female specific categories implies that the existence of roles that are gendered-based is achievable and appropriate for society. Sex-roles and other gender-related phenomena are infinitely more complex than the Bem Sex Role Inventory could ever cover because it ignores things like androgynous individuals (Spence 1984), despite Bem herself being a staunch proponent of the psychological benefits of androgyny, interested in those who expressed both feminine and masculine characteristics on her sex-role inventory. Some of the items from the inventory are being used in this research only as manipulation checks to assure that the participants viewed the profile as it was intended (i.e., masculine or feminine). 


\section{Expectations of users' attraction to the target}

Then, the participants answered a set of questions in regard to how attractive the users would find the target to be. The specific items are discussed below.

For the two sections on how heterosexual women and gay men would respond to the hypothetical target, the participants were asked "How likely would users be to reach out and contact the person portrayed in the profile? This question was followed by a 5-point response scale ranging from $1=$ not at all likely; to $5=$ extremely likely. The participants were then asked "Overall, how attractive do you think users at this site would find this man?" This question was followed by a 5-point response scale ranging from $1=$ not at all; to $5=$ extremely.

After that, the participants were asked several questions about how they believe typical users (in both categories - gay men and heterosexual women) will evaluate the target person's desirability. They were asked questions about how likely the users will want to be friends with the man, will see the man as sexually attractive, and will view the person as trustworthy. Each item was rated on a 5-point response scale ranging from $1=$ not at all agree; to $5=$ agree a great deal. The purpose of this question structure was for convenience for the participants.

The participants were asked the following two questions to assess how they view the likelihood of a short-term and/or long-term relationship. The questions were "How attractive do you believe such users would find the person in the profile to be for a short-term relationship (such as for a hookup or short fling, something that would not last very long)?" and "How attractive do you believe such users would find the person in the profile to be for a long-term relationship (such as for a committed relationship or even marriage)?”. These questions were followed by a 5-point response scale ranging from $1=$ not at all; to $5=$ a great deal . 


\section{Participants' ratings of friendship and attraction to the target}

A final section of questions was included to ask the participants how they would respond to the target. Because I cannot assume any sexual orientation of the participants, this section of questions primarily focusses on how they would rate the friendship desirability of the target, with the option to complete a few additional questions about their romantic attraction to the target, if they are attracted to men. To help measure how receptive the participants would be to being friends with the person in the profile, they were asked "Would you like to be friends with the person portrayed in the profile?" and then "How likely would you be to reach out and contact the person portrayed in the profile for a friendship?" Both of these questions were followed by a 5point response scale ranging from $1=$ not at all likely; to $5=$ extremely likely. After those two questions, the participants were asked "How much do you think this person would make a good friend?" which is followed by a 5-point response scale ranging from $1=$ not at all; to $5=$ extremely.

The next section was offered to the participants if they have the predisposition to be attracted to men. They were asked "The next section of questions requires you, the participant, to have the predisposition to be attracted to men. If you can be attracted to men, select yes and you will see the next set of questions. If not, select no" and is offered a Yes and No response scale. If the participant answered Yes they were shown the attraction questions, but if they answered No they are only shown the final question that asks them about their final responses to the survey. The next five questions were the same questions that they answered previously in regard to the reactions of heterosexual women and gay men to the target, but now aimed directly at the participants. The first question of the attraction section was "How likely would you be to agree 
to meet this man for a first meeting if he reached out to you?" This question was followed by a 5point response scale ranging from $1=$ not at all likely; to $5=$ extremely likely. The next question was "Overall, how attractive do you find this man?". This question was followed by a 5-point response scale ranging from $1=$ not at all; to $5=$ a great deal .

Then the participants were presented with the statement "The statements below are in regard to the profile you just saw. Respond to each item with the degree to which you would agree or disagree with the statements." The participants were asked to rate how sexually attractive and trustworthy they see the person in the profile. Each item was rated on a 5-point response scale ranging from $1=$ not at all agree; to $5=$ agree a great deal. The participants were then asked, "Would you want a short-term relationship (such as for a hookup or short fling, something that would not last very long) with the person in this profile?", and "Would you want a long-term relationship (such as for a committed relationship or even marriage) with the person in this profile?". Both of these questions were followed by a 5-point response scale ranging from $1=$ not at all; to $5=$ a great deal.

\section{Open-ended reactions to the sections}

For the final question at the end of each section of questions, the participants were asked about why the targeted group of that section had the reactions they had. Therefore, for the heterosexual women section, the participants were asked why heterosexual women had their reactions to the profile and for the gay men section the participants were asked why gay men had their reactions to the profile. This question at the end of each section read as follows; "If heterosexual women at the site were to be asked why they have the reactions above, what do you think they would say?", "If gay men at the site were to be asked why they have the reactions 
above, what do you think they would say?", and "If you were asked why you had the reactions above to the person in the online profile, what would you say?". Each of these questions had a text entry box for the participants to write in their own answers here. The final question in the survey was "What else, if anything, would you like to add about you experience taking this survey?" and had a text entry box so the participant could add any other thoughts they have about the survey.

\section{MTurk survey}

The survey released to the participants found on MTurk is almost identical to the survey described above except for the addition of attention checks. These attention checks were questions that were clear enough to be understood and had two matrix questions that asked for a specific answer to this part of the matrix question. The first attention check was a part of the first matrix question in the gay men question section of questions and the second attention check was in the matrix question in the participant opinion question section. If the participant chose the correct answer option, it showed they were giving informed answers to the survey questions. They were used to make sure that the people being paid to take this survey were actually paying attention to the questions being asked. 


\section{CHAPTER III: RESULTS}

This section will present the results of the statistical analyses performed for this study. I will first consider composite means obtained by combining the responses to each item referring to how the participants believed gay men would respond to the target with responses to the same item referring to how participants believed that heterosexual women would respond. Therefore, this information presents how the participants responded overall to each item, collapsing across conditions. I then examine the participants' responses as a function of the race of the target while ignoring the masculinity/femininity of the target. Then, I consider how the participants responded to a feminine target versus a masculine target (ignoring the race of the target). Next, I examine the differences in how the participants believed gay men would view the target versus how they believed heterosexual women would view the target. Thus, I engage in a piecemeal approach - by examining each independent variable one at a time - to fully examine the effects

of the variables on the outcome variables. These analyses are conducted with Independent t-tests (to examine the effects of the between-subject variables, masculinity/femininity and race) and with Paired samples t-tests (to examine the effects of the within-subjects variable, perspective of gay men versus heterosexual women).

Then, I move up to analyses that consider multiple independent variables. First, I conduct 2 (masculinity vs. femininity of target) x 2 (race of target) ANOVAs. This analysis allows me to examine in particular any interactions that may have occurred between the race of the target and the masculinity/femininity of the target, for the dependent variables. In a final analysis, I focus on overall perceived attraction to the target (with a composite score) and conduct a repeated measures-mixed ANOVA, which allows me to examine all three independent variables in one 
analysis - the between-subjects variables of masculinity/femininity and race and the withinsubjects variable of perspective (gay men vs. heterosexual women). See Appendix A for tables.

In the presentation of the results below, I have divided the dependent variables into two main groups for presentation in the tables. The first group of items consisted of the ratings of target's characteristics (assumed from the user's perspective). This group contained the dependent variables that referred to how the participants believed gay men and heterosexual women would perceive the target's personality on several characteristics. The second group consisted of the items that asked about how much participants assumed that users would be attracted to the target.

In a final section I cover some general themes found in the responses of the participants to the prompts they were given at the end of each section of questions.

\section{Overall Responses}

First, and as noted above, I present the overall responses of the participants to the items, without consideration of the effects of the independent variables. For each item, I created a composite based on the mean of participants' responses to how they believed that gay men would respond to the item (in regard to the target) and their responses to how they believed that heterosexual women would respond to the item. Table A-1 presents these overall means (collapsed over conditions), along with their standard deviations.

\section{Ratings of target characteristics}

As can be seen in the top portion of Table A-1, most of the items had a composite mean score above the midpoint of the items. Thus, overall, the participants assumed that the users 
would attribute these characteristics to the target. The specific items that had the highest means were strong personality, warm, and gentle. The specific items that had the lowest means in this section were feminine and dominant, with feminine having the lowest mean of 3 . These results indicate that the participants believed that almost every characteristic applied at least somewhat

to a great deal to the target except for being feminine, collapsing over the conditions. Later, I will discuss how the perceptions of the target's femininity and dominance (and the other characteristics) depend on the condition.

\section{Expectations of users' attraction}

As can be seen in the bottom portion of Table A-1, most of the items referring to expected user attraction to the target had composite mean scores above the midpoint of the items. Thus, overall, the participants assumed that the users would be attracted to the target and perceive the target to be desirable for a partner (collapsing across the conditions). The items that had the highest means referred to expectations that users would want to be friends with the target and users would find the target sexually attractive. The item that had the lowest mean in this section was the perception that users would desire a short-term relationship with target. These results indicate that the participants believed that the users would find the target moderately attractive in every regard represented by the dependent variables except for the desire for a shortterm relationship, overall.

\section{Independent $\mathbf{T}$ Tests Comparing Reactions to a White Target Versus a Black Target}

Next, I compared how the participants viewed the target as a function of the target's race, again using the composite scores (combining the participants' responses in regard to gay men and heterosexual women). An independent t test was conducted to compare participants who 
were randomly assigned to a white target with participants who were randomly assigned to a Black target (collapsing across the other condition, femininity/masculinity of the target) on the composite scores for each of the dependent variables. These results are presented in Table A-2.

Across both sections of items, there were only three items that had a statistically significant difference between the white target condition and the Black target condition. Those items were the affectionate item from the top portion of the table; and users' likelihood to agree to meet if contacted by the target and users' desire for a long-term relationship with the target from the bottom portion of the table. For all three items, the Black target had a higher mean than the white target, which means that participants assumed that users rated the Black target to be more affectionate than the white target, as well as assumed users would be more likely to agree to meet the Black target than the white target and would have a greater desire for a long-term relationship with the Black target. In a later section, I will discuss whether race moderates the effect of masculinity/femininity of the target on the dependent variables, which is the major focus of the study.

\section{Independent $\mathbf{T}$ Test Comparing the Masculine Versus the Feminine Target}

Next, I examined whether there were different views of the masculine target versus the feminine target. An independent t-test was conducted to compare participants randomly assigned to the masculine target with participants randomly assigned to the feminine target (collapsing across the other condition, race of the target) on the composite scores for each of the dependent variables. These results are presented in Table A-3. 


\section{Ratings of target characteristics}

As can be seen at the top portion of Table A-3, every item in this section, except for trustworthy, had a statistically significant difference between the masculine and the feminine target. The items (in the personality section) that were attributed more to the masculine target than to the feminine target were strong personality, masculine, dominant, and acts as a leader. The items (in the personality section) that were attributed more to the feminine target than to the masculine target were affectionate, warm, gentle, and feminine. The item that had the largest difference between the two versions was masculine, with the masculine target having a higher mean than the feminine target. These results reflect that the manipulation of masculinity versus femininity was successful, in that the participants viewed the target that was intended to be masculine as having more masculine traits and the target that was intended to be feminine as having more feminine traits.

\section{Expectations of users' attraction}

As can be seen at the bottom portion of Table A-3, three variables were found to be significantly different between the participants assigned to the feminine target and participants assigned to the masculine target. These variables referred to expectations that the users want to be friends with the target (higher in the feminine condition), users would find the target sexually attractive (higher in the masculine condition), and users would desire a short-term relationship with the target (higher in the masculine condition). These means show us that the participants believed that users would have more friendship attraction towards the feminine target than the masculine target, but more sexual attraction towards the masculine target than towards the 
feminine target, overall. In a later section, I will discuss how race of the target may moderate these results.

\section{Views of Gay Men versus Heterosexual Women}

Next, I consider whether there were any overall differences between the participants' expectations of how gay men would view the target and how heterosexual women would view the target (ignoring the manipulations of the study). Recall that participants were asked to respond to both types of users. The differences were examined by conducting Paired Samples ttests comparing how the participants responded to each item for gay men versus how the participants responded to the same item in regard to heterosexual women. The results are presented in Table A-4.

As can be seen in the top portion of Table A-4, no significant differences were found between participants' expectations of how gay men would rate the target person versus their expectations of how heterosexual women would rate the target person on the personality characteristics. As shown in the bottom portion of Table A-4, however, there were significant differences in three items referring to expectations of gay men's attraction versus heterosexual women's attraction to the target. For each of these items with a significant difference, the means were higher for expectations for gay men than for expectations for heterosexual women. Participants believed that gay men users would be more likely than heterosexual women users to: find the target sexually attractive, reach out to the target, and find the target attractive. 


\section{The Moderating Role of the Race of Target in Effects of Masculinity/Femininity of Target on Dependent Variables}

Next, I conducted a series of $2 \times 2$ ANOVAs to examine whether the interaction between the race of the target and the masculinity/femininity of the target was significant for any of the items, which would indicate that the race of the target moderates the effects of the masculinity/femininity of the target on the dependent variables. The results are presented in Table A-5.

\section{Ratings of target characteristics}

According to the top portion of Table A-5, a significant race $\mathrm{x}$ masculinity/femininity of target interaction was significant for three items: warm, gentle, and trustworthy. For the item warmth, the means indicated that for both the white target and the Black target, the feminine target was perceived to be warmer than the masculine target. Follow-up t-test comparisons for each race separately for the warmth item indicated that the difference on this item between the feminine and masculine target for the white target was significant and large $(t[46.079]=-5.56, p$ $<.001)$, whereas the difference on this item between the feminine and masculine target for the Black target, while significant, indicated a smaller difference $(t[55]=-2.51, p=.015)$; see the means in Table A-5. Next, for the item gentle, the means indicated that for both the white target and the Black target, the feminine target was perceived to be more gentle than the masculine target. Follow-up t-test comparisons for each race separately for the gentle item indicated that the difference on this item between the feminine and masculine target for the white target was significant and large $(t[52.943]=-6.09, p<.001)$, whereas the difference on this item between the feminine and masculine target for the Black target, while significant, showed a smaller 
difference $(t[55]=-3.10, p=.003)$; see the means in Table A-5. Then, for the item trustworthy, the means indicated that for the white target, the feminine target was perceived to be more trustworthy than the masculine target. However, for the Black target, the masculine target was perceived as more trustworthy than the feminine target. Follow-up t-test comparisons for each race separately for the trustworthy item indicated that the difference on this item between the feminine and masculine target for the white target was significant $(t[59]=-2.53, p=.014)$, whereas the difference on this item between the feminine and masculine target for the Black target was not significant $(t[49.856]=.67, p=.509)$; see the means in Table A-5.

\section{Expectations of users' attraction}

According to the bottom portion of Table A-5, the items that had a statistically significant interaction between race and masculinity/femininity of the target were: users would find target sexually attractive, users' likelihood to agree to meet if contacted by target, and users' desire for long-term relationship with target. For the item "users would find the target sexually attractive," the means indicated that for both the white target and the Black target, the masculine target was perceived as being more likely to be found sexually attractive by the users than the feminine target. Follow-up t-test comparisons for each race separately for this item indicated that the difference between the feminine and masculine target for the Black target was significant ( $t[56]$ $=3.98, p<.001$ ), whereas the difference between the feminine and masculine target for the white target was not significant $(t[59]=.42, p=.679)$; see the means in Table A-5. For the item 'users' likelihood to agree to meet if contacted by target," the means indicated that for the white target, participants were more likely to think the users would agree to meet the feminine target than the masculine target (if contacted by the target). However, for the Black target, participants were 
more likely to believe that the user would agree to meet if contacted by the target for the masculine target than for the feminine target. Follow-up t-test comparisons for each race separately indicated that the difference on this item between the feminine and masculine target for the white target was significant $(t[59]=-2.12, p=.038)$, whereas the difference between the feminine and masculine target for the Black target was not significant $(t[56]=1.11, p=.273)$; see the means in Table A-5. For the item "users' desire for long-term relationship with target," the means indicated that for the white target, the feminine target was perceived as being more desirable for a long-term relationship by the users than the masculine target. However, for the Black target, the masculine target was perceived as being more desirable for a long-term relationship by the users than the feminine target. Follow-up t-test comparisons for each race separately indicated that the difference on this item between the feminine and masculine target for the white target was significant $(t[51.874]=-2.81, p=.007)$, whereas the difference between the feminine and masculine target for the Black target, was not significant $(t[56]=.07, p=.942)$; see the means in Table A-5.

\section{Repeated Measures Analysis Assessing All of the Variables on a Composite Score on}

\section{Attraction}

Next, I conducted a repeated- Mixed ANOVA, which considers the two between-subjects variables (race and masculinity/femininity) and the within- subjects variable (perspective), including their interactions all at once. Rather than conducting this on each item, however, I conducted this on a composite attraction score. To do this I created a composite score for all of the attraction items from the perspective of gay men and a composite score for all of the attraction items from the perspective of heterosexual women. However, I first generated the 
reliability coefficient on the composite scores. The Cronbach's alpha score for the gay men composite item was .835 and the Cronbach's alpha score for the heterosexual women was .878 , both of which are high enough for the composite items to be reliable.

In this analysis, I first examine the effects of the within-subject variable (perspective). This variable was significant $(F=9.920, p=.085)$. The overall composite scores were higher for the perspective of gay men $(M=3.38, S D=.78)$ than for the perspective of heterosexual women $(M=3.14, S D=.88)$. These means indicate that the participants expected gay men to be more likely to find the target attractive than heterosexual women.

Next, I examine how the two between-subjects variables may interact with the withinsubjects variable. The race of target $\mathrm{x}$ perspective interaction was not significant $(F=.001, p=$ .975 ), indicating that the participants did not expect the user's attraction to the man in the profile to be affected by the race of said man. However, the femininity/masculinity of target $\mathrm{x}$ perspective interaction was significant $(F=29.402, p=.000)$. The data showed that the participants expected the gay men to be more attracted to a feminine target $(M=3.52, S D=.58)$ than to a masculine $\operatorname{target}(M=3.25, S D=.92)$. For the heterosexual women, however, the participants believed that the users would be more likely to be attracted to a masculine target ( $M$ $=3.43, S D=.86)$ than to a feminine target $(M=2.84, S D=.81)$.

The perspective $\mathrm{x}$ race $\mathrm{x}$ femininity/masculinity interaction was not significant $(\mathrm{F}=$ $3.547, p=.062)$. 


\section{Open-ended Questions}

In order to collect any of the personal thoughts that the participants had about the survey, I asked them four open-ended questions and reviewed them to find any themes. Their responses are presented verbatim in Table A-7. Some participants said they did not like that there was no profile picture and said they wouldn't trust a profile without a picture. Furthermore, some participants who viewed the masculine target described he was being standoffish and headstrong whereas other participants who viewed a feminine target described him as being in touch with their emotions and genuine. Finally, several participants viewed the masculine target as a good potential partner because the target seemed sexually attractive. 


\section{CHAPTER IV: DISCUSSION}

The purpose of this study was to examine whether people believed users at dating website would respond differently to a man in a hypothetical online dating profile based on their degree of masculinity versus femininity (reflected in their profile description) in combination with their race (reflected by the race written in their profile). The participants were asked how two sets of online dating site users would react to the male target in an online dating profile - gay men and heterosexual women (i.e., two groups that would be attracted to men). The participants completed an anonymous online survey created through Qualtrics in which they were randomly assigned a vignette of either a Black masculine man, a Black feminine man, a white masculine man, or a white feminine man. Thus, the design was a 2 (masculine profile vs. feminine profile) x 2 (white or Black target). Type of online user (gay men vs. heterosexual women) was a withinsubjects variable. I had three main questions that helped to guide my research. The main focus was to examine whether the race of the target moderated the effects of the masculinity versus the femininity of the target on the participants' expectations for users' attraction to and views of the target (on several personality characteristics). Below, I summarize the findings and discuss the implications.

\section{Summary of Findings and Their Implications}

When considering the masculinity vs. femininity of the target, the data showed that the masculine target, without consideration of the target's race or the perspective, was expected to be perceived by users at online dating sites to be more sexually attractive and that the users would have a greater desire to be in a short-term relationship with them than the feminine target. The participants also expected the online dating site users to view the feminine target to be higher in 
friendship attraction than the masculine target. Also, the two types of targets were perceived differently on personality characteristics as the feminine target was seen as being more affectionate, warm, gentle, feminine, and trustworthy than the masculine target. Likewise, the masculine target was seen as having a stronger personality, acting more as a leader, and being more masculine and dominant than the feminine target. These results are important because they exhibit that the manipulation was successful, as the participants perceived that the users would attribute masculine characteristics to masculine targets and feminine characteristics to feminine targets.

However, when I also considered the degree to which race of target moderated the effects of the masculinity versus femininity of the target, I found participants expected the online dating site users to find a target that was masculine and Black to be more trustworthy, more likely to be contacted by the users, and more desirable for long-term relationships than a feminine and Black target. The participants also expected online dating site users to find a target that was feminine and white more trustworthy, more likely to be contacted by the users, and more desirable for long-term relationships than the masculine and white target. The conclusion that masculinity is not universally valued when race is taken into account can be tied back to research done by Fiore (2008). Fiore's (2008) research found that a profile with a photo and text demographic information was rated as attractive if perceived as masculine but a profile with only a photo was rated as attractive if perceived as feminine. It would stand to reason that I found similar data as Fiore because we both found evidence to suggest that people do not always perceive masculinity as being more attractive. 
Furthermore, data in my research on the attraction towards Black male masculinity/femininity are congruent with previous research on Black men that ties the value of Black men to controlling images of their masculinity (Ferber 2007). Furthermore, the data reflecting that white men are valued for their femininity, thus allowing them more flexibility in how they can act socially, follows the theory that white men have more erotic capital and gender maneuverability than Black men (Daroya 2018; Winder 2020:1029; Riggs 2018). The gender role flexibility that white men possess is something that Black men do not, as they are socially expected to maintain a strong, dominant, and masculine appearance in order to be given any value.

An important finding from my research was that the participants believed that the users would have more friendship attraction towards the feminine target than the masculine target, but more sexual attraction towards the masculine target than the feminine target, overall. This is an interesting finding in that is follows a social stereotype that people would generally find masculine men more sexually attractive than feminine men, and the feminine men would be "friend zoned", but it goes against the previous findings that would suggest that gender role incongruence was becoming more desirable. The previous literature from Fiore (2008) and Chappetta and Barth (2016) both suggested that gender role incongruence was becoming more likely to be found attractive, but these data suggest that the traditional belief that masculinity in men is more sexually attractive than femininity in men. These could both be true, in that people who go against gender roles are starting to be seen as more attractive while masculinity in men is still seen as very attractive. 
Another important finding from my study was that the participants perceived that gay men would be more attracted to a feminine target than a masculine target. This is an interesting finding due to the fact that previous literature suggests that gay men would prefer more masculine men instead of feminine men. According to Lanzieri and Hildebrandt (2011), previous representations of attraction for gay men in media show that gay men are more likely to be attracted to men with muscular, hairless, and athletic body types. This kind of body type is referred to as "gay masculinity", a term from Lanzieri and Hildebrandt (2011), and it has been used to describe the specific type of masculinity that gay men are often attracted to. Furthermore, some gay men may also aspire to have this body type in order to obtain a form of masculinity in a very heteronormative society (Lanzieri and Hildebrandt 2011; Lanzieri and Hildebrandt 2016). This may be another example of gender role incongruence becoming more popular in the online dating world.

Finally, these data reflected that the participants perceived that gay men in online dating sites would have higher attraction to the target than heterosexual women in online dating sites. Furthermore, the participants perceived that gay men would have higher attraction to a feminine target than to a masculine target, regardless of the target's race. This may be because, according to prior literature, respondents potentially consider men to have a greater "sex drive" than women (Matsick et al 2021; Peplau 2003). This could then mean that people perceive that both heterosexual and gay men use online dating sites for sexual gratification due to the stereotype that men desire sex more than women. However, the previous data on men's greater desire for sexual activity is based on research done on men directly while my research covered how men, specifically gay men, were perceived. The combination of Peplau's (2003) and Matsick's (2021) 
research and my own implies that the social bias that people have about men having a greater desire for sexual activity has data to support it.

\section{Strengths and Limitations of the Study}

My current research has several strengths. The first strength is that my study fills the gap in present literature about how race and masculinity/femininity interact in online attraction, as there has not been much research that has explored how race and masculinity/femininity affect attraction. A second strength is that my vignette study was an experiment which gave me more control over my survey questions. Experimental designs in research allows for a great understanding of causal relationships as well as allowing researchers to assess the mindsets and behaviors of the participants (Aguinis and Bradley 2014). Also, every vignette was randomly assigned to each participant. Another strength of my research was that I added attention checks to the survey released to my MTurk participants in order to maximize the reliability of their data and did not include anyone who failed the attention checks. The use of vignettes was a strength here in that the use of vignettes allows researchers to efficiently present experiments with things like videos, images, and other forms of media as well as bringing up potentially sensitive issues through hypothetical scenarios (Aguinis and Bradley 2014; Aviram 2012; Collett and Childs 2011). One additional strength of my study was that I was able to collect from both a student sample and an MTurk sample that included post college age, or older than the traditional age, respondents, which helped to further diversify my data.

Although my research does have strengths and fills a gap in current literature, it also has several limitations. The first limitation comes from my research using an experimental design, which means that the results cannot always be easily generalized, and it could be said that my 
results only reflect that these outcomes could possibly happen (Aguinis and Bradley 2014). One limitation was that the sample size was not large, and was not representative (i.e., was a convenience sample). Another limitation was that the participants may have not been familiar with the situation being presented in the survey, which could mean their responses were not genuine. Essentially this means that when using vignettes, the participant is responding how they believe someone should respond and not necessarily how they would actually respond (Aguinis and Bradley 2014; Aviram 2012; Collett and Childs 2011). One possible limitation was that my survey did not include a photo in the vignettes. This did seem to affect how the participants responded to the survey questions as a few did express that they would not interact with an online profile that did not include a profile picture, which can be seen in the responses represented in Table A-7. Another limitation from my research was that the sample was significantly skewed, as $75 \%$ of the sample were men, $80 \%$ were white, and $80 \%$ were straight, which makes it extremely difficult to make generalizations about my findings. One more limitation was that I only used male targets and it might have been beneficial to have a female target as well, and then ask the participant to answer the survey questions on how they think a heterosexual man and a lesbian woman would respond to the target.

\section{Future Directions of Research}

A possible future direction for this kind of research could be to look into researching attraction based on the interaction of race and masculinity/femininity, but also seeing how participants react to both a vignette with a profile picture and one without a profile picture. Most of the current research on online attraction utilized a photograph of some kind when collecting data (Chopik and Johnson 2021; Chappetta and Barth 2016; Fiore et al 2008). One way this 
could be used in future research is having a large sample with two versions of each vignette, one with a picture of the target and one without. The data collected from such a study could provide a deeper understanding of how people react to the race of a person in a profile picture versus when race is just mentioned in a text statement. My data demonstrated a clear division in how the participants believe gay men and heterosexual women are attracted to a man in online dating. Then, future research on this topic could seek different or more diverse samples to collect their data from. I collected my data from college students, friends, and MTurk respondents out of convenience, but future researchers could attempt to study a specific population (i.e., only having straight male participants who are white) to see how they perceive attraction. On that note, future researchers could use a completely different design to research attraction in online dating based on race and masculinity/femininity that is not experimental. One more direction future research could take is to manipulate the independent variable of race when studying attraction in online dating like I did. To keep the study focused and not becoming too complex, I only included a Black man and a white man. Future studies could benefit from researching how other ethnicities are affected by perceived masculinity/femininity, an example being Latinx men and/or Asian men. This could go further by including female and male targets instead of just using male targets like I did. It could also go even further and explore any differences in how transgender people perceive attraction online when compared to cisgender people.

\section{General Conclusion}

This research examined how people believe online dating site users would perceive a man on these sites based on their femininity and masculinity in combination with their race (Black or white). The lack of a picture in the vignettes may have influenced how participants 
reacted to the targets. I believe that my research has some noticeable theoretical implications to the research into attraction in online dating. My finding that masculinity is not universally valued when race is involved is useful because it gives further evidence that adherence to traditional gender roles may no longer be as important in online dating. The data that showed Black masculine men as more attractive than Black feminine men further refines the theory of Black men's social connection to masculinity and hypersexuality. Then the data that suggested that gay men would be more sexually attracted to a profile than were heterosexual women implies that it is possible that some people could believe gay men to be hypersexual. 


\section{WORKS CITED}

Aguinis, Herman, and Kyle J. Bradley. 2014. "Best Practice Recommendations for Designing and Implementing Experimental Vignette Methodology Studies." Organizational Research Methods 17(4): 351-371.

Alhabash, Saleem, Kayla Hales, Jong-hwan Baek, and Hyun Jung Oh. 2014. "Effects of Race, Visual Anonymity, and Social Category Salience on Online Dating Outcomes." Computers in Human Behavior 35: 22-32.

Anderson, Ashton, Sharad Goel, Gregory Huber, Neil Malhotra, and Duncan J. Watts. 2014. "Political Ideology and Racial Preferences in Online Dating." Sociological Science 1: 2840.

Anderson, Traci L. 2005. "Relationships among Internet Attitudes, Internet Use, Romantic Beliefs, and Perceptions of Online Romantic Relationships." CyberPsychology \& Behavior 8(6): 521-531.

Aviram, Hadar. 2012 "What Would You Do? Conducting Web-Based Factorial Vignette Surveys." Pp. 463-473 in Handbook of Survey Methodology for the Social Sciences, New York, NY: Springer.

Branchik, Blaine J. 2002. "Out in the Market: A History of the Gay Market Segment in the United States." Journal of Macromarketing 22(1): 86-97. 
Brand, Rebecca J., Abigail Bonatsos, Rebecca D’Orazio, and Hilary DeShong. 2012. "What is Beautiful is Good, even Online: Correlations between Photo Attractiveness and Text Attractiveness in Men's Online Dating Profiles." Computers in Human Behavior 28(1): 166-170.

Buhrmester, Michael, Tracy Kwang, and Samuel D. Gosling. 2016. "Amazon's Mechanical Turk: A new source of inexpensive, yet high-quality data?." Perspectives on Psychological Science 6(3): 1-4.

Campbell, John Edward. 2014. Getting It On Online: Cyberspace, Gay Male Sexuality, and Embodied Identity. NY: Routledge.

Chappetta, Kelsey C., and Joan M. Barth. 2016. "How Gender Role Stereotypes Affect Attraction in an Online Dating Scenario." Computers in Human Behavior 63: 738-746.

Chopik, William J., and David J. Johnson. 2021. "Modeling Dating Decisions in a Mock Swiping Paradigm: An Examination of Participant and Target Characteristics." Journal of Research in Personality 92: 104076.

Clayton, Dewey M., Sharon E. Moore, and Sharon D. Jones-Eversley. 2021 "A Historical Analysis of Racism Within the US Presidency: Implications for African Americans and the Political Process." Journal of African American Studies 25(3): 383-401.

Collett, Jessica L., and Ellen Childs. 2011. "Minding the Gap: Meaning, Affect, and the Potential Shortcomings of Vignettes." Social Science Research 40(2): 513-522. 
Darden, Donna K., and Patricia R. Koski. 1988. "Using the Personals Ads: A Deviant Activity?." Deviant Behavior 9(4): 383-400.

Daroya, Emerich. 2018. "The psychic life of racism in gay men's communities." 67-80.

Doll, Leslie M., Alexander K. Hill, Michelle A. Rotella, Rodrigo A. Cárdenas, Lisa LM Welling, John R. Wheatley, and David A. Puts. 2014. "How Well Do Men’s Faces and Voices Index Mate Quality and Dominance?." Human Nature 25(2): 200-212.

Eastwick, Paul W., Alice H. Eagly, Eli J. Finkel, and Sarah E. Johnson. 2011, "Implicit and Explicit Preferences for Physical Attractiveness in a Romantic Partner: A Double Dissociation in Predictive Validity." Journal of Personality and Social Psychology 101(5): 993-1011.

Ellison, Nicole, Rebecca Heino, and Jennifer Gibbs. 2006. "Managing Impressions Online: SelfPresentation Processes in the Online Dating Environment." Journal of ComputerMediated Communication 11(2): 415-441.

Farley, Reynolds. 1997. "Racial Trends and Differences in the United States 30 Years after the Civil Rights Decade." Social Science Research 26(3): 235-262.

Ferber, Abby L. 2007. "The Construction of Black Masculinity: White Supremacy Now and Then." Journal of Sport and Social Issues 31(1): 11-24.

Finkel, Eli J., Paul W. Eastwick, Benjamin R. Karney, Harry T. Reis, and Susan Sprecher. 2012. "Online Dating: A Critical Analysis From the Perspective of Psychological Science." Psychological Science in the Public Interest 13(1): 3-66. 
Fiore, Andrew T., Lindsay Shaw Taylor, Gerald A. Mendelsohn, and Marti Hearst. 2008.

"Assessing Attractiveness in Online Dating Profiles." Pp. 797-806 in Proceedings of the SIGCHI Conference on Human Factors in Computing Systems.

Hale, Sadie E., and Tomás Ojeda. 2018. "Acceptable femininity? Gay Male Misogyny and the Policing of Queer Femininities." European Journal of Women's Studies 25(3): 310-324.

Hitsch, Gunter J., Ali Hortaçsu, and Dan Ariely. 2010. "Matching and Sorting in Online Dating." American Economic Review 100(1): 130-63.

Jones, Jeffrey M. 2021. "LGBT identification rises to 5.6\% in latest US estimate," Gallup. com, February 24, pp. 1-7.

Kogan, Lori, and Shelly Volsche. 2020. "Not the Cat's Meow? The Impact of Posing with Cats on Female Perceptions of Male Dateability." Animals 10(6): 1007: 1-11.

Kranz, Dirk, Katharina Pröbstle, and Alkis Evidis. 2017. "Are All the Nice Guys Gay? The Impact of Sociability and Competence on the Social Perception of Male Sexual Orientation." Psychology of Men \& Masculinity 18(1): 32-39.

Lanzieri, Nicholas, and Tom Hildebrandt. 2011. "Using hegemonic masculinity to explain gay male attraction to muscular and athletic men." Journal of Homosexuality 58(2): 275-293.

Lanzieri, Nicholas, and Tom Hildebrandt. 2016. "Using objectification theory to examine the effects of media on gay male body image." Clinical Social Work Journal 44(1): 105-113.

Leonhardt, David. 2006. "The Famous Founder of Operation Match." The New York Times.

Mathews, T. Jay. 1965. “Operation Match.” The Harvard Crimson. 
Matsick, Jes L., Mary Kruk, Terri D. Conley, Amy C. Moors, and Ali Ziegler. 2021. "Gender Similarities and Differences in Casual Sex Acceptance Among Lesbian Women and Gay Men." Archives of Sexual Behavior 50(3): 1151-1166.

McGloin, Rory, and Amanda Denes. 2018. "Too Hot to Trust: Examining the Relationship Between Attractiveness, Trustworthiness, and Desire to Date in Online Dating." New Media \& Society 20(3): 919-936.

Peplau, Letitia Anne. 2003. "Human Sexuality: How Do Men and Women Differ?." Current Directions in Psychological Science 12(2): 37-40.

Riggs, Damien W, ed. 2018. The Psychic Life of Racism in Gay Men's Communities. London, England: Lexington Books.

Rodriguez, Nathian Shae, Jennifer Huemmer, and Lindsey Erin Blumell. 2016. "Mobile Masculinities: An Investigation of Networked Masculinities in Gay Dating Apps." Masculinities \& Social Change 5(3): 241-267.

Rosenfeld, Michael J., Reuben J. Thomas, and Sonia Hausen. 2019. "Disintermediating your Friends: How Online Dating in the United States Displaces Other Ways of Meeting." Proceedings of the National Academy of Sciences 116(36): 17753-17758.

Spence, Janet T. 1984. "Masculinity, Femininity, and Gender-related Traits: A Conceptual Analysis and Critique of Current Research." Progress in Experimental Personality Research 13: 1-97. 
Sprecher, Susan, Pepper Schwartz, John Harvey, and Elaine Hatfield. 2008.

"Thebusinessoflove.com: Relationship Initiation at Internet Matchmaking Services." Pp. 249-265 in Handbook of Relationship Initiation, edited by S. Sprecher, A. Wenzel, \& J. Harvey. Erlbaum.

Wade, Ryan M., and Gary W. Harper. 2020. "Racialized Sexual Discrimination (RSD) in the Age of Online Sexual Networking: Are Young Black Gay/Bisexual Men (YBGBM) at Elevated Risk for Adverse Psychological Health?." American Journal of Community Psychology 65(3-4): 504-523.

Winder, Terrell JA. 2020. “The Psychic Life of Racism in Gay Men’s Communities." 10291031.

Zebrowitz, Leslie A., and Joann M. Montepare. 2008. "Social Psychological Face Perception: Why Appearance Matters." Social and Personality Psychology Compass 2(3): 14971517.

Zhang, Bingbing, and Sherice Gearhart. 2020. "Collecting Online Survey Data: A Comparison of Data Quality among a Commercial Panel \& MTurk." Survey Practice 13(1): 1-10. 


\section{APPENDIX A: TABLES}

Table A-1. Grand Means and Standard Deviations of the Variables

\begin{tabular}{|l|l|l|}
\hline \multicolumn{1}{|c|}{ Composite Variable } & \multicolumn{1}{c|}{ Mean } & \multicolumn{1}{c|}{ Standard Deviation } \\
\hline Ratings of Target Characteristics (Assumed from the Users' Perspective) \\
\hline Strong personality & 3.54 & 1.09 \\
\hline Masculine & 3.35 & 1.29 \\
\hline Dominant & 3.19 & 1.25 \\
\hline Acts as a leader & 3.13 & 1.18 \\
\hline Affectionate & 3.46 & 1.09 \\
\hline Warm & 3.54 & 1.12 \\
\hline Gentle & 3.47 & 1.24 \\
\hline Feminine & 2.77 & 1.34 \\
\hline Trustworthy & 3.75 & 0.94 \\
\hline Expectations of Users' Attraction to the Target & 0.90 \\
\hline $\begin{array}{l}\text { Users want to be friends with } \\
\text { target }\end{array}$ & 3.69 & 0.99 \\
\hline $\begin{array}{l}\text { Users would find target } \\
\text { sexually attractive }\end{array}$ & 3.38 & 0.87 \\
\hline $\begin{array}{l}\text { Users' likelihood to reach out } \\
\text { to target }\end{array}$ & 3.22 & 0.80 \\
\hline $\begin{array}{l}\text { Users' likelihood to agree to } \\
\text { meet if contacted by target }\end{array}$ & 3.18 & 0.87 \\
\hline $\begin{array}{l}\text { Overall, how attractive user } \\
\text { would find target }\end{array}$ & 3.23 & 0.97 \\
\hline $\begin{array}{l}\text { Users' desire for short-term } \\
\text { relationship with target }\end{array}$ & 2.97 & 0.95 \\
\hline $\begin{array}{l}\text { Users' desire for long-term } \\
\text { relationship with target }\end{array}$ & 3.16 & \\
\hline
\end{tabular}

Note. The response scale for each of the above items ranged from 1 to 5.1 represented not at all, not at all agree, and not at all likely while 5 represented extremely, a great deal, and agree a great deal. 
Table A-2. Independent t-test: Means, Standard Deviations, and t Values Comparing the Two Vignette Conditions of White Targets and Black Targets

\begin{tabular}{|c|c|c|c|c|c|}
\hline \multirow[t]{2}{*}{ Composite Variable } & \multicolumn{2}{|c|}{ White target } & \multicolumn{2}{|c|}{ Black target } & \multirow{3}{*}{$t$-value } \\
\hline & Mean & $\mathrm{SD}$ & Mean & $\mathrm{SD}$ & \\
\hline \multicolumn{5}{|c|}{ Ratings of Target Characteristics (Assumed from the Users' Perspective) } & \\
\hline Strong personality & 3.58 & 1.13 & 3.50 & 1.06 & .41 \\
\hline Masculine & 3.45 & 1.30 & 3.25 & 1.28 & .86 \\
\hline Dominant & 3.20 & 1.28 & 3.18 & 1.22 & .09 \\
\hline Acts as a leader & 3.02 & 1.14 & 3.25 & 1.22 & -1.04 \\
\hline Affectionate & 3.24 & 1.13 & 3.70 & 1.00 & $-2.36^{*}$ \\
\hline Warm & 3.45 & 1.21 & 3.63 & 1.02 & -.88 \\
\hline Gentle & 3.30 & 1.36 & 3.68 & 1.07 & -1.70 \\
\hline Feminine & 2.62 & 1.44 & 2.93 & 1.20 & -1.26 \\
\hline Trustworthy & 3.65 & 0.89 & 3.86 & 0.98 & -1.25 \\
\hline \multicolumn{5}{|c|}{ Expectations of Users' Attraction to the Target } & \\
\hline $\begin{array}{l}\text { Users want to be friends } \\
\text { with target }\end{array}$ & 3.59 & 0.88 & 3.80 & 0.92 & -1.29 \\
\hline $\begin{array}{l}\text { Users would find target } \\
\text { sexually attractive }\end{array}$ & 3.31 & 1.01 & 3.45 & 0.96 & -.75 \\
\hline $\begin{array}{l}\text { Users' likelihood to reach } \\
\text { out to target }\end{array}$ & 3.11 & 0.78 & 3.33 & 0.94 & -1.35 \\
\hline $\begin{array}{l}\text { Users' likelihood to agree } \\
\text { to meet if contacted by } \\
\text { target }\end{array}$ & 3.02 & 0.81 & 3.35 & 0.77 & $-2.33^{*}$ \\
\hline $\begin{array}{l}\text { Overall, how attractive } \\
\text { user would find target }\end{array}$ & 3.11 & 0.84 & 3.36 & 0.90 & -1.61 \\
\hline $\begin{array}{l}\text { Users' desire for short- } \\
\text { term relationship with } \\
\text { target }\end{array}$ & 2.98 & 0.92 & 2.96 & 1.03 & .10 \\
\hline $\begin{array}{l}\text { Users' desire for long- } \\
\text { term relationship with } \\
\text { target }\end{array}$ & 2.93 & 0.96 & 3.41 & 0.90 & $-2.76^{* *}$ \\
\hline
\end{tabular}

Note. $* \mathrm{p}<.05 . * * \mathrm{p}<.01 . * * * \mathrm{p}<.001$. 
Table A-3. Independent t-test: Means, Standard Deviations, and t Values Comparing the Two Vignette Conditions of Masculine Targets and Feminine Targets

\begin{tabular}{|c|c|c|c|c|c|}
\hline \multirow[t]{2}{*}{ Composite Variable } & \multicolumn{2}{|c|}{ Masculine target } & \multicolumn{2}{|c|}{ Feminine target } & \multirow[t]{3}{*}{$t$-value } \\
\hline & Mean & SD & Mean & SD & \\
\hline \multicolumn{5}{|c|}{ Ratings of Target Characteristics (Assumed from the Users' Perspective) } & \\
\hline Strong personality & 4.01 & 0.90 & 3.09 & 1.08 & $5.00^{* * * *}$ \\
\hline Masculine & 4.18 & 0.87 & 2.55 & 1.12 & $8.85^{* * *}$ \\
\hline Dominant & 3.93 & 0.86 & 2.47 & 1.14 & $7.92 * * *$ \\
\hline Acts as a leader & 3.67 & 1.01 & 2.61 & 1.10 & $5.48^{* * * *}$ \\
\hline Affectionate & 2.94 & 1.07 & 3.97 & 0.85 & $-5.76 * * *$ \\
\hline Warm & 3.01 & 1.10 & 4.05 & 0.87 & $-5.68 * * *$ \\
\hline Gentle & 2.84 & 1.22 & 4.11 & 0.89 & $-6.40 * * *$ \\
\hline Feminine & 2.03 & 1.24 & 3.49 & 0.99 & $-7.11 * * *$ \\
\hline Trustworthy & 3.65 & 0.92 & 3.85 & 0.96 & -1.15 \\
\hline \multicolumn{5}{|c|}{ Expectations of Users' Attraction to the Target } & \\
\hline $\begin{array}{l}\text { Users want to be friends } \\
\text { with target }\end{array}$ & 3.51 & 1.00 & 3.88 & 0.75 & $-2.25^{*}$ \\
\hline $\begin{array}{l}\text { Users would find target } \\
\text { sexually attractive }\end{array}$ & 3.63 & 1.02 & 3.13 & 0.90 & $2.81 * *$ \\
\hline $\begin{array}{l}\text { Users' likelihood to } \\
\text { reach out to target }\end{array}$ & 3.25 & 0.96 & 3.18 & 0.76 & .45 \\
\hline $\begin{array}{l}\text { Users' likelihood to } \\
\text { agree to meet if } \\
\text { contacted by target }\end{array}$ & 3.13 & 0.88 & 3.23 & 0.73 & -.72 \\
\hline $\begin{array}{l}\text { Overall, how attractive } \\
\text { user would find target }\end{array}$ & 3.34 & 0.93 & 3.13 & 0.81 & 1.34 \\
\hline $\begin{array}{l}\text { Users' desire for short- } \\
\text { term relationship with } \\
\text { target }\end{array}$ & 3.41 & 0.87 & 2.53 & 0.88 & $5.46^{* * * *}$ \\
\hline $\begin{array}{l}\text { Users' desire for long- } \\
\text { term relationship with } \\
\text { target }\end{array}$ & 3.00 & 1.01 & 3.33 & 0.87 & -1.88 \\
\hline
\end{tabular}

Note. $* \mathrm{p}<.05 . * * \mathrm{p}<.01 . * * * \mathrm{p}<.001$ 
Table A-4. Paired Samples t-tests: Means, Standard Deviations, and t Values Comparing the Views of Gay Men versus Heterosexual Women

\begin{tabular}{|c|c|c|c|c|c|}
\hline \multirow[t]{2}{*}{ Variables } & \multicolumn{2}{|c|}{$\begin{array}{l}\text { Participants' response in } \\
\text { regard to Gay Men }\end{array}$} & \multicolumn{2}{|c|}{$\begin{array}{c}\text { Participants' response in } \\
\text { regard to Heterosexual } \\
\text { Women } \\
\end{array}$} & \multirow[t]{3}{*}{$t$-value } \\
\hline & Mean & SD & Mean & $\mathrm{SD}$ & \\
\hline \multicolumn{5}{|c|}{ Ratings of Target Characteristics (Assumed from the Users' Perspective) } & \\
\hline Strong personality & 3.63 & 1.19 & 3.49 & 1.32 & 1.23 \\
\hline Masculine & 3.38 & 1.34 & 3.38 & 1.42 & .09 \\
\hline Dominant & 3.21 & 1.33 & 3.25 & 1.40 & -.33 \\
\hline Acts as a leader & 3.04 & 1.30 & 3.26 & 1.36 & -1.97 \\
\hline Affectionate & 3.49 & 1.24 & 3.41 & 1.17 & .85 \\
\hline Warm & 3.54 & 1.22 & 3.48 & 1.23 & .66 \\
\hline Gentle & 3.29 & 1.35 & 3.54 & 1.32 & -1.71 \\
\hline Feminine & 2.86 & 1.45 & 2.73 & 1.48 & 1.14 \\
\hline Trustworthy & 3.67 & 1.16 & 3.82 & 1.05 & -1.46 \\
\hline \multicolumn{5}{|c|}{ Expectations of Users' Attraction to the Target } & \\
\hline $\begin{array}{l}\text { Users want to be friends } \\
\text { with target }\end{array}$ & 3.71 & 1.10 & 3.70 & 1.08 & .08 \\
\hline $\begin{array}{l}\text { Users would find target } \\
\text { sexually attractive }\end{array}$ & 3.58 & 1.11 & 3.17 & 1.30 & $3.14 * *$ \\
\hline $\begin{array}{l}\text { Users' likelihood to reach } \\
\text { Out to target }\end{array}$ & 3.35 & 1.11 & 3.06 & 1.11 & $2.17 *$ \\
\hline $\begin{array}{l}\text { Users' likelihood to agree } \\
\text { to meet if contacted by } \\
\text { target }\end{array}$ & 3.31 & 1.15 & 3.07 & 1.02 & 1.76 \\
\hline $\begin{array}{l}\text { Overall, how attractive } \\
\text { user would find target }\end{array}$ & 3.42 & 1.02 & 3.04 & 1.09 & $3.61 * * *$ \\
\hline $\begin{array}{l}\text { Users' desire for short- } \\
\text { term relationship with } \\
\text { target }\end{array}$ & 3.06 & 1.01 & 2.96 & 1.25 & .97 \\
\hline $\begin{array}{l}\text { Users' desire for long- } \\
\text { term relationship with } \\
\text { target }\end{array}$ & 3.29 & 1.14 & 3.03 & 1.20 & 1.93 \\
\hline
\end{tabular}

Note. ${ }^{*} \mathrm{p}<.05 . * * \mathrm{p}<.01 . * * * \mathrm{p}<.001$. 
Table A-5. Results of $2 \times 2$ ANOVAs: Means, Standard Deviations, and F for the

Interaction of Race and Masculinity/Femininity

\begin{tabular}{|c|c|c|c|c|c|c|c|c|c|}
\hline \multirow{3}{*}{ Composite Variables } & \multicolumn{4}{|c|}{ White Target } & \multicolumn{4}{|c|}{ Black Target } & \multirow{3}{*}{$\begin{array}{c}\mathrm{F} \\
\text { interaction }\end{array}$} \\
\hline & \multicolumn{2}{|c|}{ Masculine } & \multicolumn{2}{|c|}{ Feminine } & \multicolumn{2}{|c|}{ Masculine } & \multicolumn{2}{|c|}{ Feminine } & \\
\hline & Mean & $\mathrm{SD}$ & Mean & $\mathrm{SD}$ & Mean & $\mathrm{SD}$ & Mean & $\mathrm{SD}$ & \\
\hline \multicolumn{9}{|c|}{ Ratings of Target Characteristics (Assumed from the Users' Perspective) } & \\
\hline Strong personality & 4.00 & .96 & 3.18 & 1.14 & 4.02 & .84 & 3.00 & 1.02 & .28 \\
\hline Masculine & 4.22 & .95 & 2.71 & 1.17 & 4.14 & .78 & 2.38 & 1.05 & .48 \\
\hline Dominant & 3.98 & .95 & 2.44 & 1.09 & 3.88 & .75 & 2.50 & 1.20 & .21 \\
\hline Acts as a leader & 3.63 & 1.21 & 2.44 & 1.01 & 3.75 & .89 & 2.79 & 1.18 & .38 \\
\hline Affectionate & 2.58 & 1.08 & 3.87 & .77 & 3.32 & .94 & 4.07 & .93 & 2.46 \\
\hline Warm & 2.73 & 1.21 & 4.15 & .70 & 3.30 & .91 & 3.95 & 1.03 & $4.54 *$ \\
\hline Gentle & 2.45 & 1.23 & 4.13 & .89 & 3.27 & 1.08 & 4.09 & .91 & $5.08^{*}$ \\
\hline Feminine & 1.78 & 1.26 & 3.44 & 1.12 & 2.29 & 1.18 & 3.55 & .86 & .88 \\
\hline Trustworthy & 3.37 & .95 & 3.92 & .75 & 3.98 & .79 & 3.78 & 1.15 & $5.01 *$ \\
\hline \multicolumn{9}{|c|}{ Expectations of Users' Attraction to the Target } & \\
\hline $\begin{array}{l}\text { Users want to be friends } \\
\text { with target }\end{array}$ & 3.27 & .97 & 3.90 & .65 & 3.82 & .94 & 3.84 & .86 & 3.73 \\
\hline $\begin{array}{l}\text { Users would find target } \\
\text { sexually attractive }\end{array}$ & 3.37 & 1.16 & 3.26 & .86 & 3.96 & .69 & 3.00 & .94 & $6.22 *$ \\
\hline $\begin{array}{l}\text { Users' likelihood to reach } \\
\text { out to target }\end{array}$ & 3.05 & .89 & 3.18 & .67 & 3.55 & .90 & 3.19 & .87 & 2.56 \\
\hline $\begin{array}{l}\text { Users' likelihood to agree } \\
\text { to meet if contacted by } \\
\text { target }\end{array}$ & 2.80 & .89 & 3.23 & .67 & 3.52 & .70 & 3.24 & .80 & $6.16^{*}$ \\
\hline $\begin{array}{l}\text { Overall, how attractive } \\
\text { user would find target }\end{array}$ & 3.07 & .91 & 3.15 & .77 & 3.62 & .87 & 3.10 & .86 & 3.61 \\
\hline $\begin{array}{l}\text { Users' desire for short- } \\
\text { term relationship with } \\
\text { target }\end{array}$ & 3.42 & .87 & 2.55 & .77 & 3.45 & .85 & 2.52 & 1.00 & .04 \\
\hline $\begin{array}{l}\text { Users' desire for long- } \\
\text { term relationship with } \\
\text { target }\end{array}$ & 2.60 & 1.05 & 3.26 & .74 & 3.45 & .79 & 3.40 & 1.00 & $4.50^{*}$ \\
\hline
\end{tabular}

Note. $* \mathrm{p}<.05 . * * \mathrm{p}<.01 . * * * \mathrm{p}<.001$ 
Table A-6. Within-Between Subject Test Means and Standard Deviations

\begin{tabular}{|c|c|c|c|c|}
\hline Total Attraction & Race & Femininity/Masculinity & Mean & SD \\
\hline \multirow[t]{9}{*}{ Total Gay Men Attraction } & \multirow[t]{3}{*}{ White } & Masculine & 2.92 & .99 \\
\hline & & Feminine & 3.61 & .61 \\
\hline & & Total & 3.26 & .89 \\
\hline & \multirow[t]{3}{*}{ Black } & Masculine & 3.59 & .70 \\
\hline & & Feminine & 3.43 & .55 \\
\hline & & Total & 3.51 & .63 \\
\hline & \multirow[t]{3}{*}{ Total } & Masculine & 3.25 & .92 \\
\hline & & Feminine & 3.52 & .58 \\
\hline & & Total & 3.38 & .78 \\
\hline \multirow{9}{*}{$\begin{array}{l}\text { Total Heterosexual } \\
\text { Women Attraction }\end{array}$} & \multirow[t]{3}{*}{ White } & Masculine & 3.25 & .79 \\
\hline & & Feminine & 2.79 & .85 \\
\hline & & Total & 3.02 & .85 \\
\hline & \multirow[t]{3}{*}{ Black } & Masculine & 3.63 & .89 \\
\hline & & Feminine & 2.90 & .78 \\
\hline & & Total & 3.28 & .91 \\
\hline & \multirow[t]{3}{*}{ Total } & Masculine & 3.43 & .86 \\
\hline & & Feminine & 2.84 & .81 \\
\hline & & Total & 3.14 & .88 \\
\hline
\end{tabular}




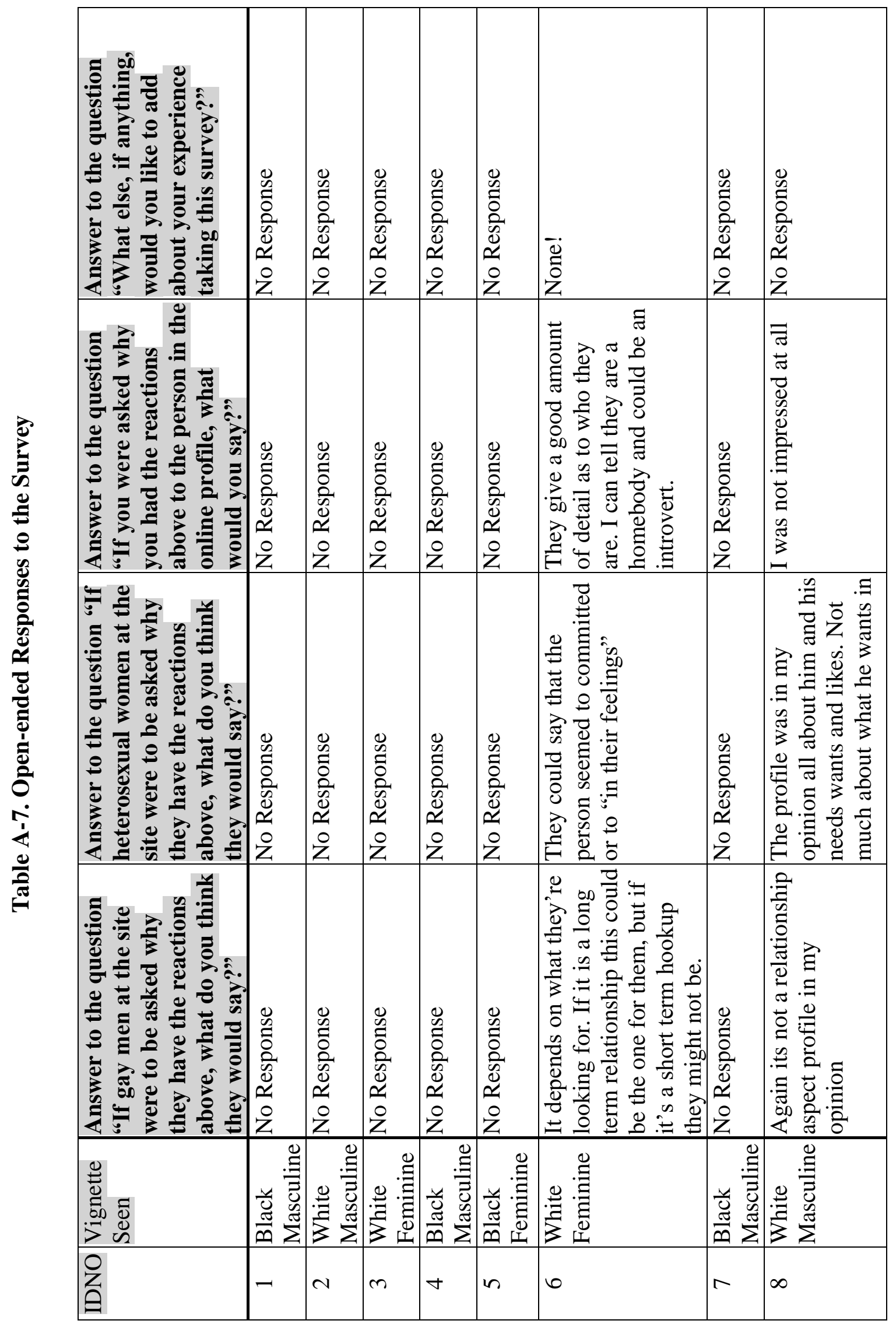




\begin{tabular}{|c|c|c|}
\hline & 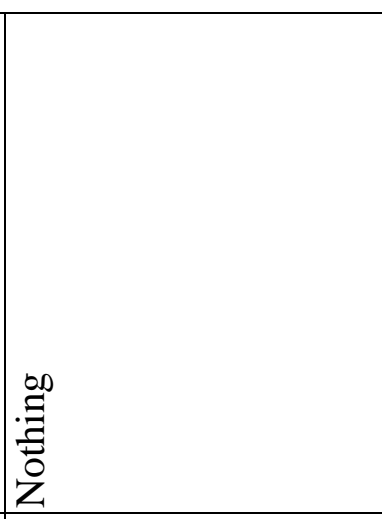 & 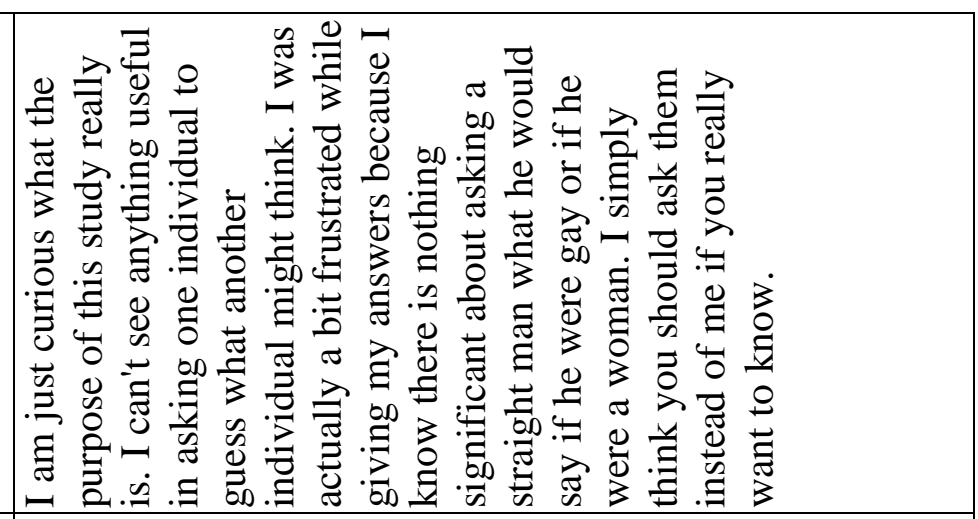 \\
\hline & 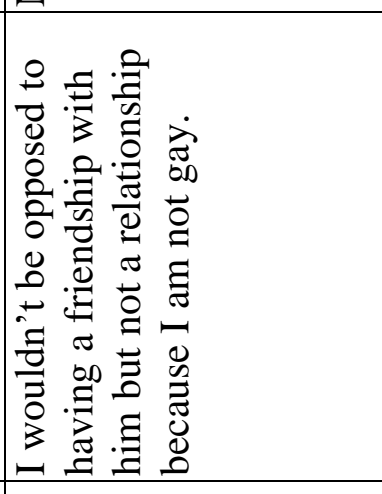 & 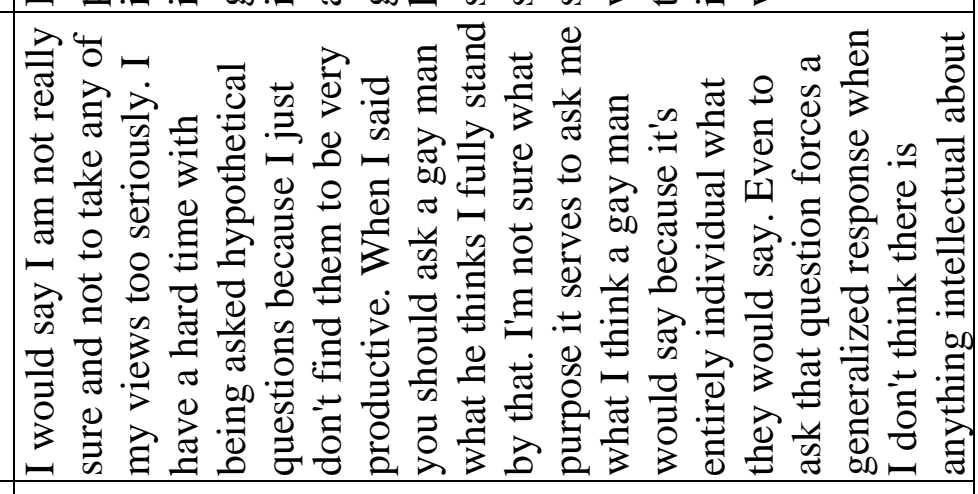 \\
\hline 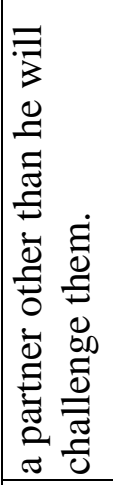 & 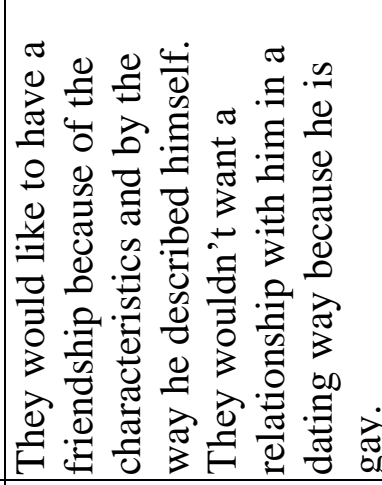 & 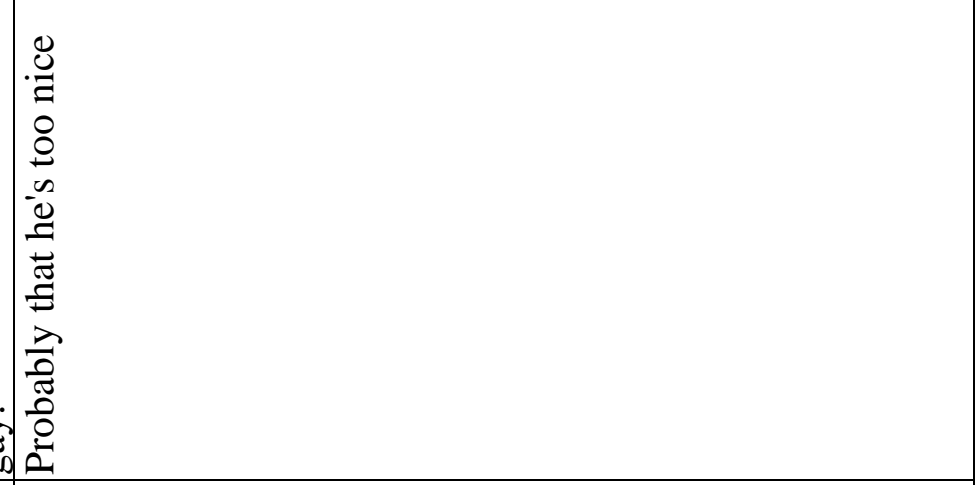 \\
\hline & 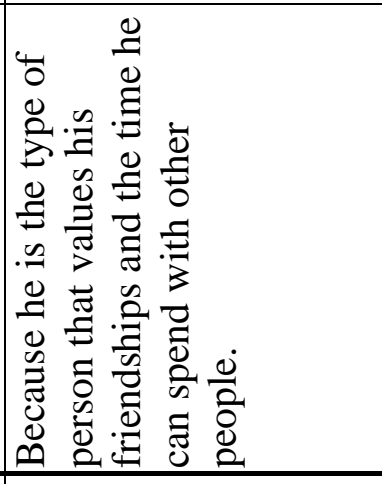 & 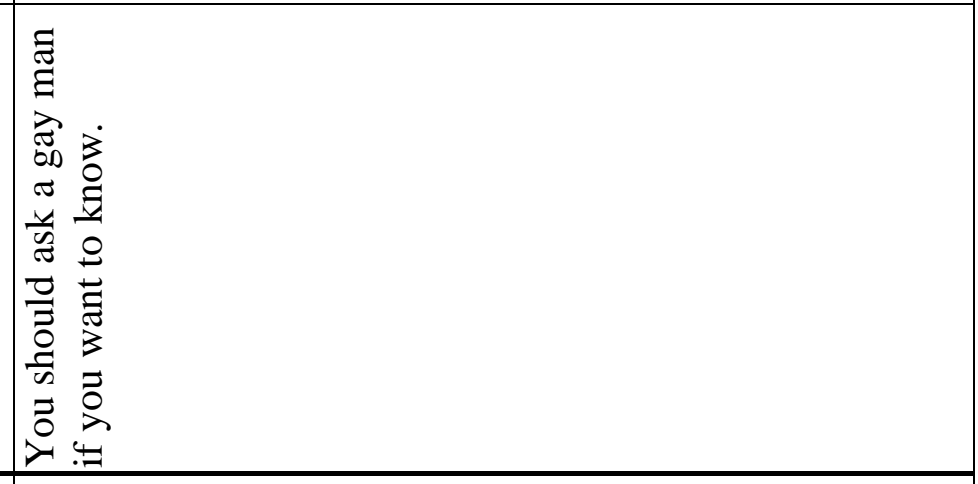 \\
\hline & 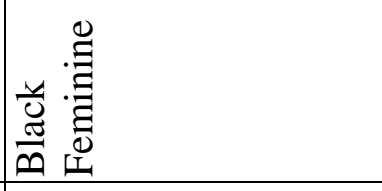 & 咅 \\
\hline & $a$ & 은 \\
\hline
\end{tabular}




\begin{tabular}{|c|c|c|c|}
\hline & $\begin{array}{l}00 \\
. \Xi \\
\vdots \\
\vdots \\
0 \\
Z \\
\end{array}$ & 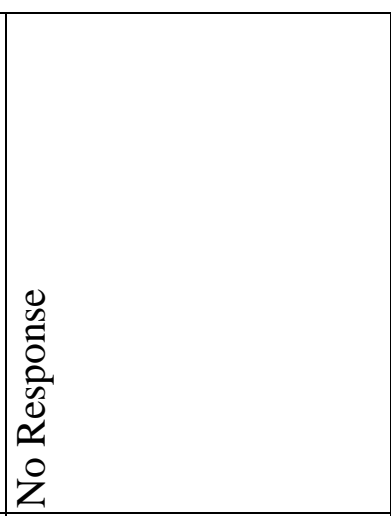 & 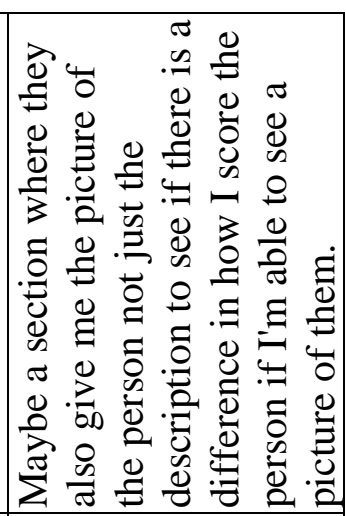 \\
\hline \multirow[t]{5}{*}{ 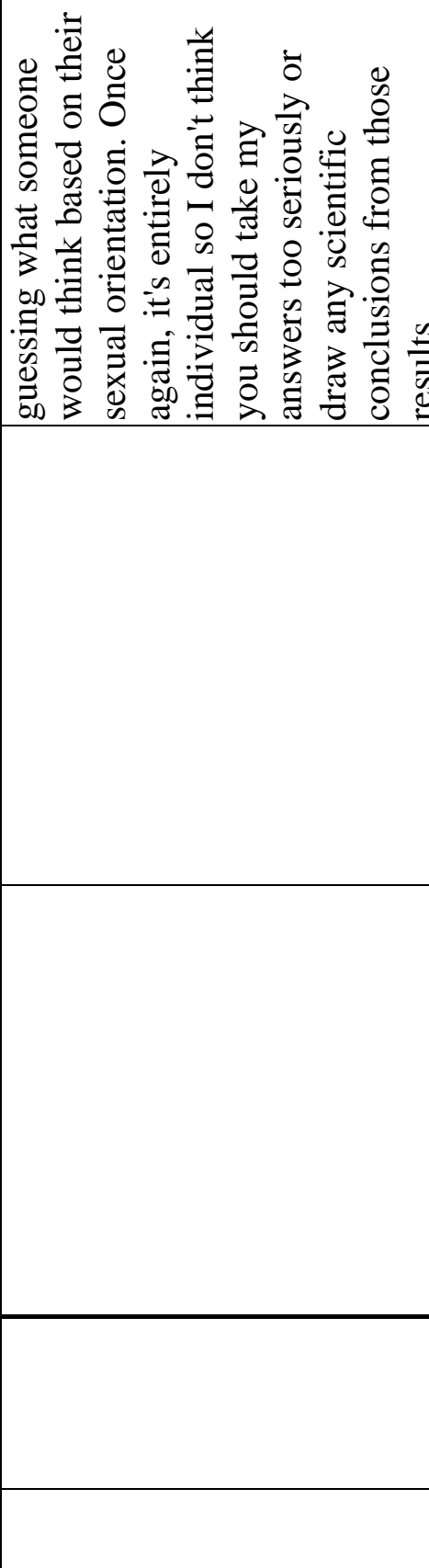 } & 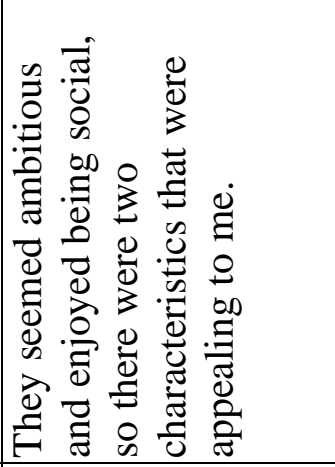 & 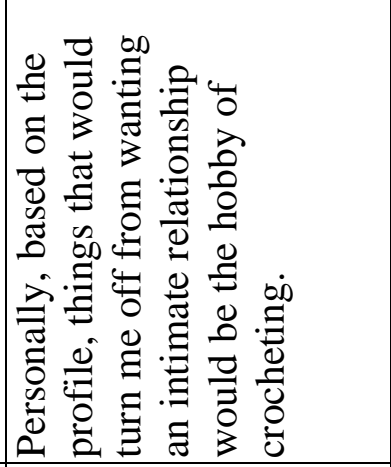 & 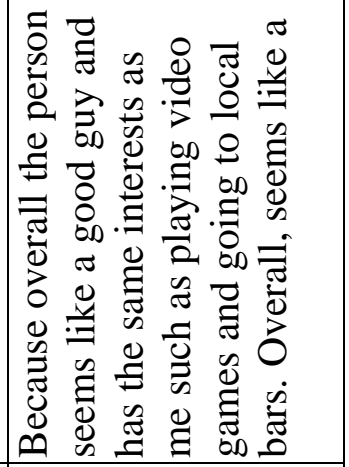 \\
\hline & 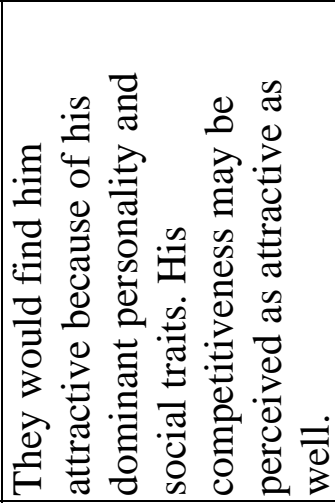 & 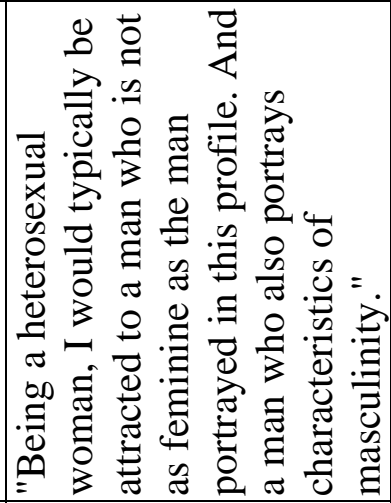 & 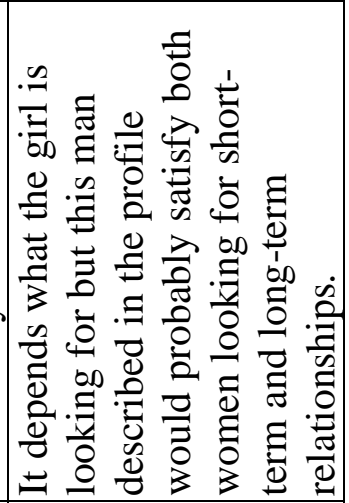 \\
\hline & 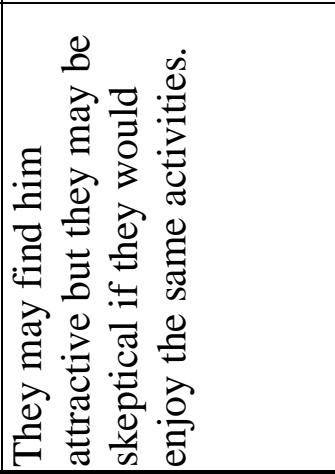 & 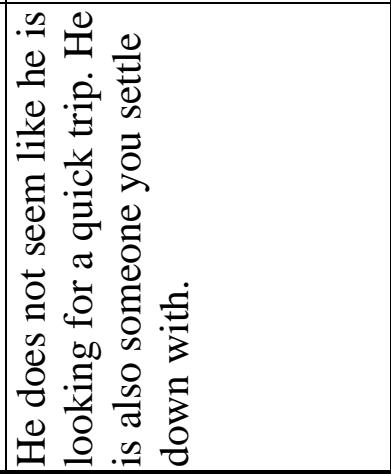 & 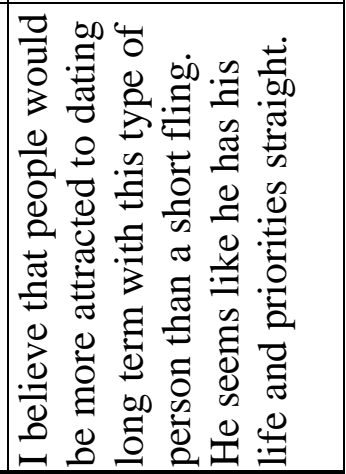 \\
\hline & 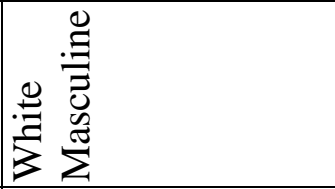 & 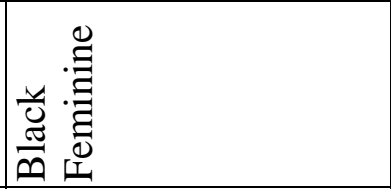 & 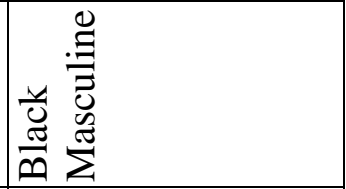 \\
\hline & 二 & $\simeq$ & 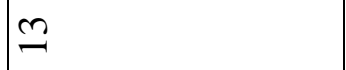 \\
\hline
\end{tabular}




\begin{tabular}{|c|c|c|c|c|c|}
\hline & $\begin{array}{l}0 \\
0 \\
0 \\
0 \\
0.0 \\
0 \\
2 \\
0 \\
0 \\
z\end{array}$ & 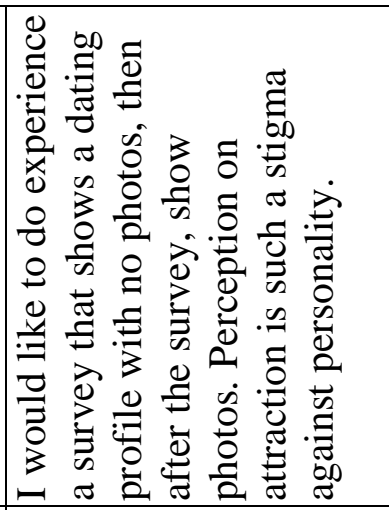 & 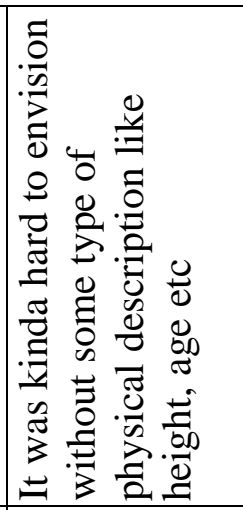 & 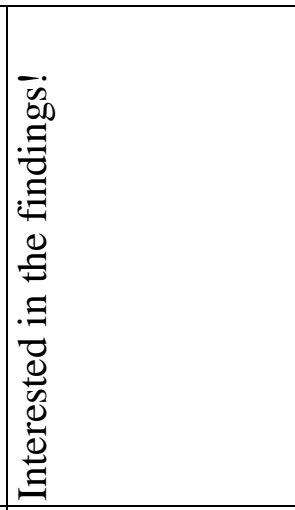 & 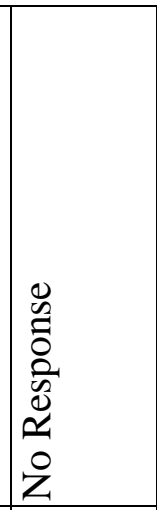 \\
\hline \multirow[t]{5}{*}{ 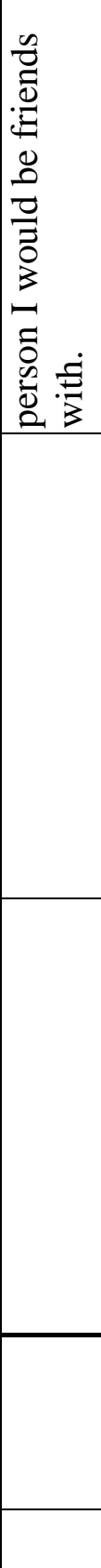 } & 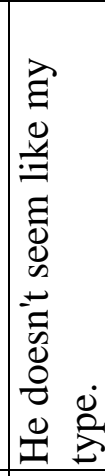 & 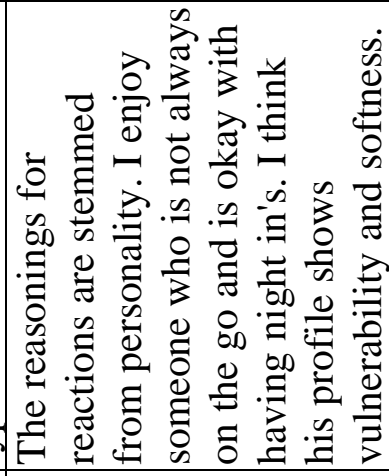 & 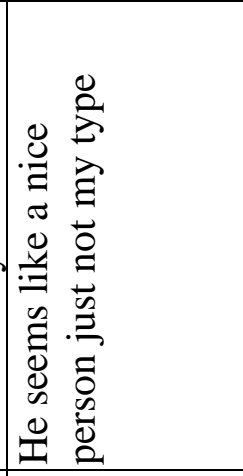 & 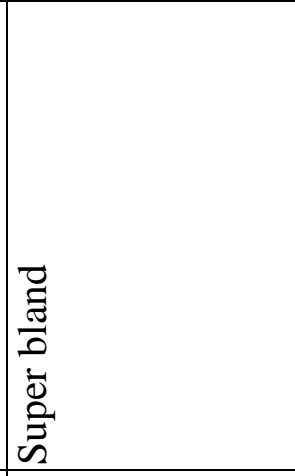 & 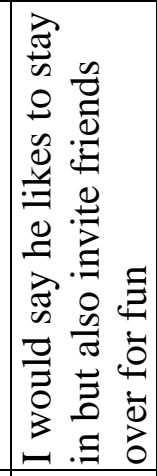 \\
\hline & 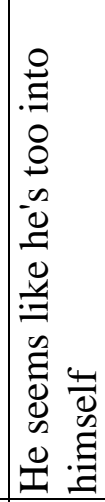 & 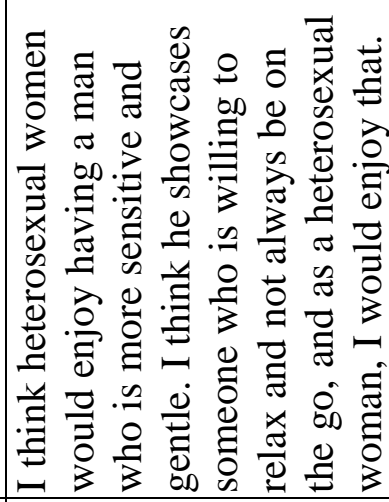 & 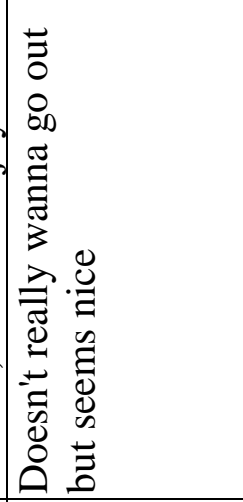 & 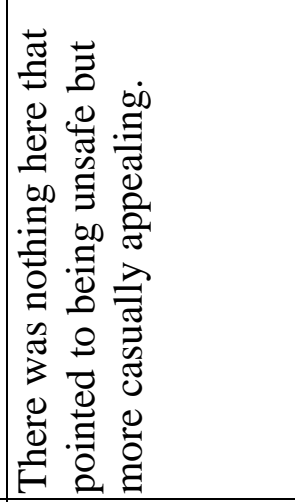 & 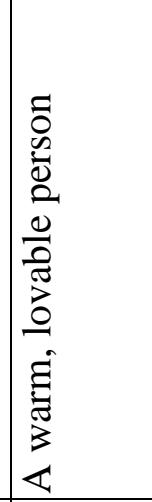 \\
\hline & 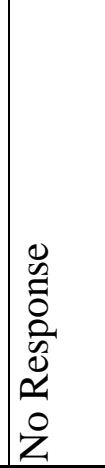 & 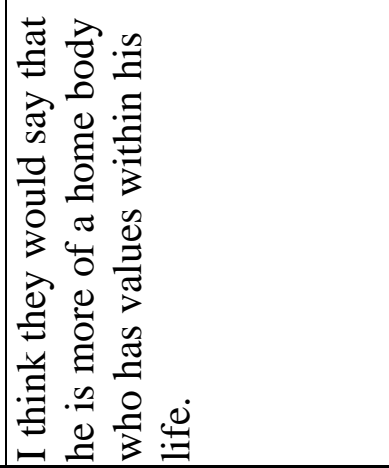 & 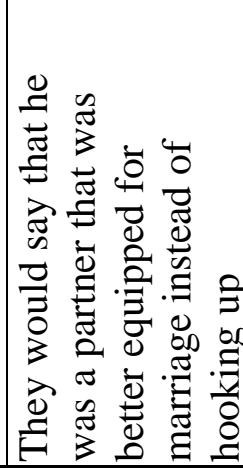 & 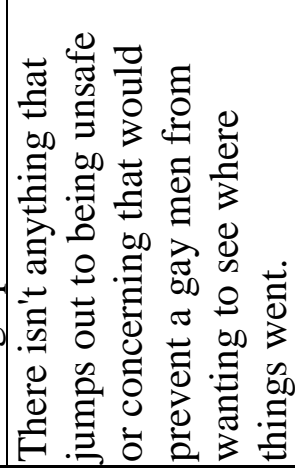 & 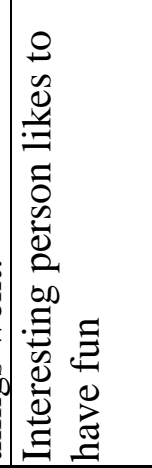 \\
\hline & 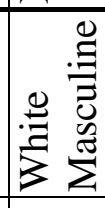 & 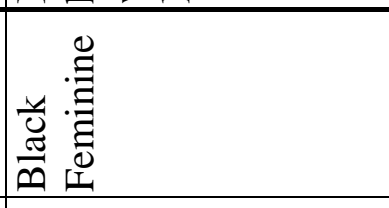 & 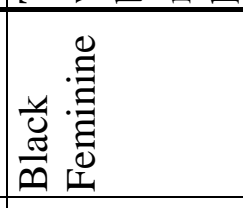 & 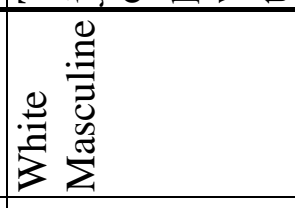 & 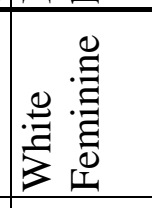 \\
\hline & \pm & 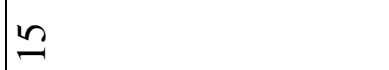 & $\underline{0}$ & $=$ & $\infty$ \\
\hline
\end{tabular}




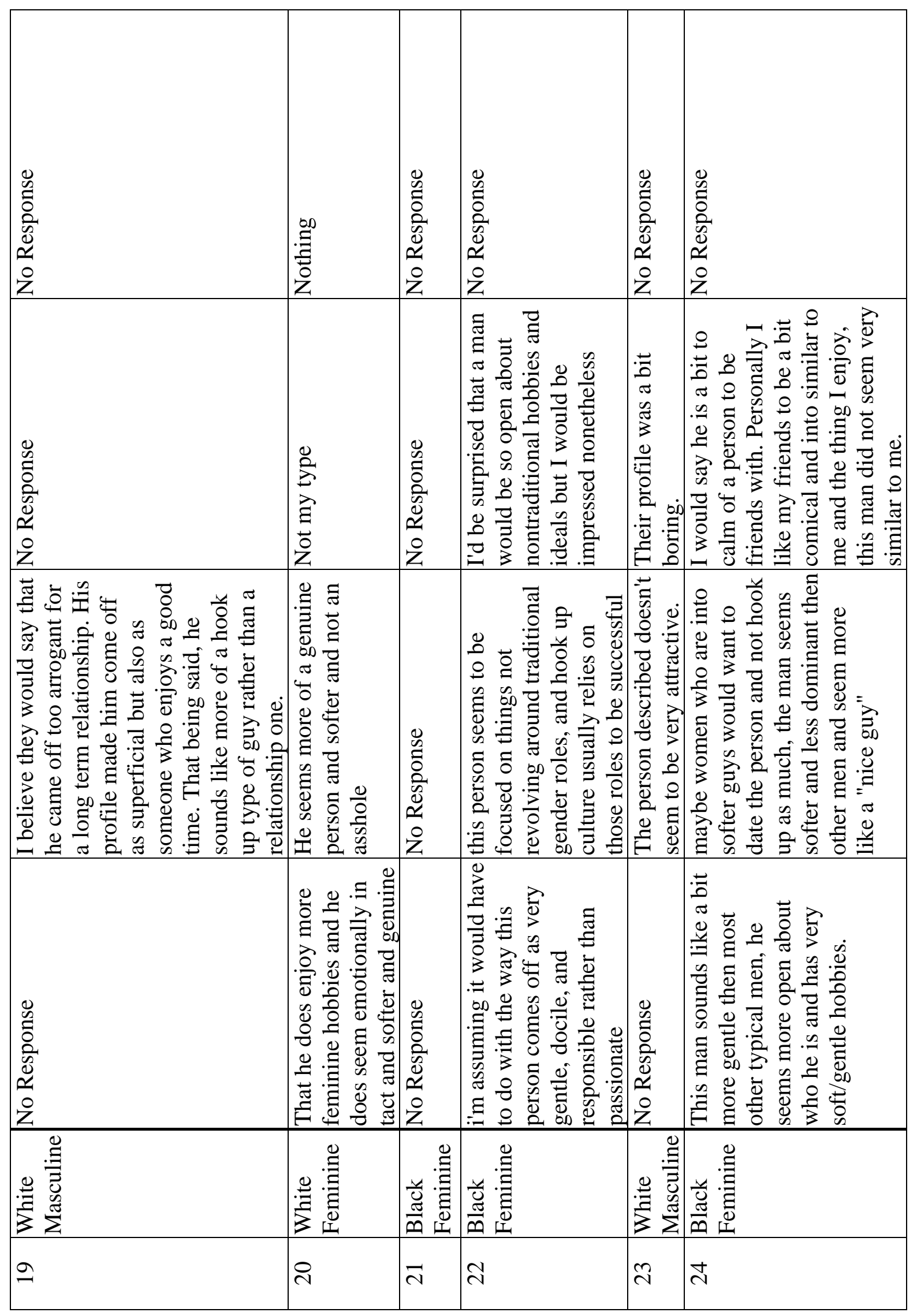




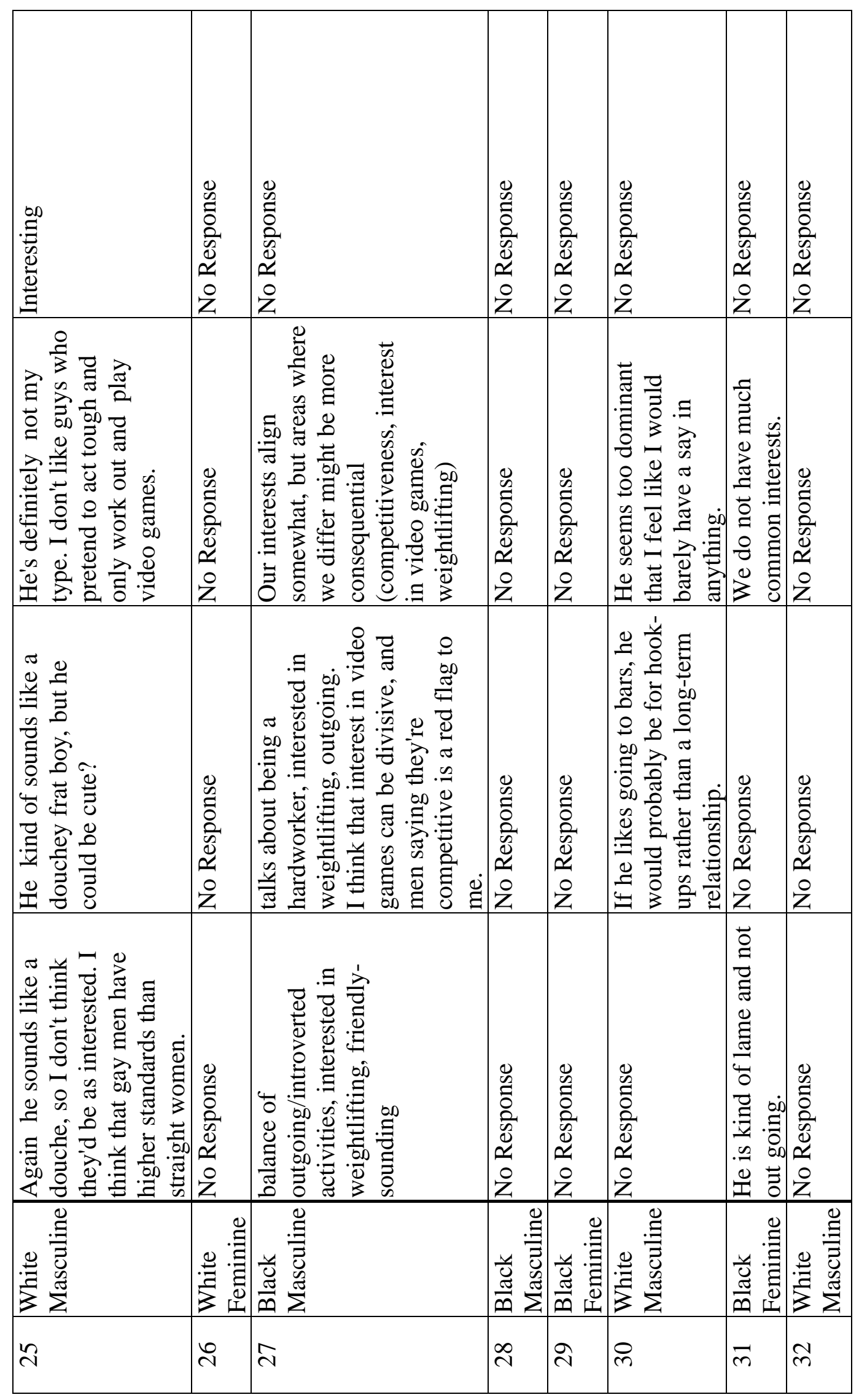




\begin{tabular}{|c|c|c|c|c|c|}
\hline & 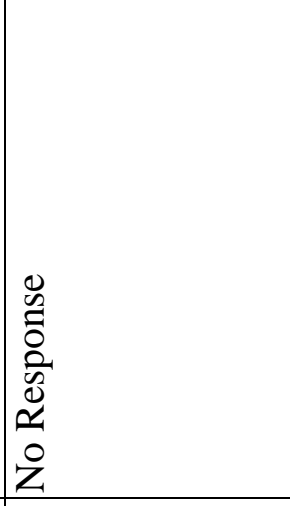 & 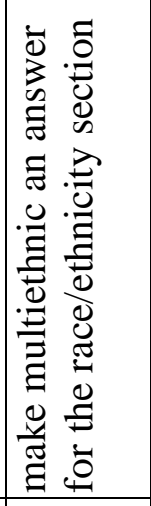 & 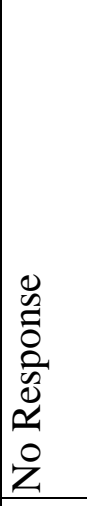 & 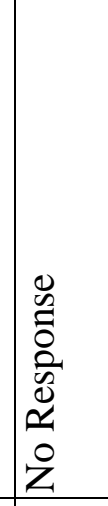 & 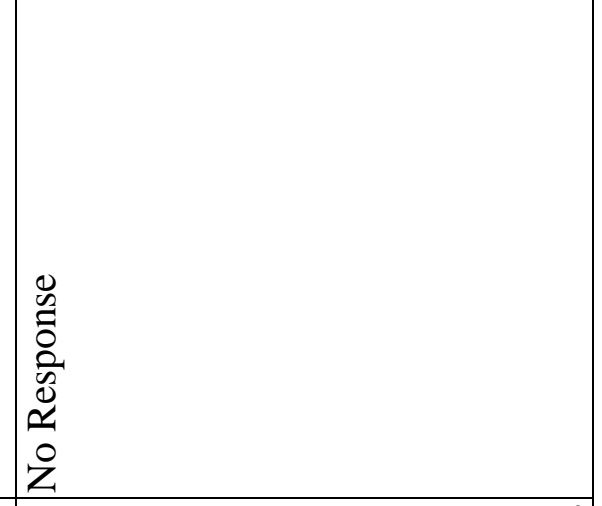 \\
\hline 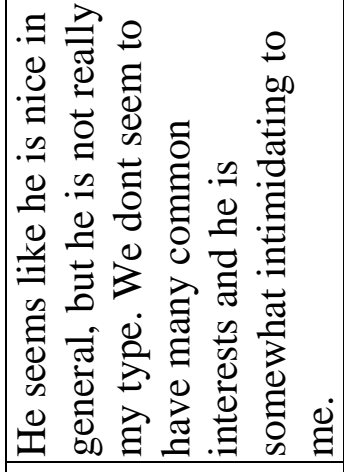 & 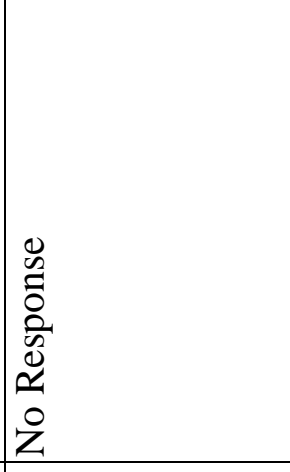 & 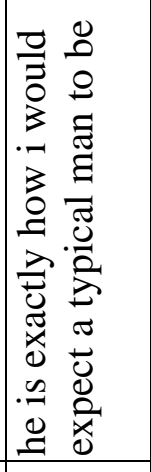 & 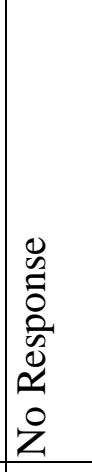 & 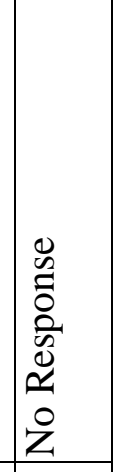 & 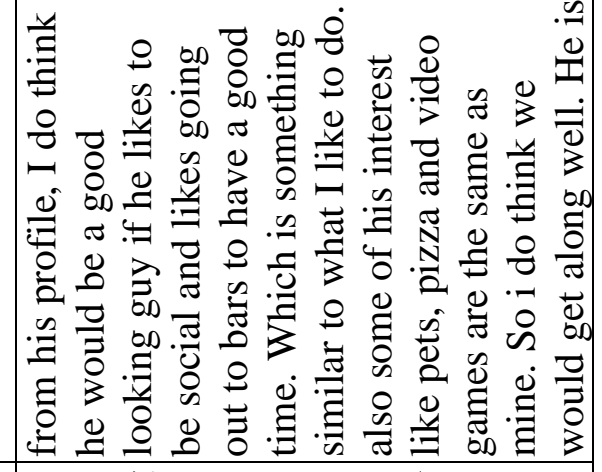 \\
\hline 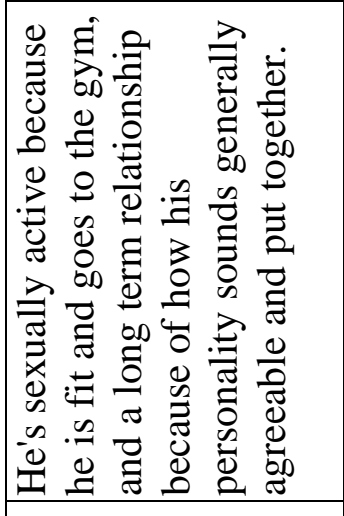 & 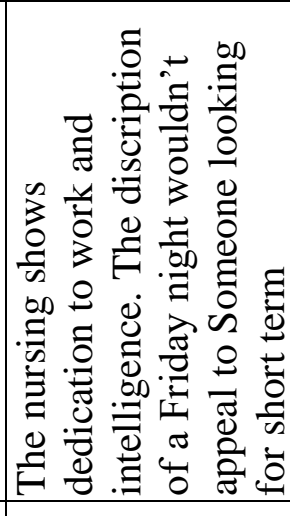 & 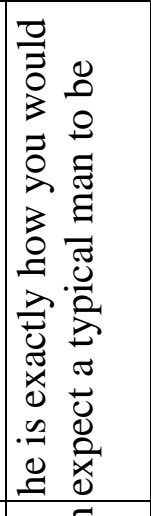 & 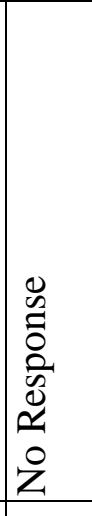 & 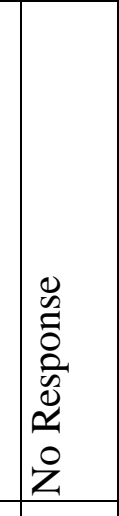 & 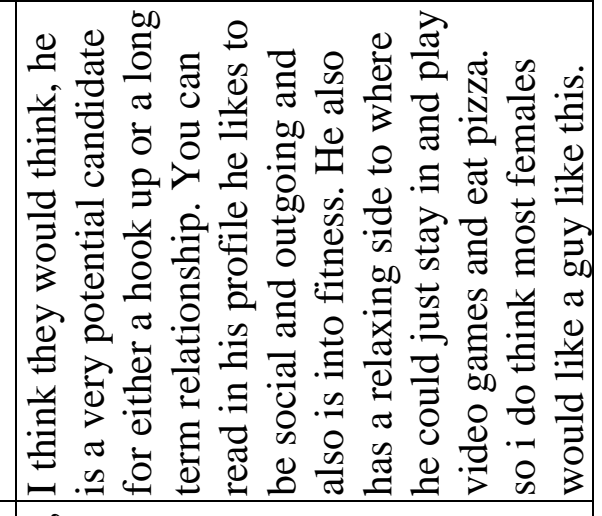 \\
\hline 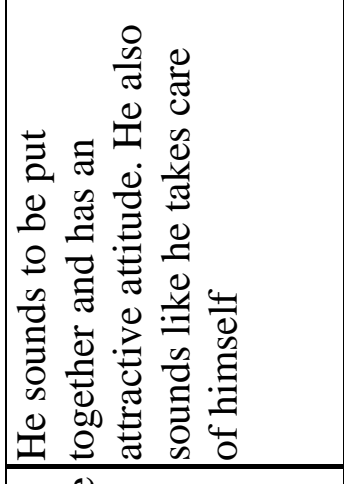 & 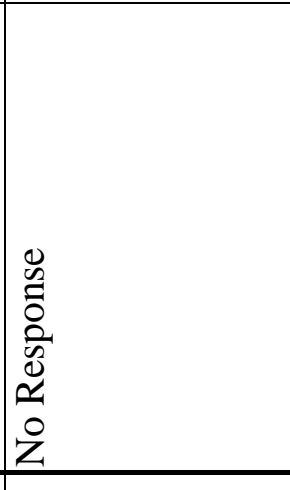 & 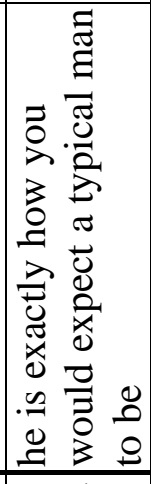 & 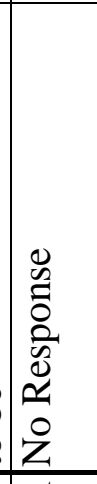 & 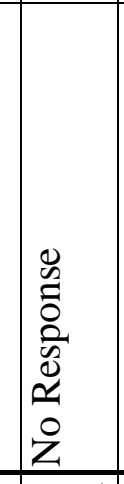 & 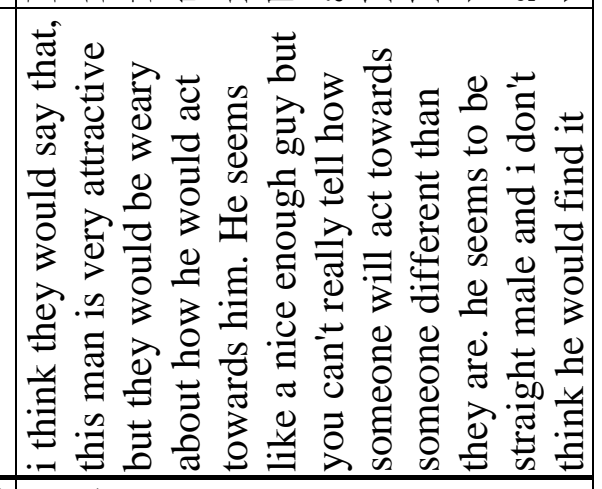 \\
\hline 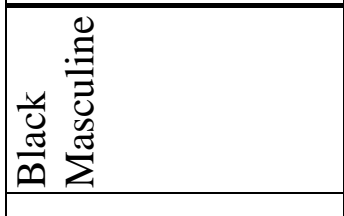 & 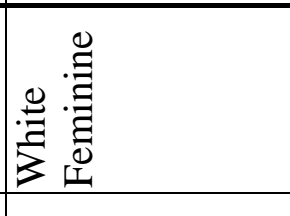 & 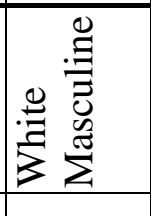 & 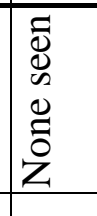 & 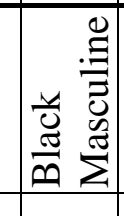 & 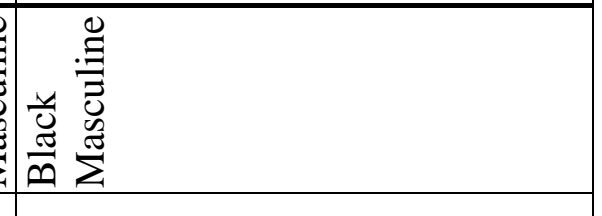 \\
\hline$m$ & m) & $m$ & ల) & ñ & $\underset{m}{\infty}$ \\
\hline
\end{tabular}




\begin{tabular}{|c|c|c|c|c|}
\hline & $\mid \begin{array}{l}\Xi \\
\Xi \\
5 \\
\vdots \\
3\end{array}$ & 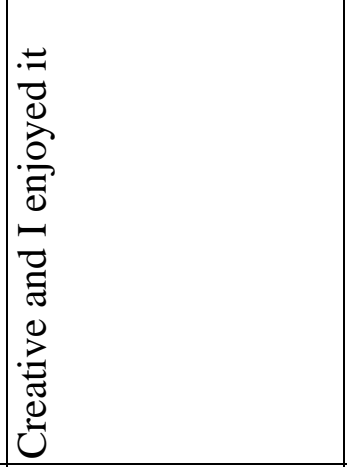 & 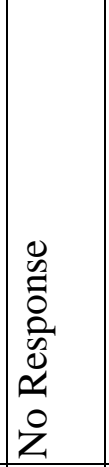 & 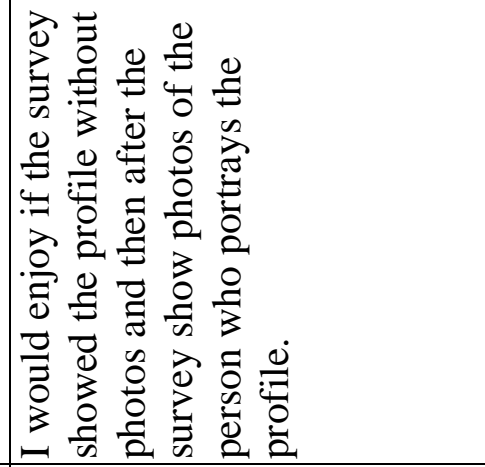 \\
\hline \multirow[t]{2}{*}{ 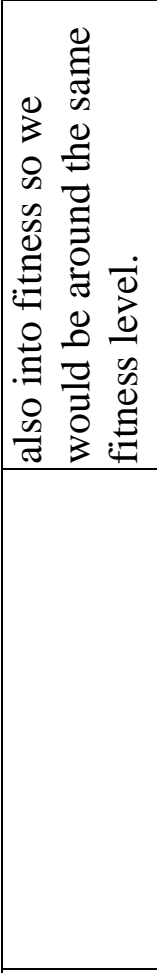 } & 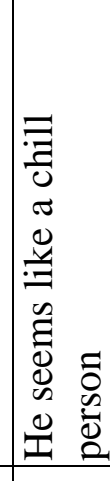 & 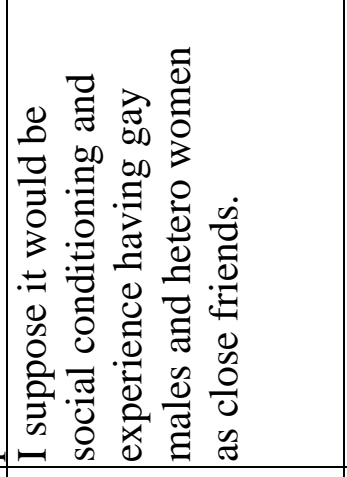 & 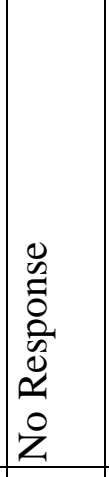 & 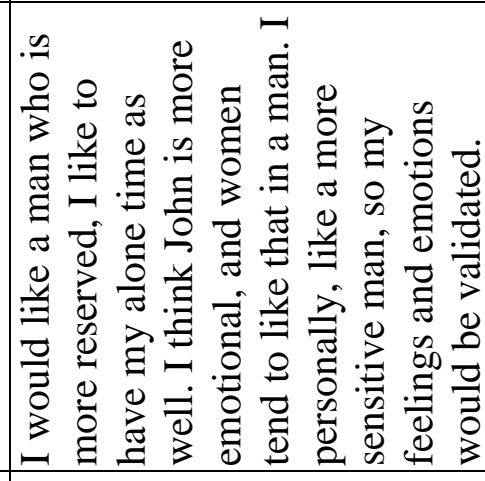 \\
\hline & 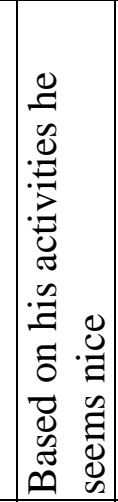 & 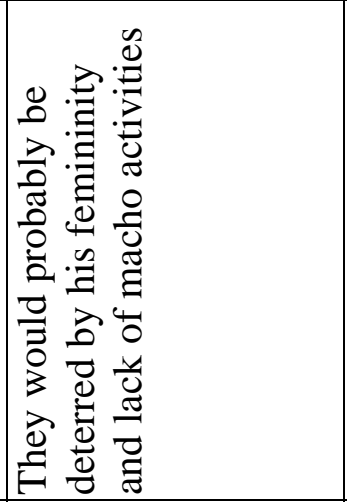 & 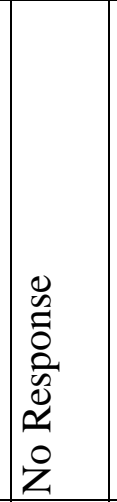 & 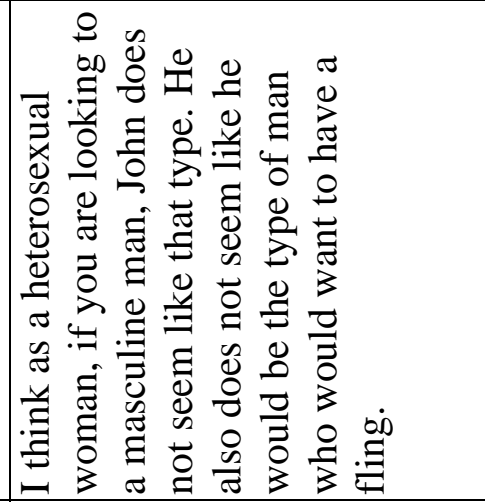 \\
\hline \multirow[t]{3}{*}{ 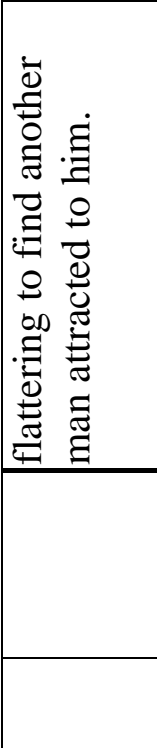 } & $\begin{array}{l}0 \\
0 \\
0 \\
0 \\
0 \\
0 \\
\infty \\
0 \\
0 \\
0 \\
\end{array}$ & 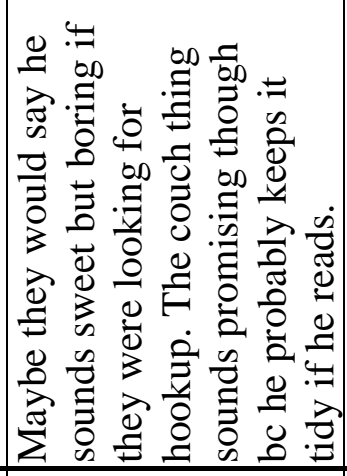 & 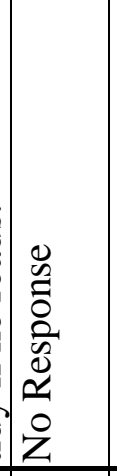 & 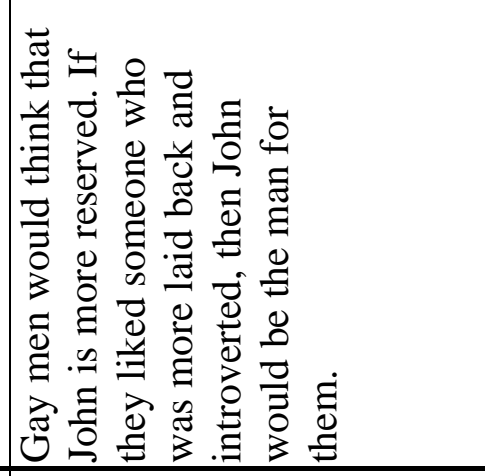 \\
\hline & 章 & 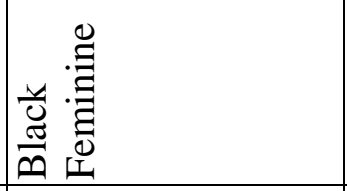 & 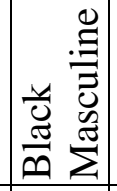 & : \\
\hline & ले & q & $F$ & F \\
\hline
\end{tabular}




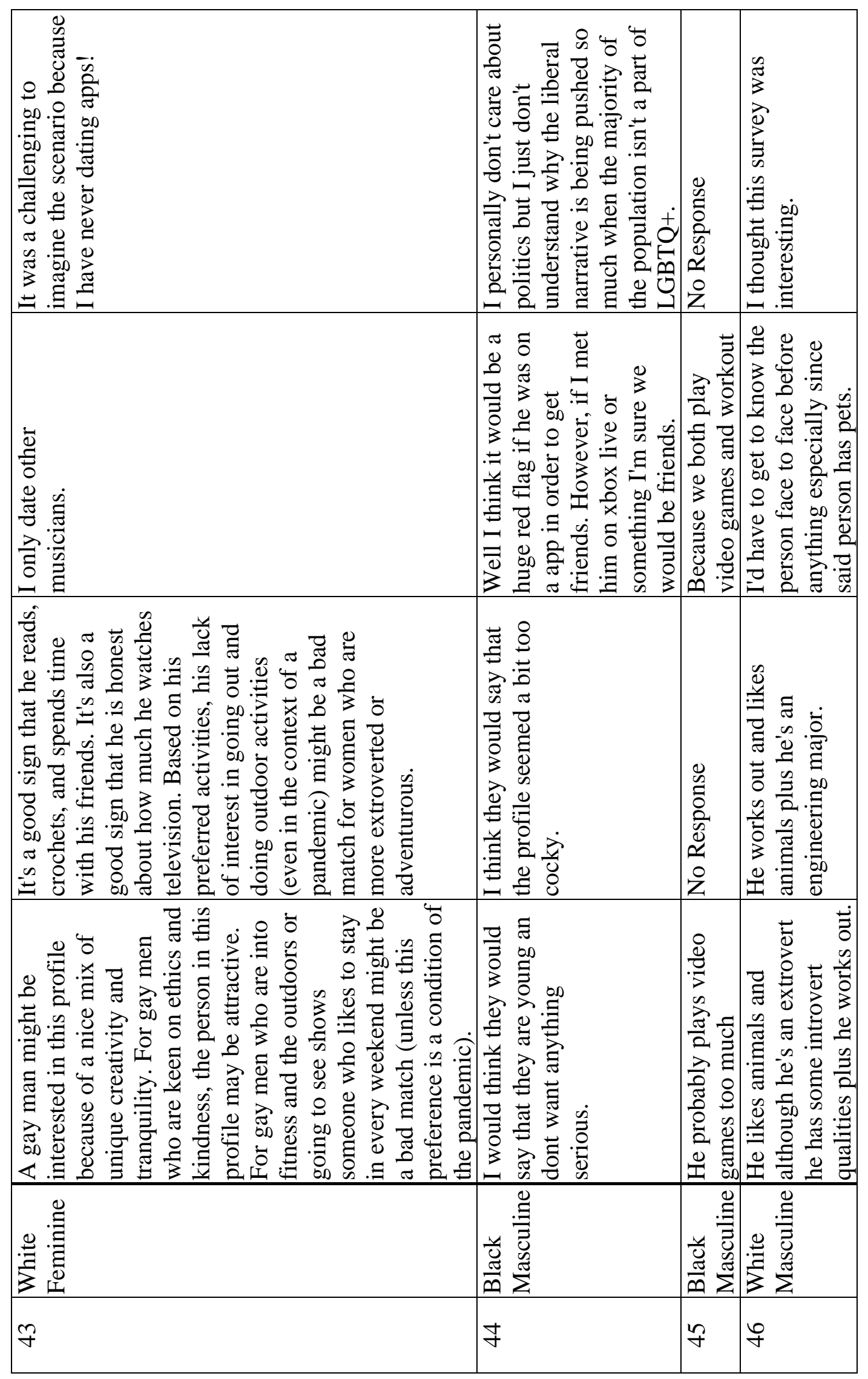




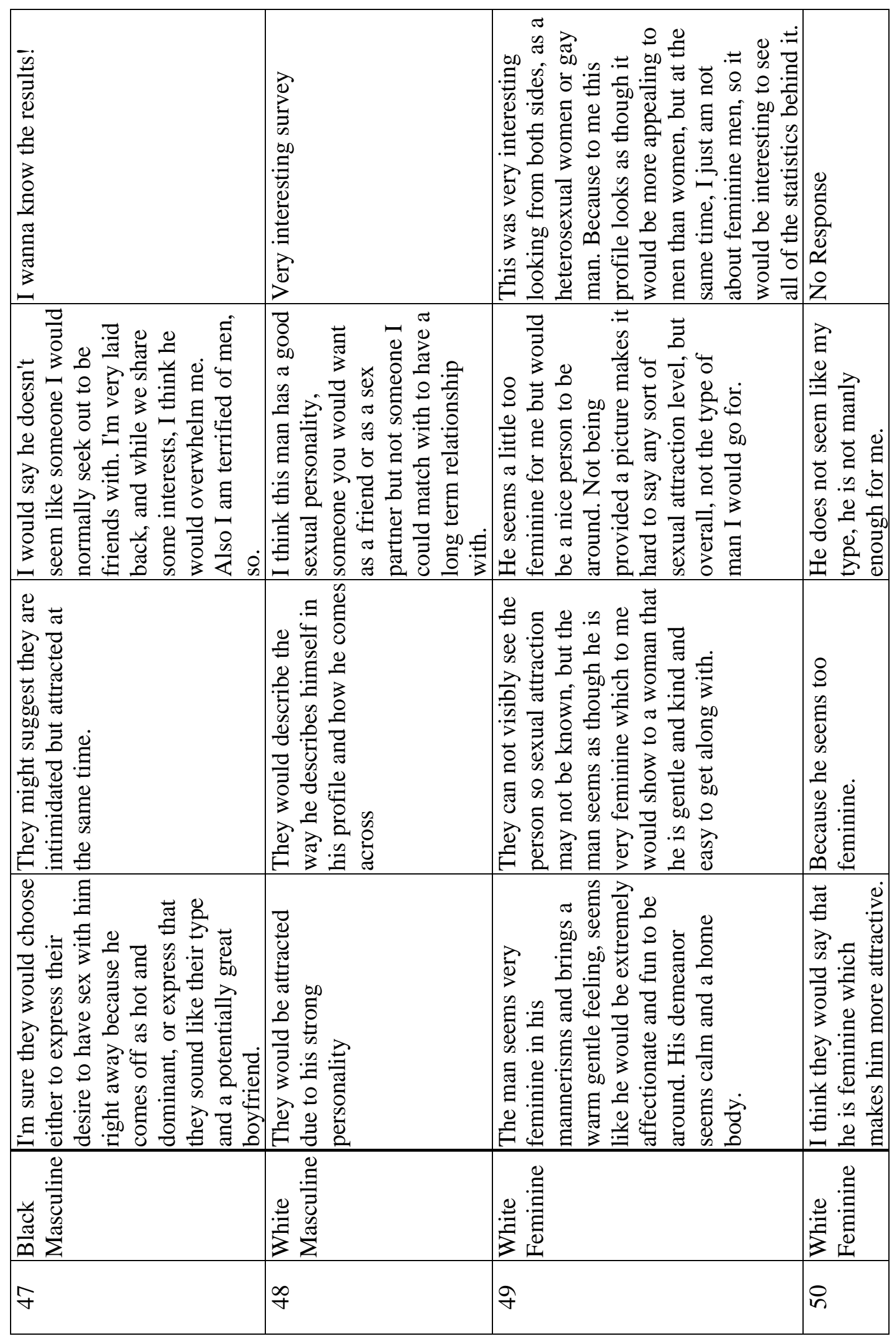




\begin{tabular}{|c|c|c|c|}
\hline 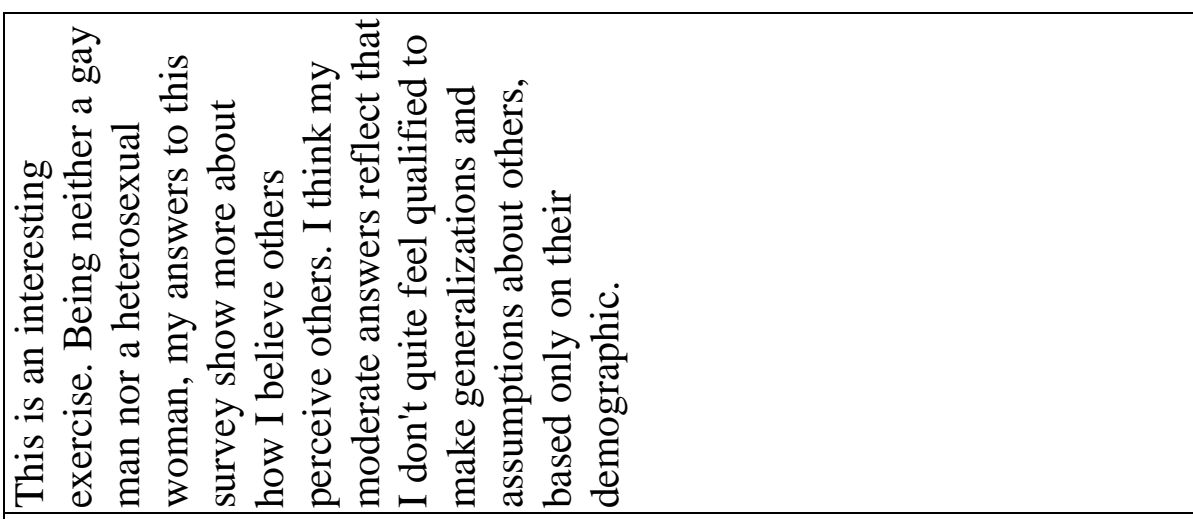 & $\begin{array}{l}\overrightarrow{8} \\
8 \\
00 \\
.2 \\
\pm\end{array}$ & $\begin{array}{l}\mathscr{\Xi} \\
\stackrel{\Xi}{\Xi}\end{array}$ & 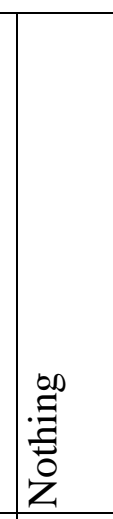 \\
\hline 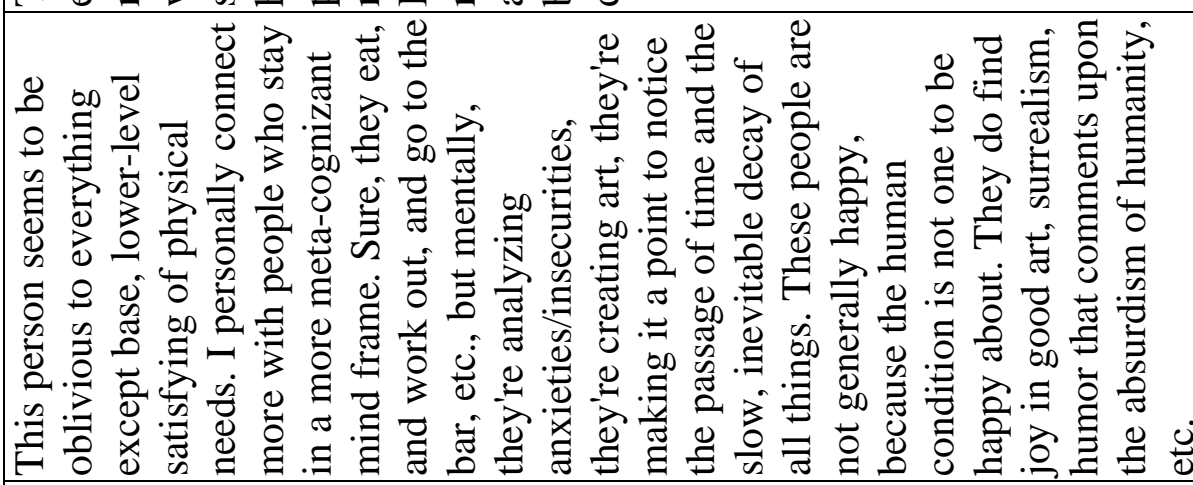 & 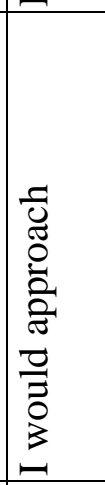 & 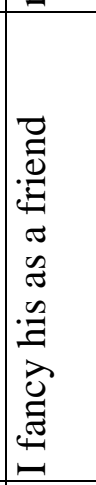 & 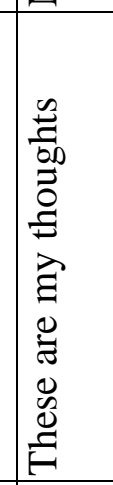 \\
\hline 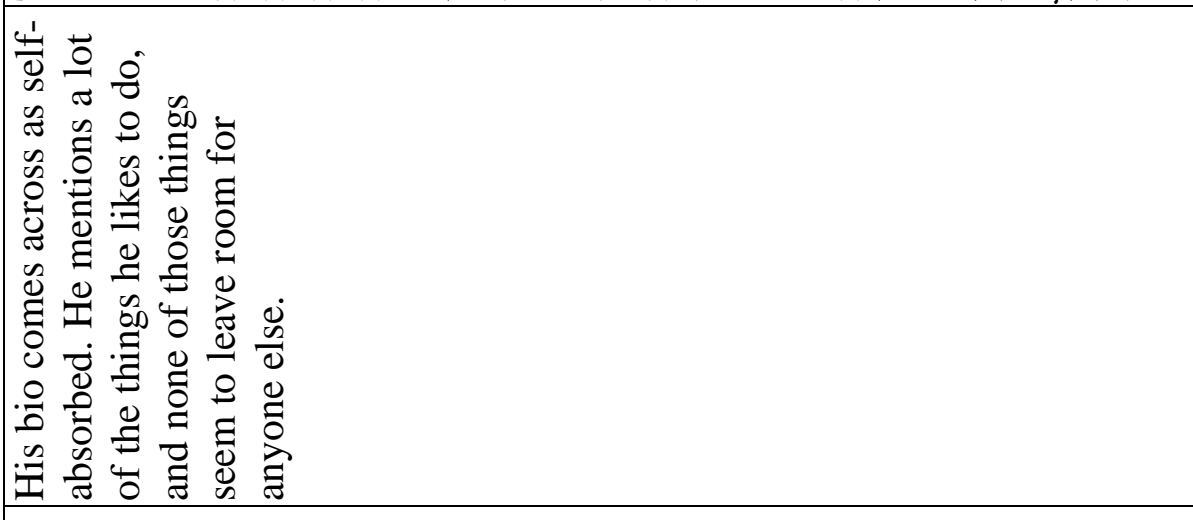 & 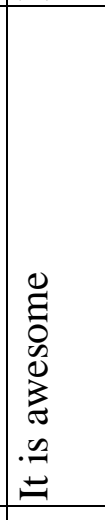 & 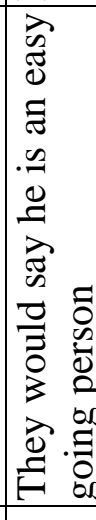 & 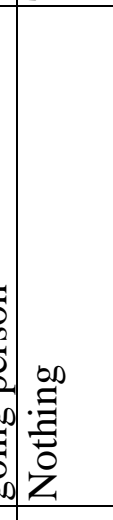 \\
\hline 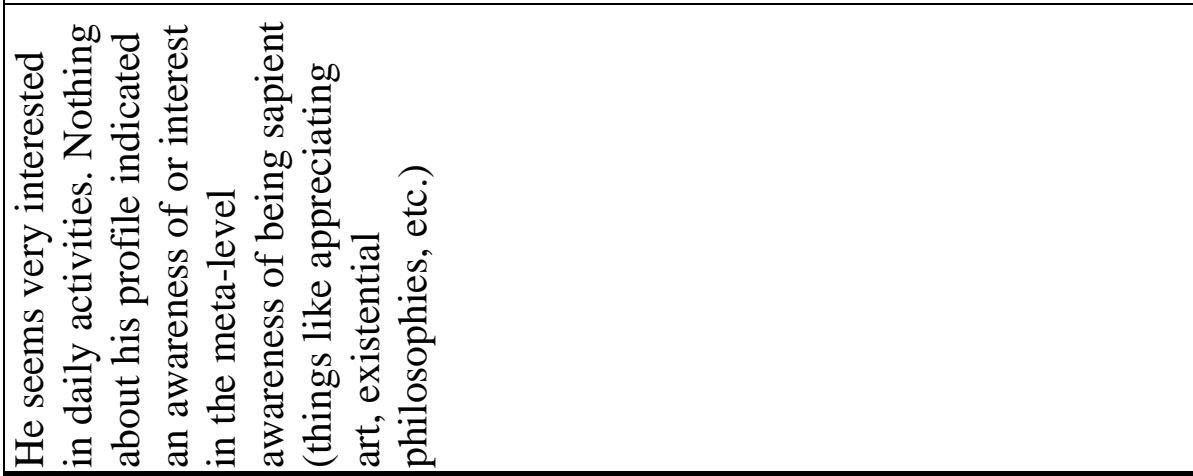 & $\begin{array}{l}\overrightarrow{0} \\
8 \\
\infty \\
.0 \\
.2 \\
\end{array}$ & 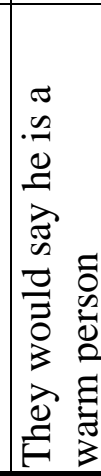 & 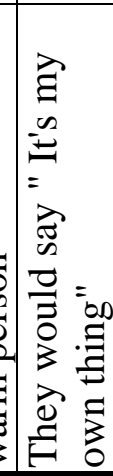 \\
\hline 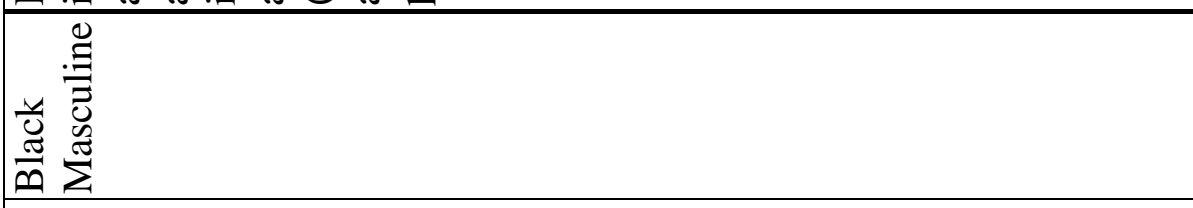 & 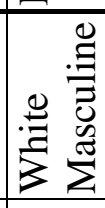 & & 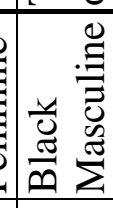 \\
\hline & in & 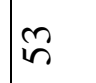 & $\vec{n}$ \\
\hline
\end{tabular}




\begin{tabular}{|c|c|c|c|c|c|c|c|}
\hline $\mathbb{z}$ & 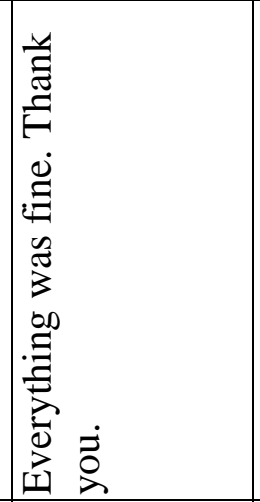 & 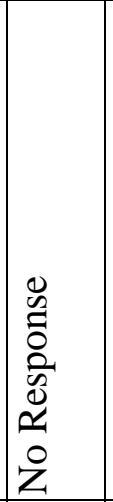 & 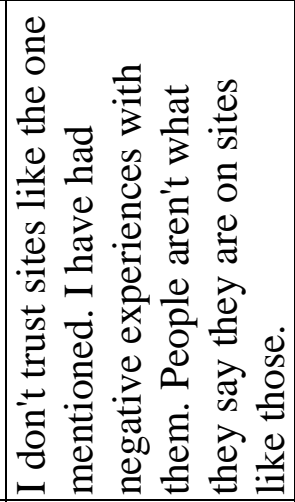 & 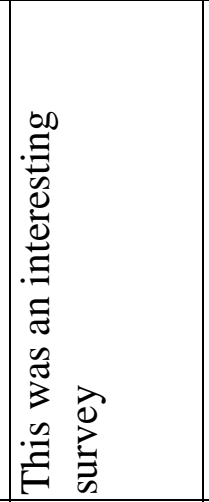 & 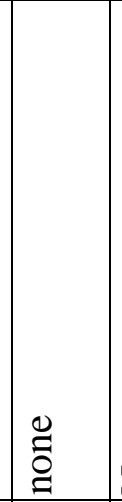 & 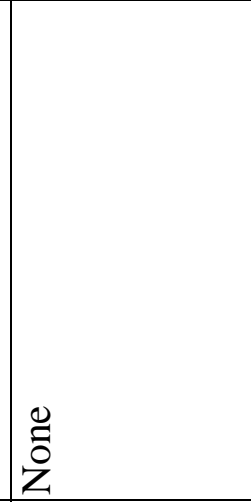 & 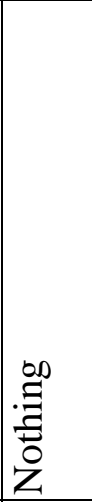 \\
\hline 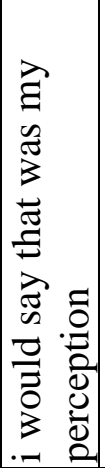 & 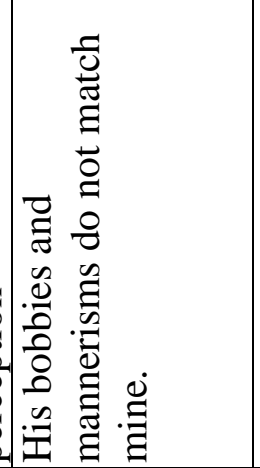 & 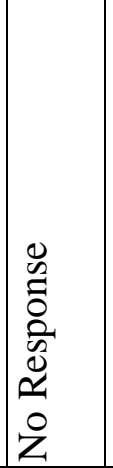 & 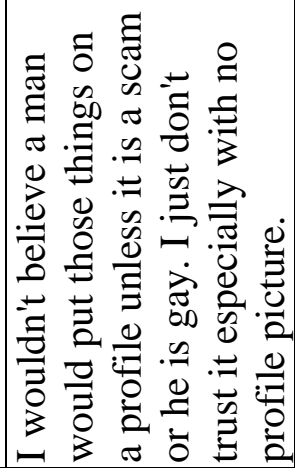 & 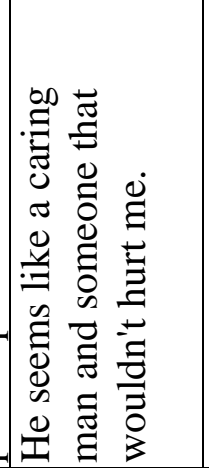 & 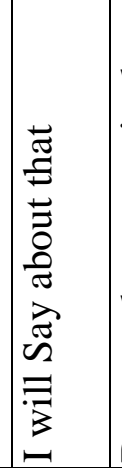 & 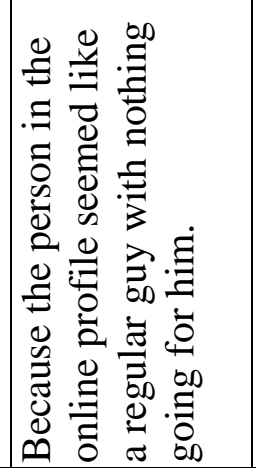 & $\begin{array}{l}7 \\
8 \\
0 \\
00 \\
0 \\
0 \\
\mathbb{0} \\
1\end{array}$ \\
\hline 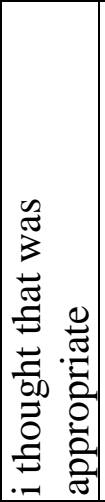 & 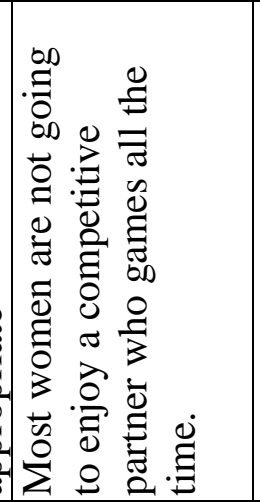 & $\begin{array}{l}0 \\
0 \\
0 \\
0 \\
0 \\
0 \\
\simeq \\
0 \\
0\end{array}$ & 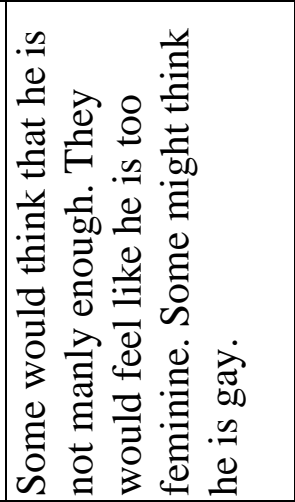 & 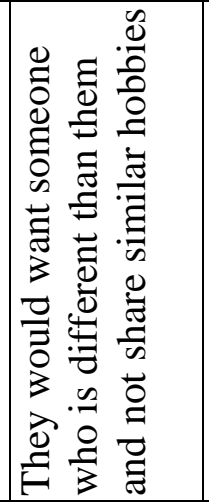 & 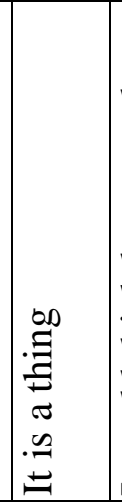 & 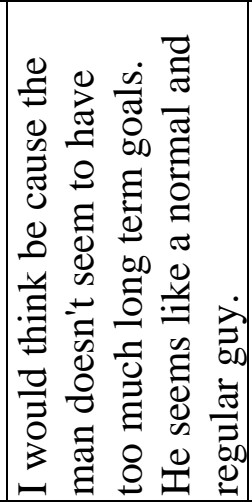 & $\mid \begin{array}{l}0 \\
0 \\
0 \\
0 \\
0 \\
0 \\
0 \\
2 \\
0 \\
z\end{array}$ \\
\hline 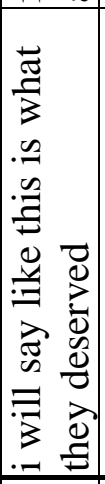 & 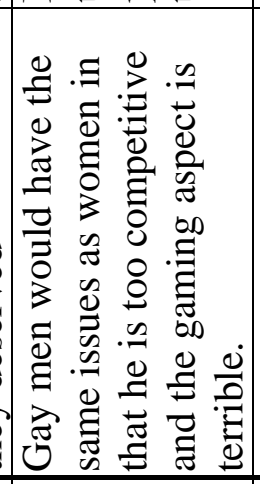 & 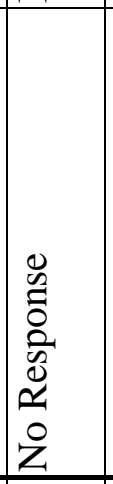 & 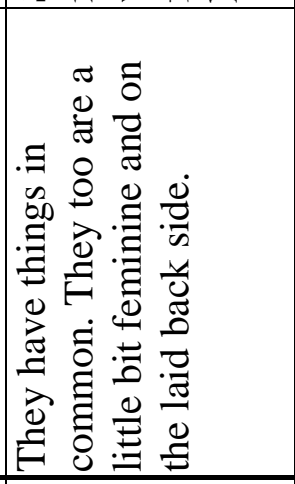 & 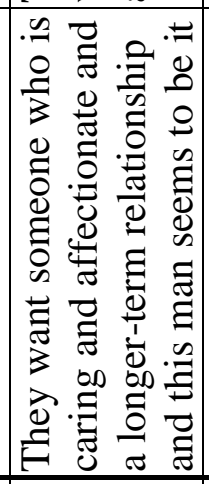 & 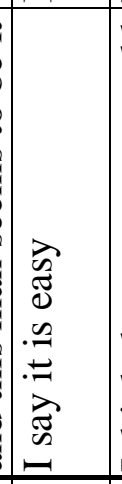 & 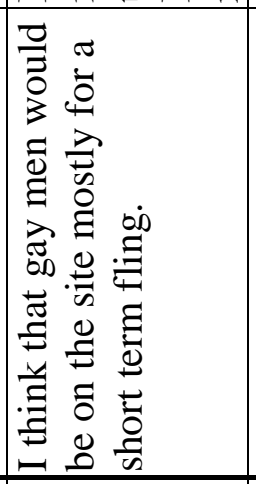 & \begin{tabular}{|l}
7 \\
8 \\
0 \\
00 \\
0 \\
0 \\
0 \\
01 \\
\end{tabular} \\
\hline : & 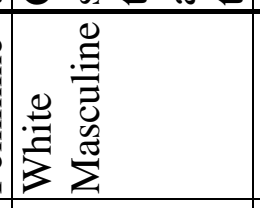 & 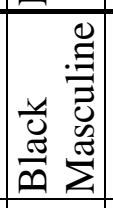 & 章 & 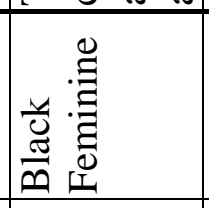 & : & 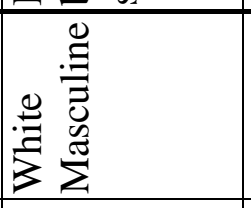 & 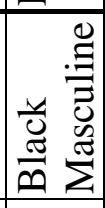 \\
\hline$n$ & $\stackrel{0}{n}$ & in & $\stackrel{\infty}{n}$ & in & 8 & 6 & రิ \\
\hline
\end{tabular}




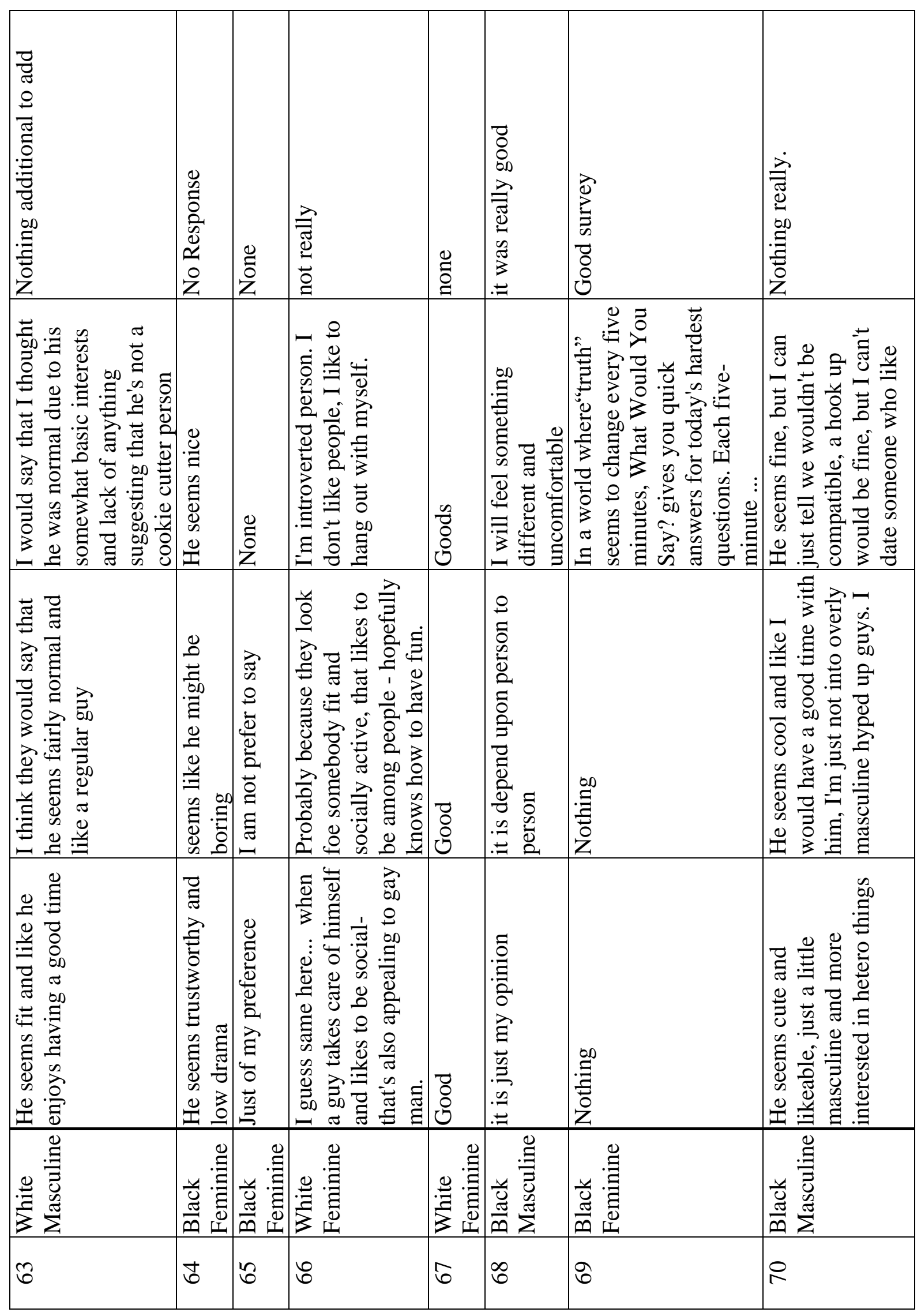




\begin{tabular}{|c|c|c|c|c|c|c|c|}
\hline & 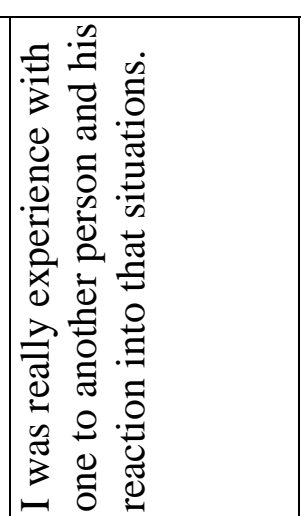 & 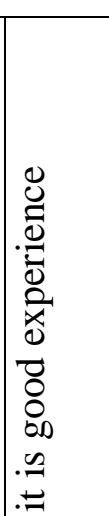 & 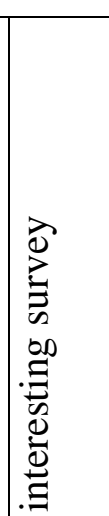 & 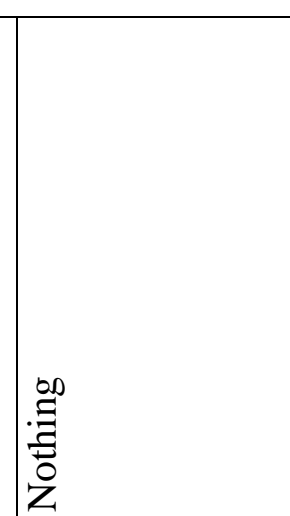 & 竞咅 & 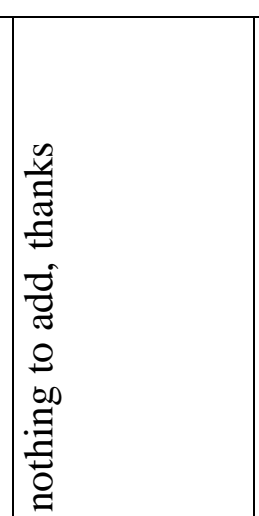 & 這 \\
\hline 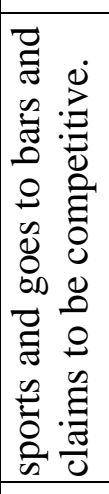 & 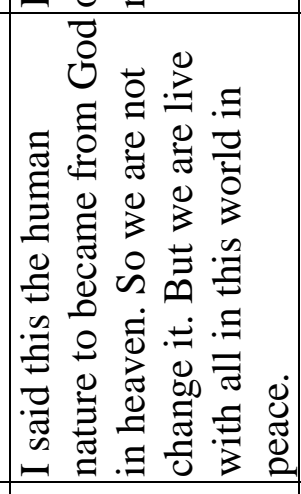 & 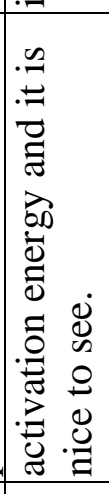 & 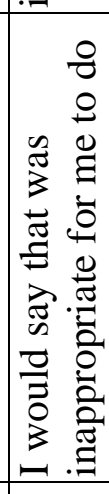 & 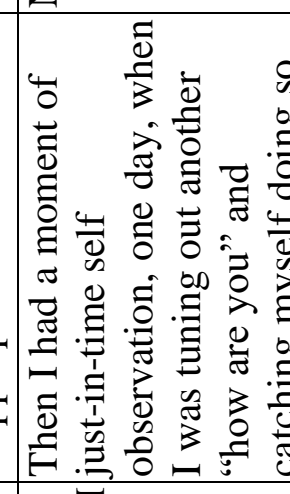 & 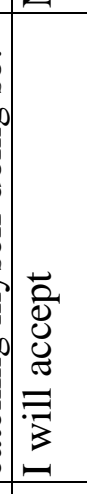 & 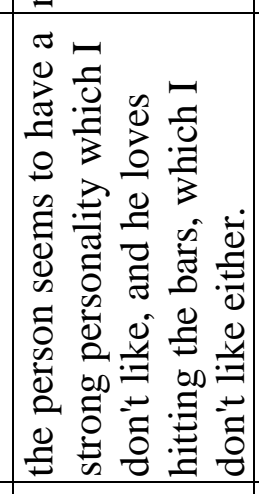 & 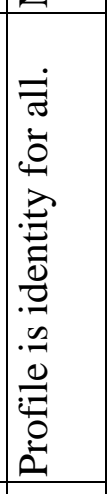 \\
\hline 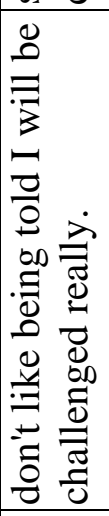 & 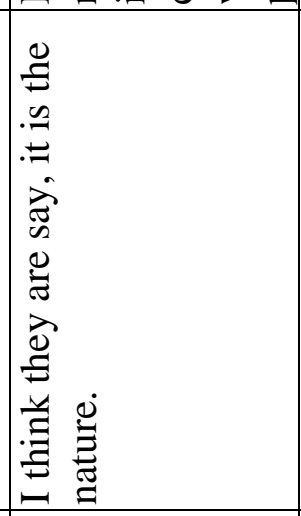 & 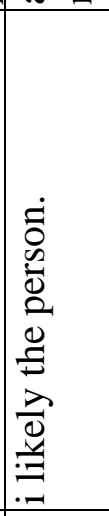 & 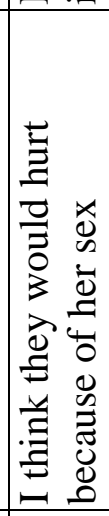 & 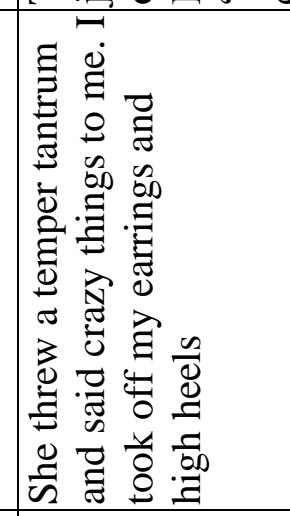 & 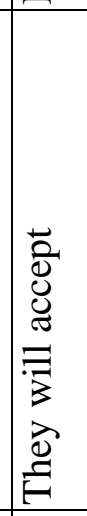 & 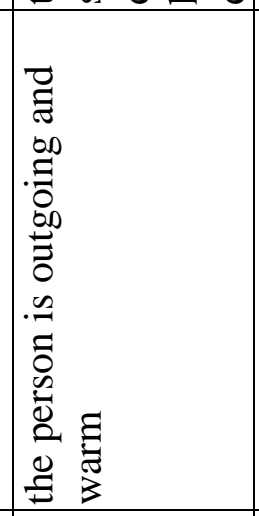 & 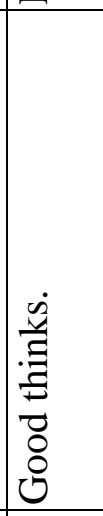 \\
\hline \multirow[t]{3}{*}{ 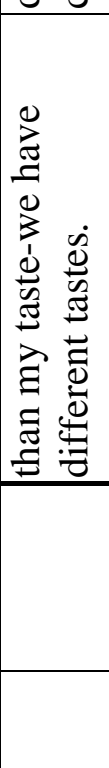 } & 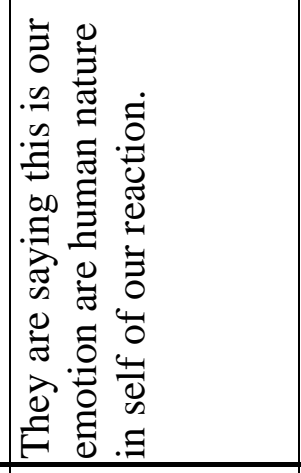 & 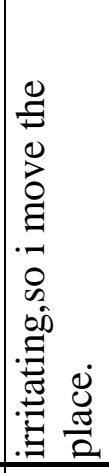 & 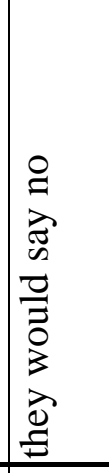 & 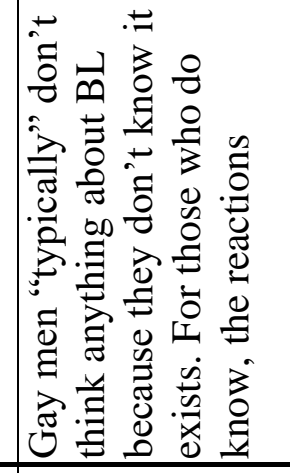 & 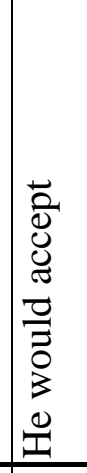 & 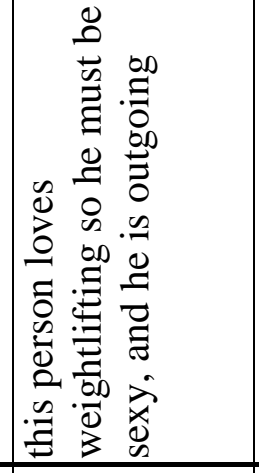 & 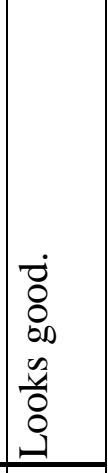 \\
\hline & 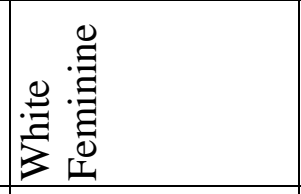 & 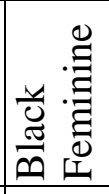 & 章 & 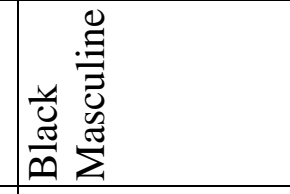 & 要 & 竞 & 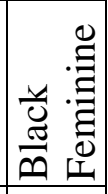 \\
\hline & $\vec{r}$ & $\approx$ & $\cong$ & I & 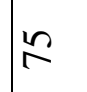 & 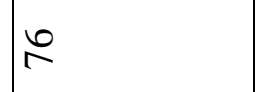 & 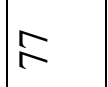 \\
\hline
\end{tabular}




\begin{tabular}{|c|c|c|c|c|c|c|c|}
\hline & 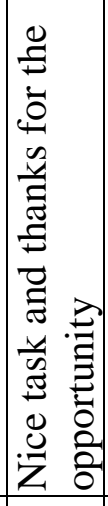 & 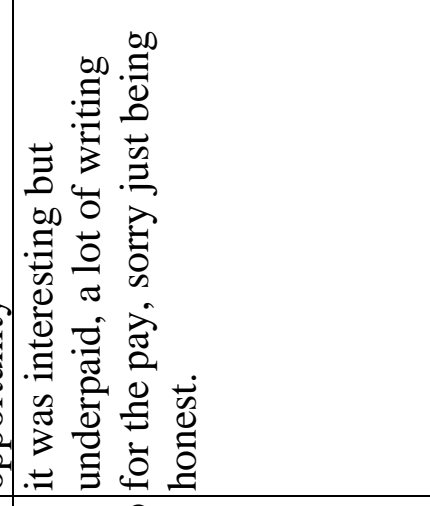 & 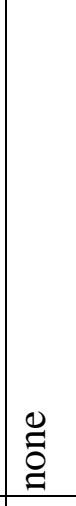 & 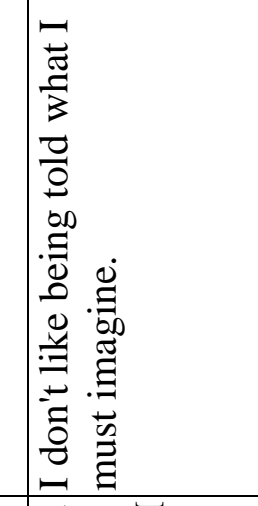 & 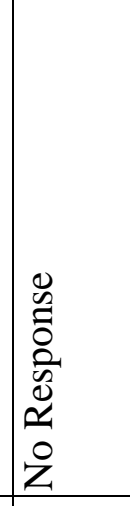 & @ & 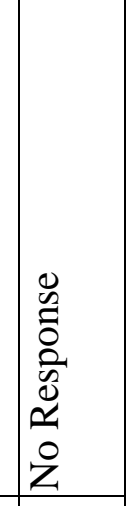 \\
\hline 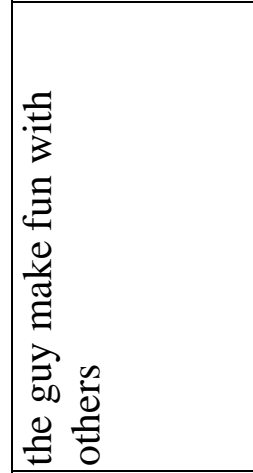 & 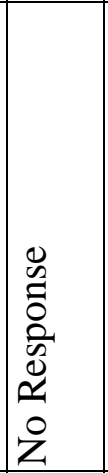 & 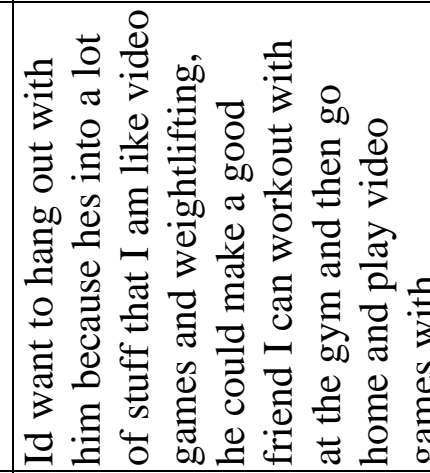 & $\stackrel{0}{\tilde{z}}$ & 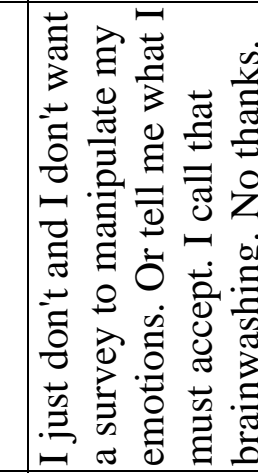 & 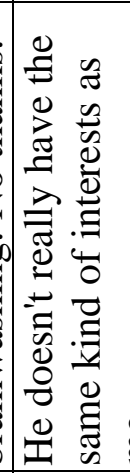 & 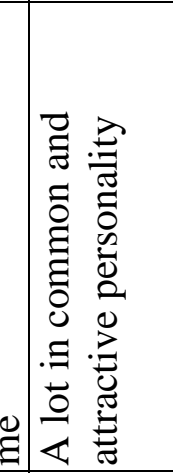 & 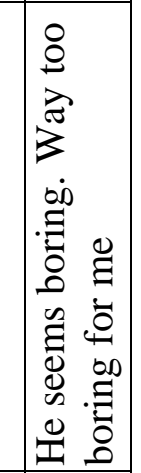 \\
\hline 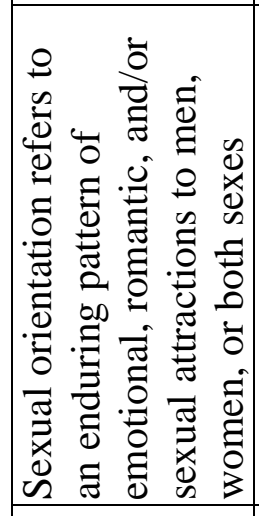 & 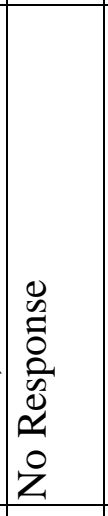 & 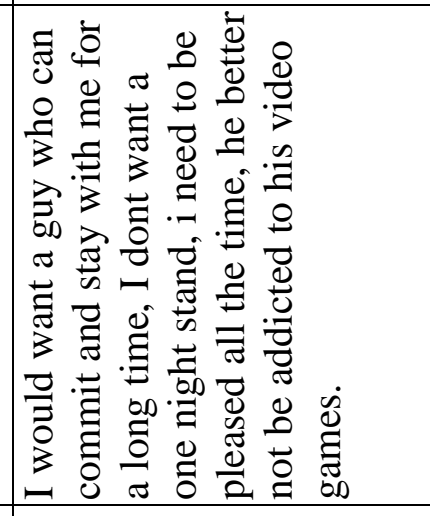 & 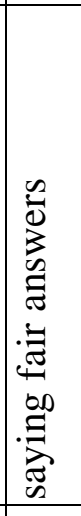 & 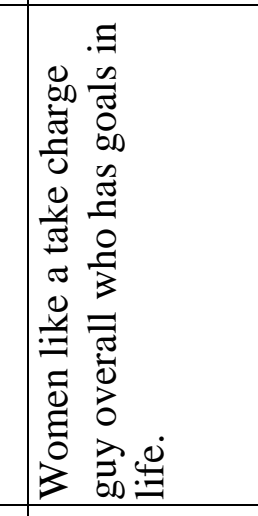 & 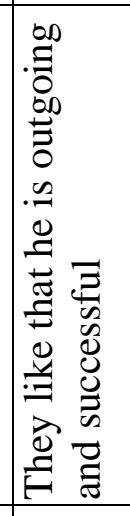 & 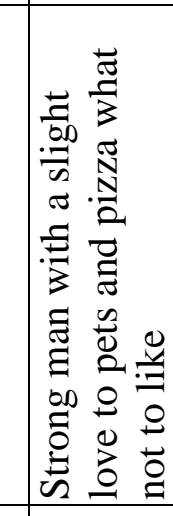 & 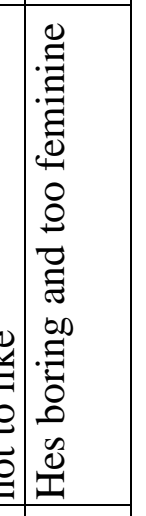 \\
\hline 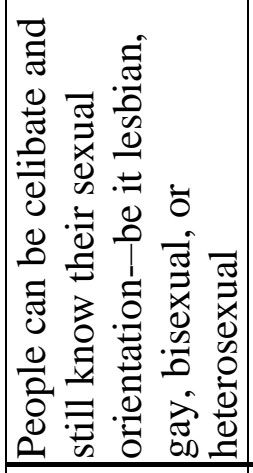 & 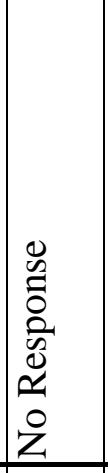 & 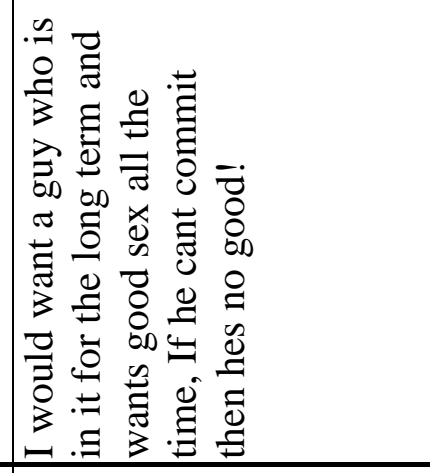 & & 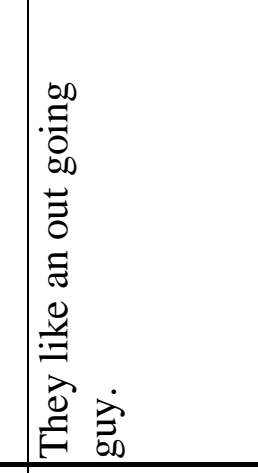 & 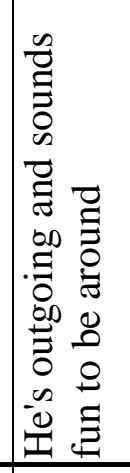 & 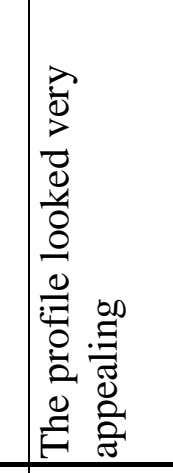 & 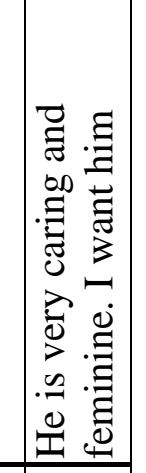 \\
\hline 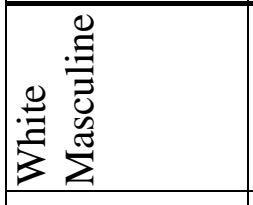 & 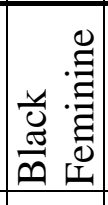 & 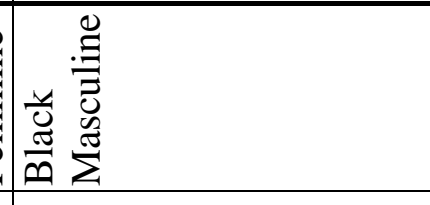 & & 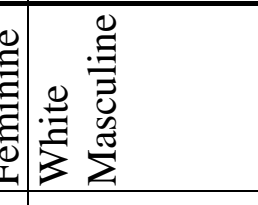 & 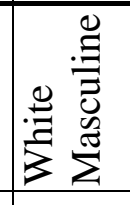 & 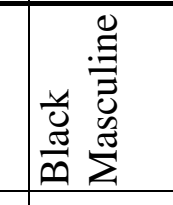 & 兽 \\
\hline & \& & 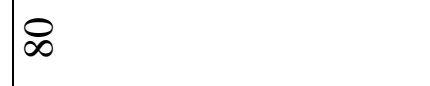 & & $\infty$ & $\infty$ & $\Phi$ & 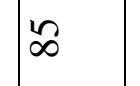 \\
\hline
\end{tabular}




\begin{tabular}{|c|c|c|c|}
\hline & 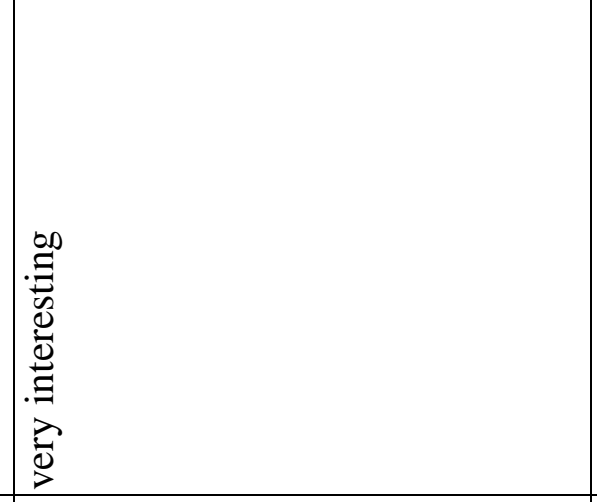 & 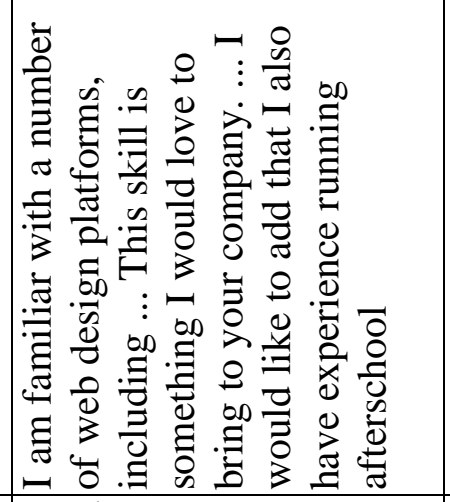 & 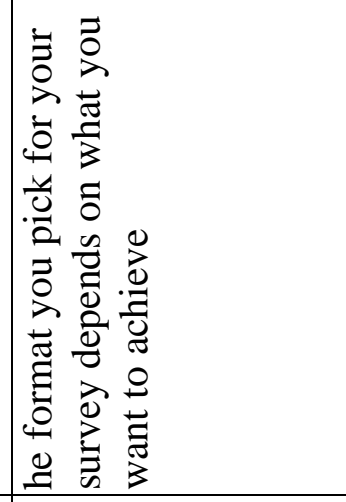 \\
\hline 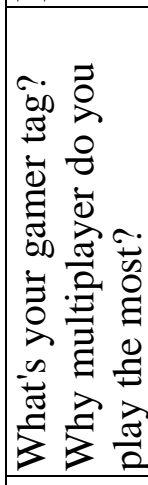 & 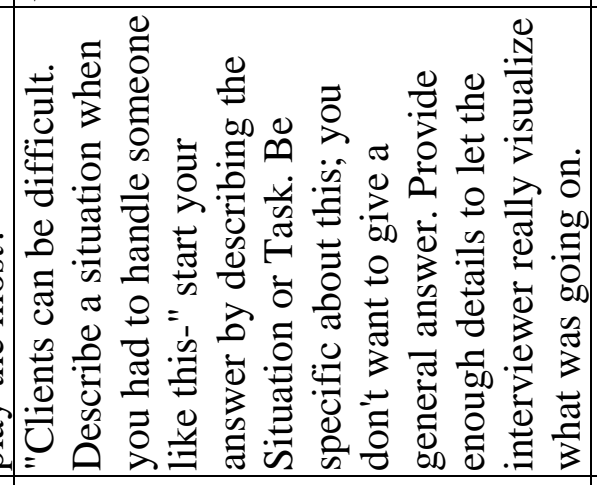 & 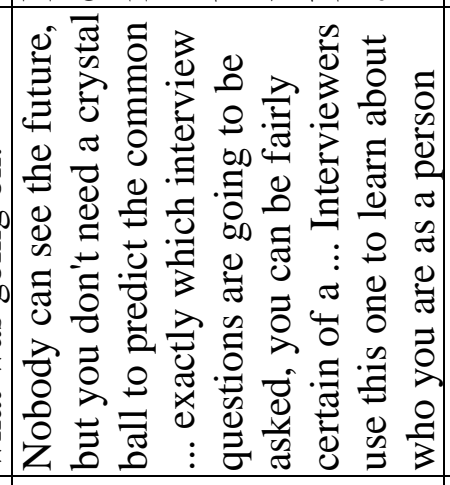 & 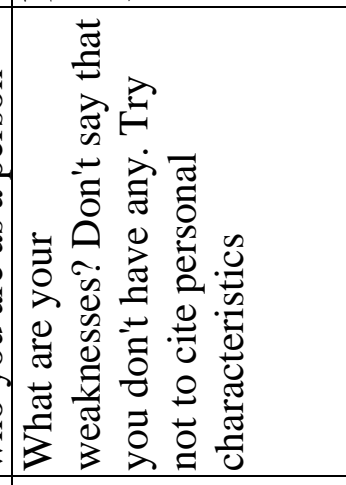 \\
\hline 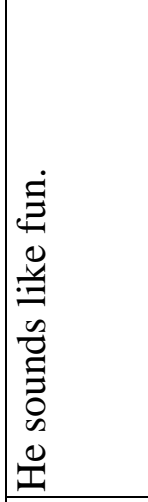 & 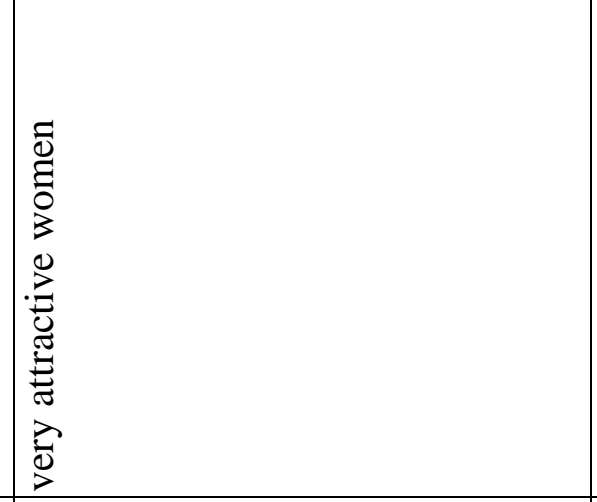 & 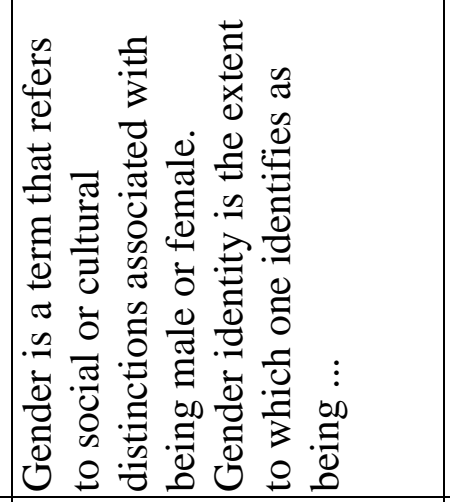 & 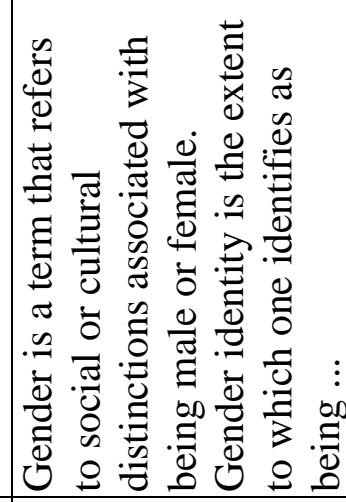 \\
\hline 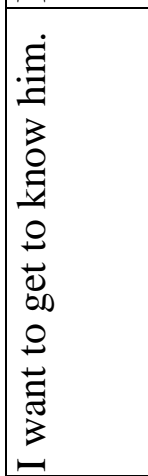 & 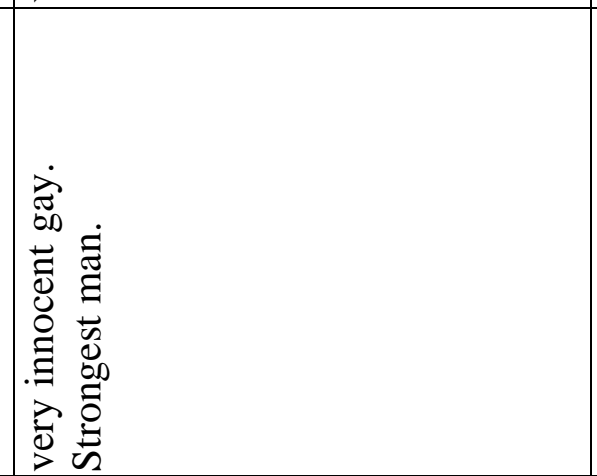 & 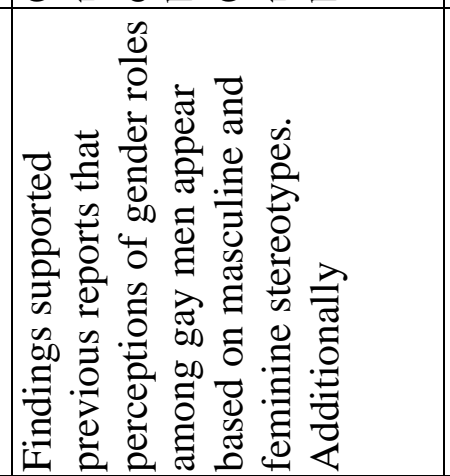 & 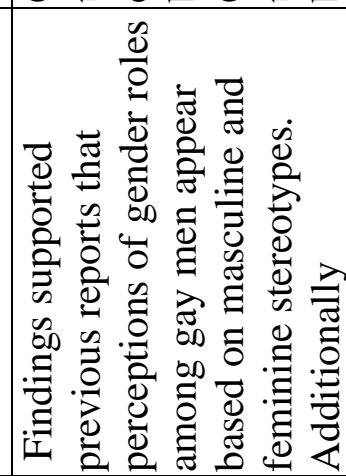 \\
\hline : & 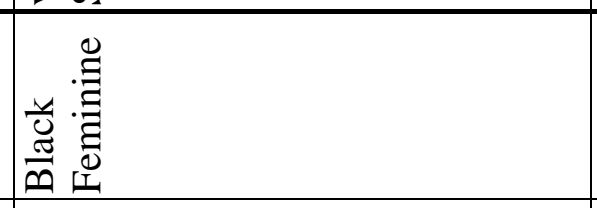 & 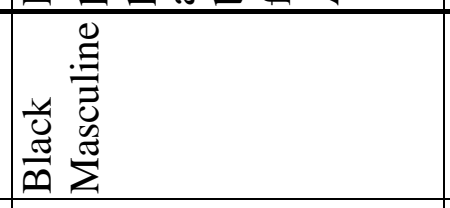 & 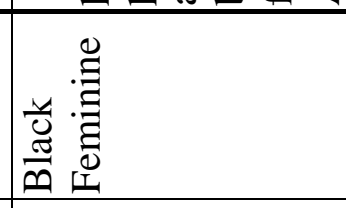 \\
\hline$\infty$ & $\infty$ & $\infty$ & ஓे \\
\hline
\end{tabular}




\begin{tabular}{|c|c|c|c|c|c|c|c|c|}
\hline 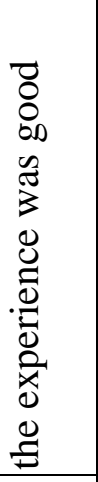 & 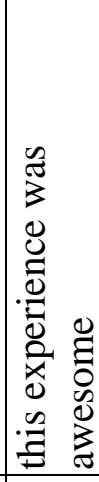 & $\begin{array}{l} \\
\stackrel{0}{0} \\
\check{Z}\end{array}$ & 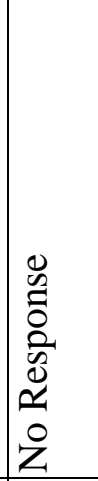 & & $\begin{array}{l}0 \\
\tilde{z} \\
z\end{array}$ & 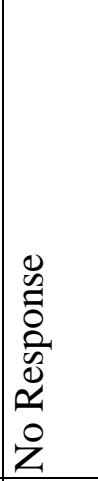 & 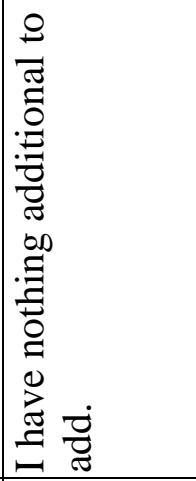 & 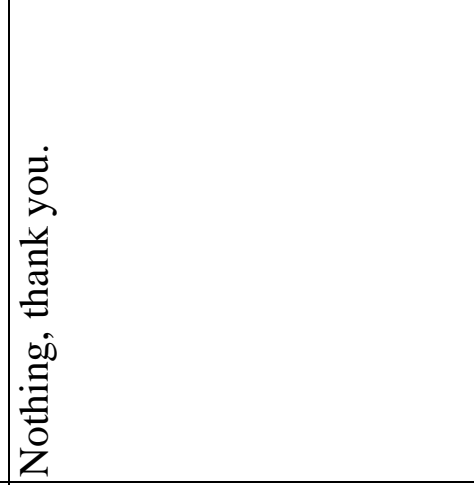 \\
\hline$\stackrel{\circ}{Z}$ & $\begin{array}{l}\infty \\
. \\
\Xi \\
\Xi \\
0 \\
Z \\
\end{array}$ & 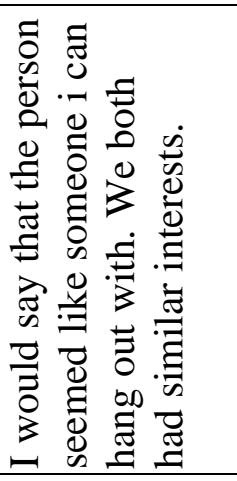 & 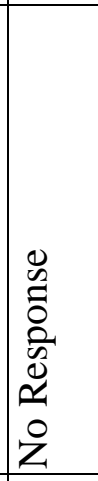 & 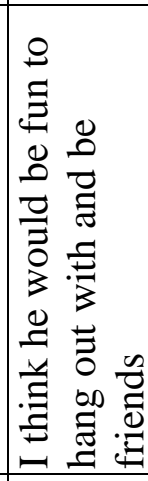 & 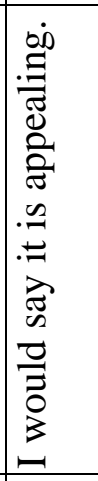 & 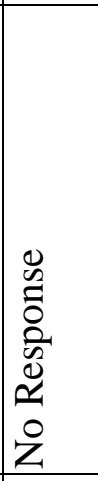 & 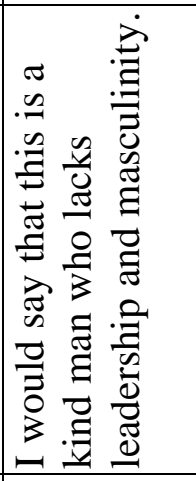 & 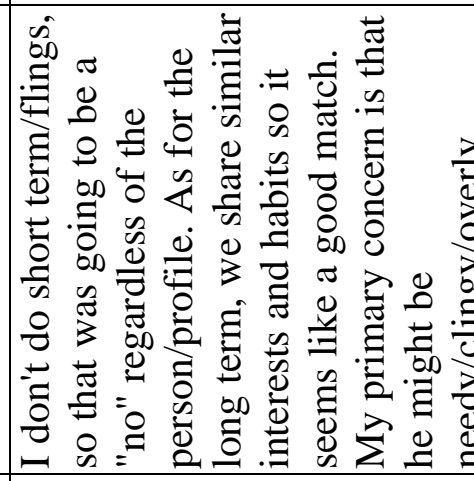 \\
\hline Z & Z & 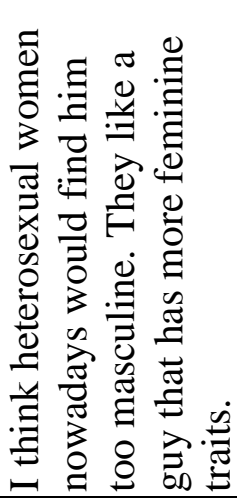 & 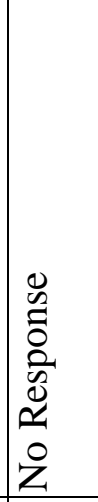 & 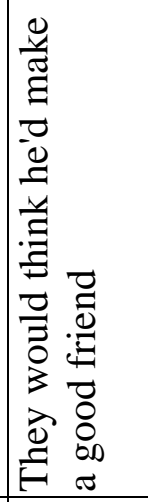 & 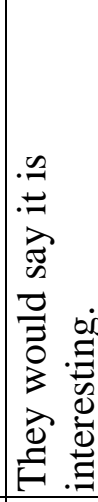 & $\begin{array}{l}0 \\
0 \\
0 \\
0 \\
0 \\
0 \\
0 \\
\alpha \\
0 \\
0 \\
z\end{array}$ & 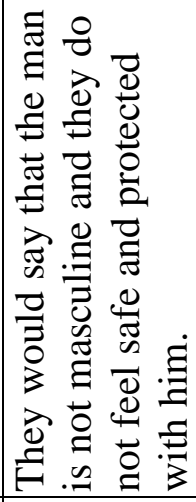 & 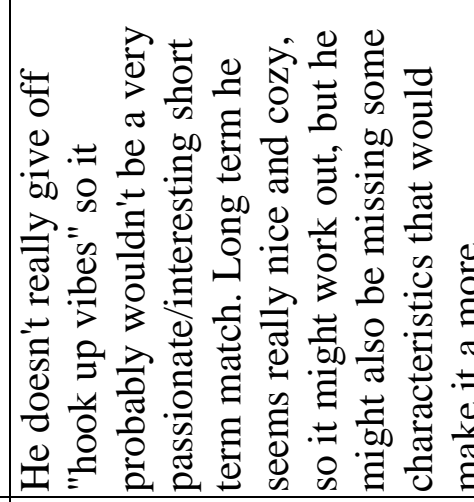 \\
\hline$\stackrel{\circ}{z}$ & Z & 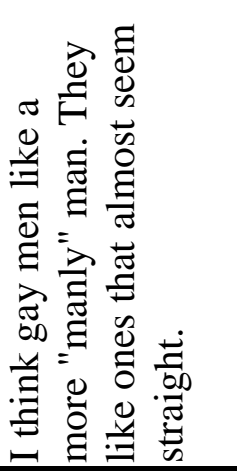 & 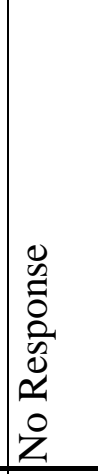 & 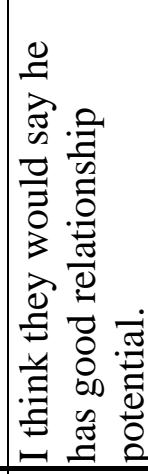 & 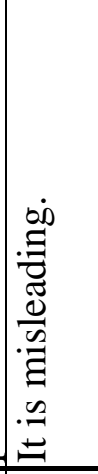 & 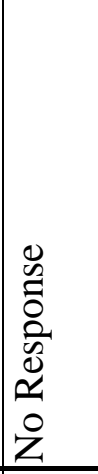 & 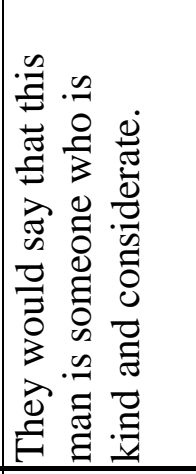 & 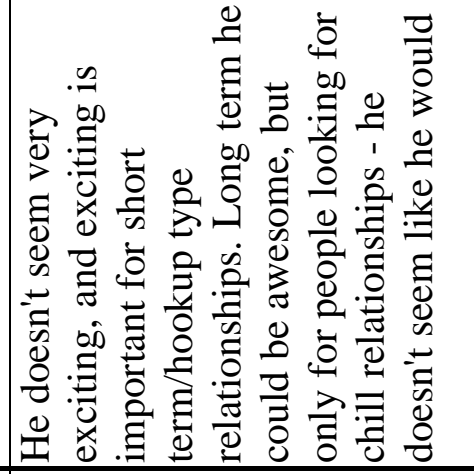 \\
\hline 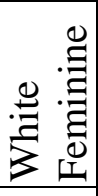 & 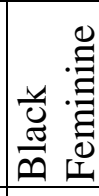 & 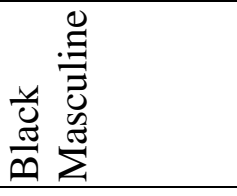 & 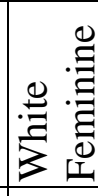 & 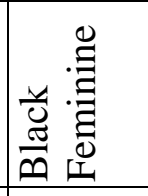 & 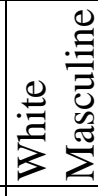 & 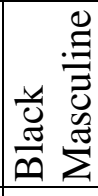 & 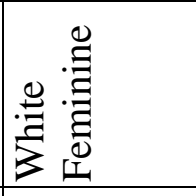 & 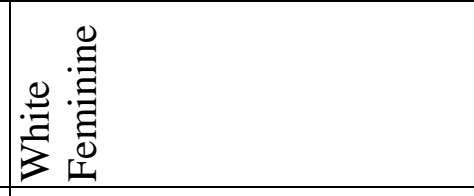 \\
\hline ๙ & $\bar{a}$ & ๙ু & ă & よ & $\curvearrowleft$ & ๙๐ & $\hat{a}$ & $\infty$ \\
\hline
\end{tabular}




\begin{tabular}{|c|c|c|c|c|c|c|c|c|c|}
\hline & 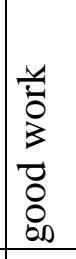 & $\begin{array}{l}\stackrel{\Xi}{\tilde{\Xi}} \\
\stackrel{g}{g}\end{array}$ & 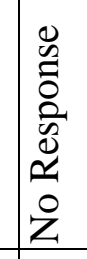 & 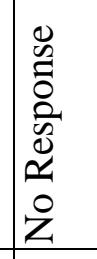 & 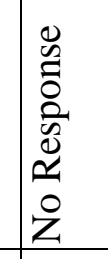 & 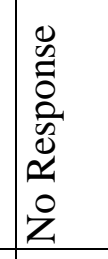 & 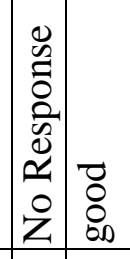 & $\mathbb{z}$ & 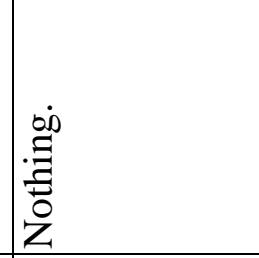 \\
\hline 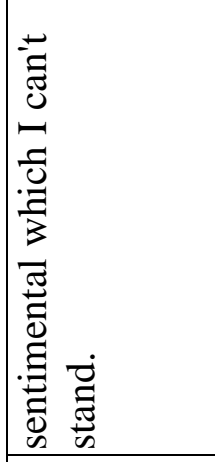 & 总 & 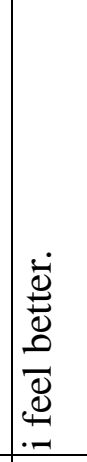 & 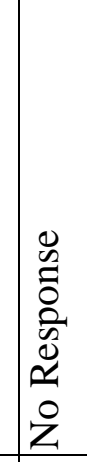 & 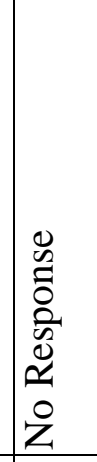 & 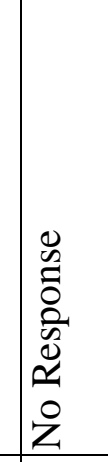 & 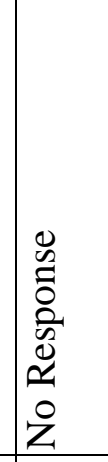 & 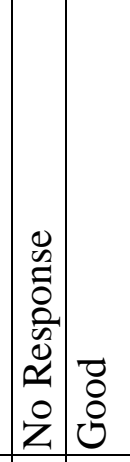 & 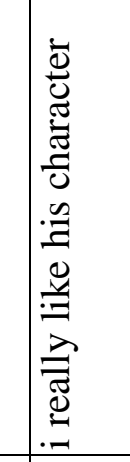 & 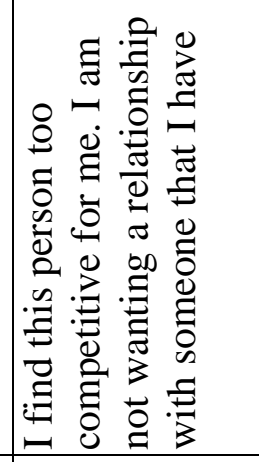 \\
\hline 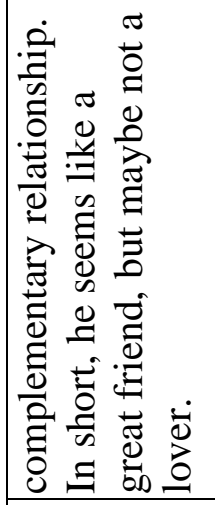 & 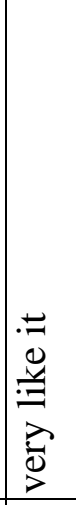 & 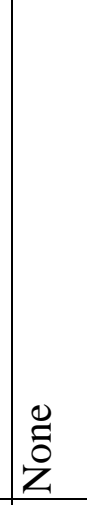 & 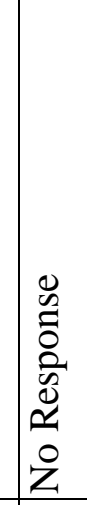 & 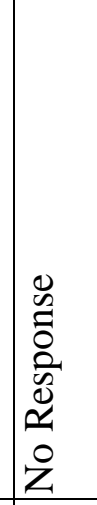 & 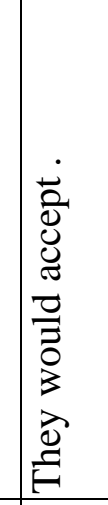 & 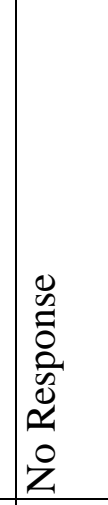 & 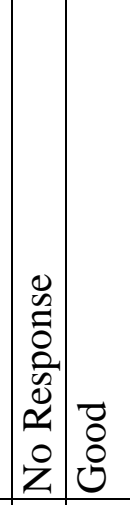 & 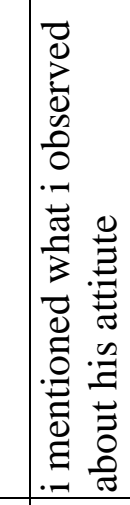 & 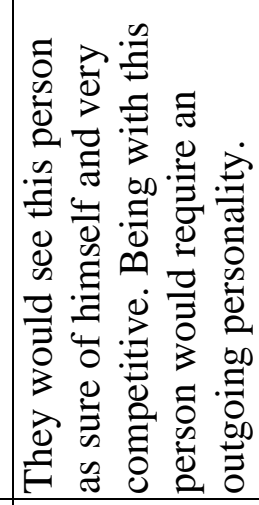 \\
\hline 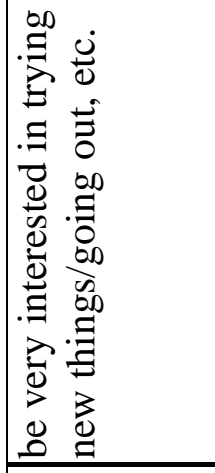 & 总 & 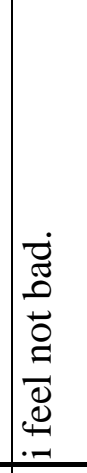 & 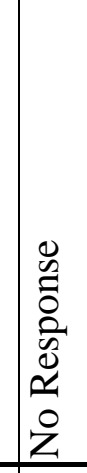 & 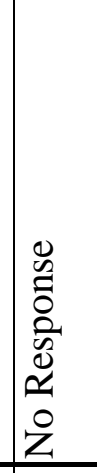 & $\begin{array}{l}0 \\
0 \\
0 \\
0 \\
\tilde{z} \\
\tilde{Q} \\
\tilde{z} \\
0 \\
z \\
\end{array}$ & 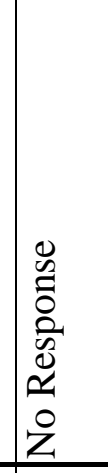 & 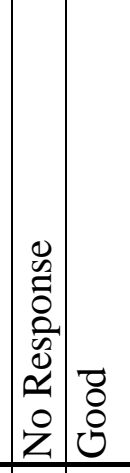 & 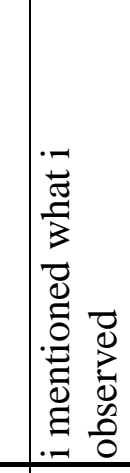 & 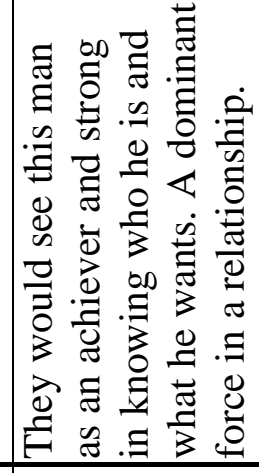 \\
\hline & & & & & : & 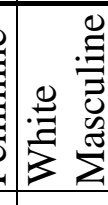 & 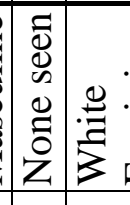 & 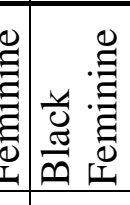 & 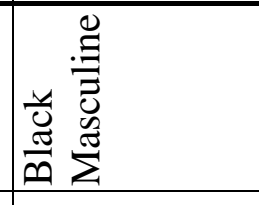 \\
\hline & 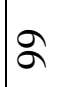 & 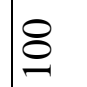 & $\overline{\underline{\sigma}}$ & $\stackrel{\mathrm{d}}{\varrho}$ & $\cong$ & $\stackrel{t}{\Xi}$ & $\cong$ & 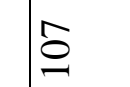 & $\stackrel{\circ}{0}$ \\
\hline
\end{tabular}




\begin{tabular}{|c|c|c|c|c|c|c|c|c|c|}
\hline & 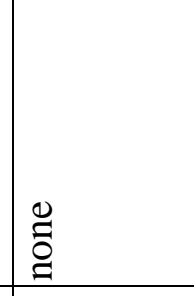 & 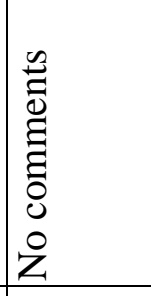 & 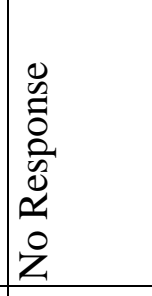 & 点 & $\stackrel{\Xi}{\Xi}$ & 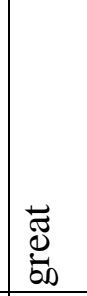 & 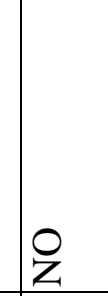 & 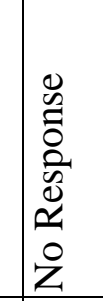 & 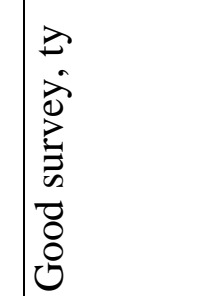 \\
\hline \multirow[t]{5}{*}{ 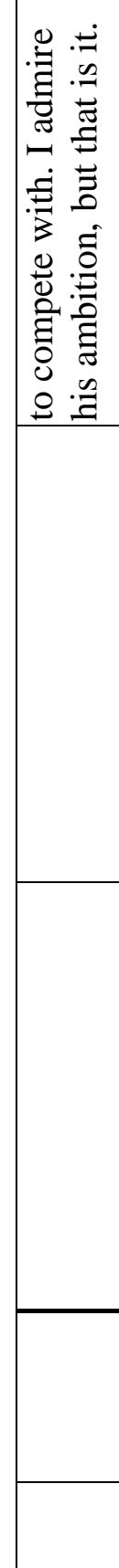 } & 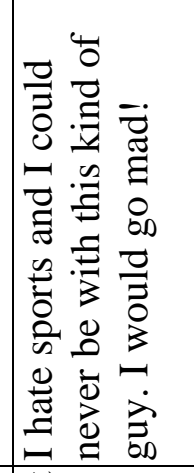 & 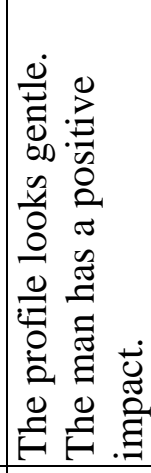 & 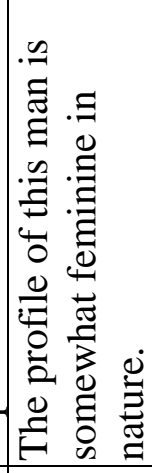 & 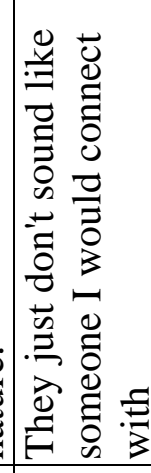 & 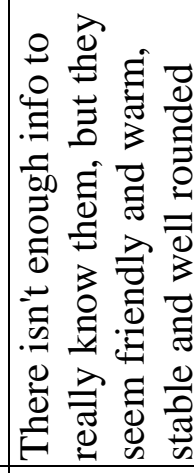 & 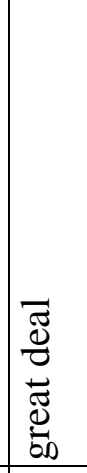 & 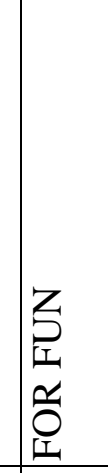 & 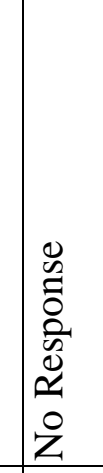 & 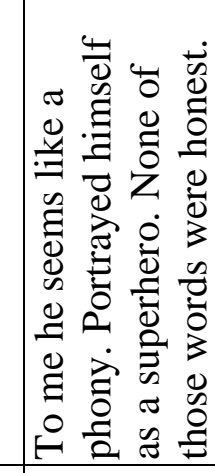 \\
\hline & 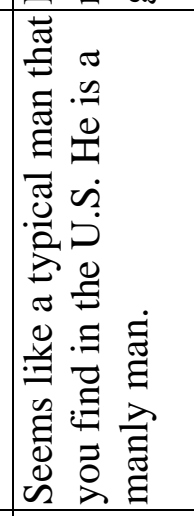 & 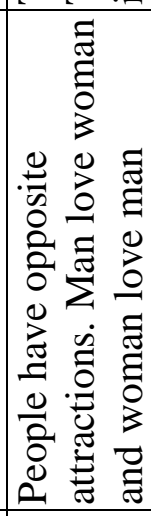 & 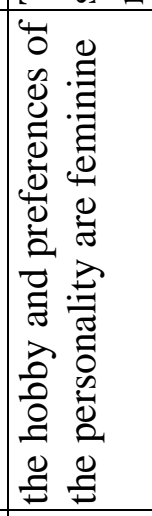 & 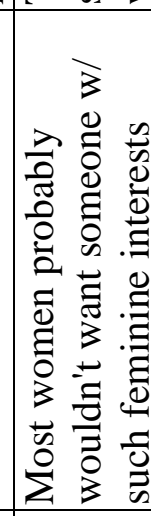 & 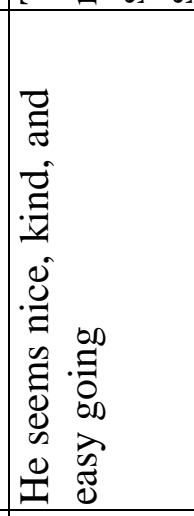 & $\begin{array}{l}\square \\
8 \\
0\end{array}$ & 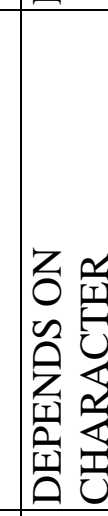 & 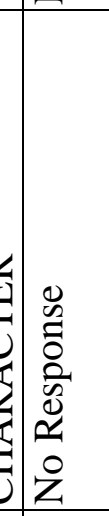 & 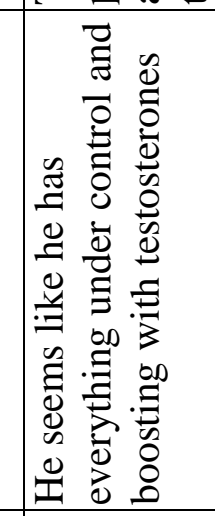 \\
\hline & 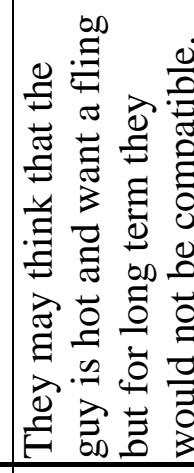 & 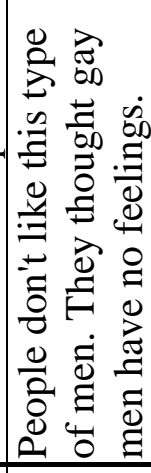 & 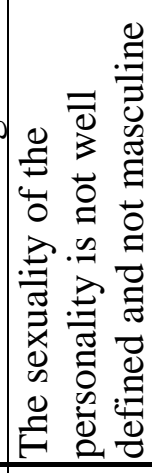 & 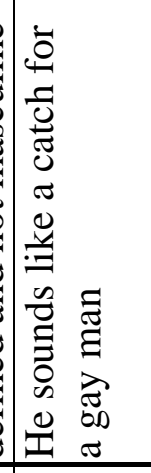 & 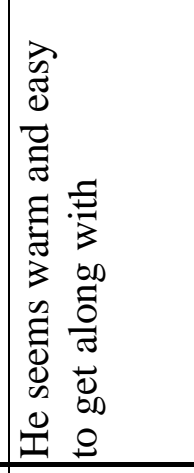 & 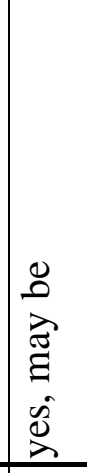 & 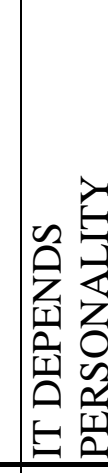 & 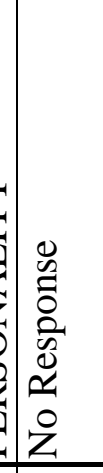 & 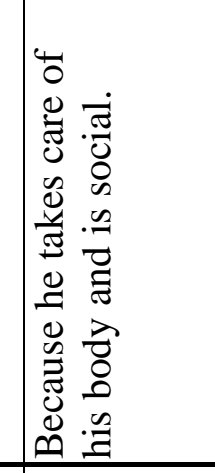 \\
\hline & 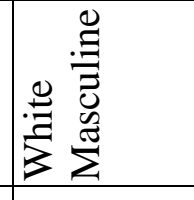 & 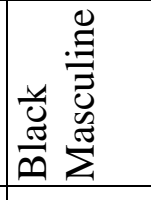 & 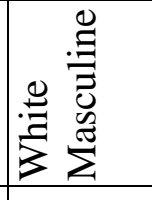 & 兽 & 量 & 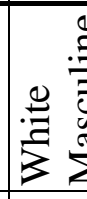 & 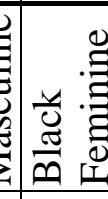 & 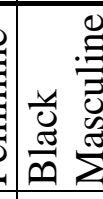 & 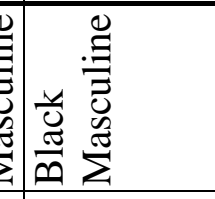 \\
\hline & $\stackrel{g}{g}$ & 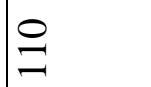 & $\Xi$ & $\cong$ & $\cong$ & 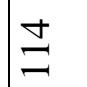 & $\stackrel{n}{\exists}$ & $\stackrel{\varrho}{=}$ & $\Xi$ \\
\hline
\end{tabular}




\begin{tabular}{|c|c|c|c|c|c|c|}
\hline & 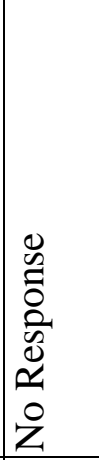 & $\stackrel{\Xi}{\Xi}$ & 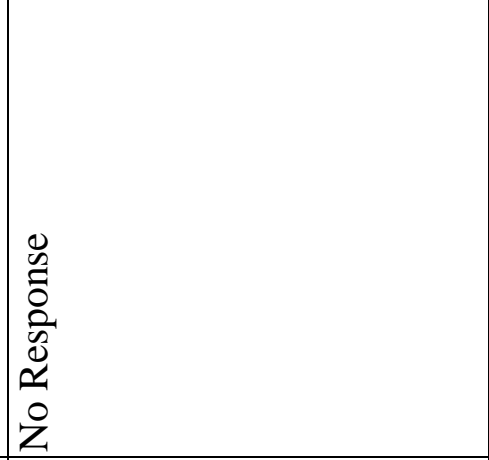 & $\Xi$ & 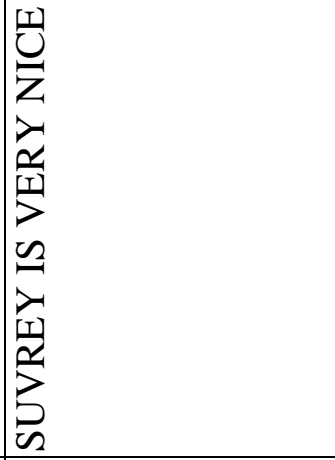 & 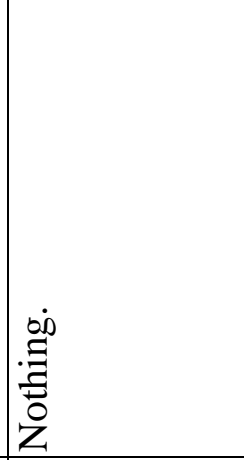 \\
\hline & 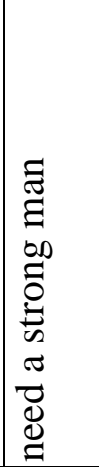 & 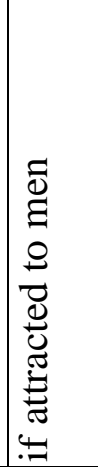 & 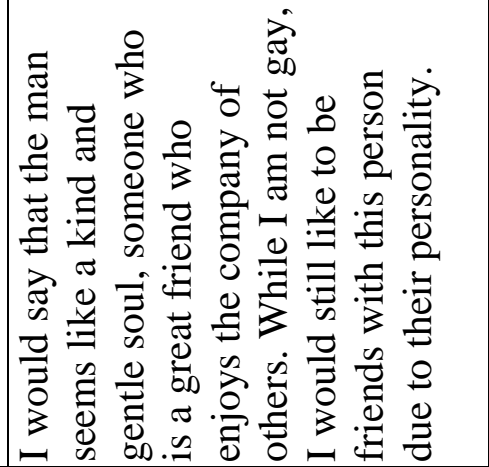 & 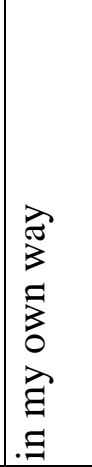 & 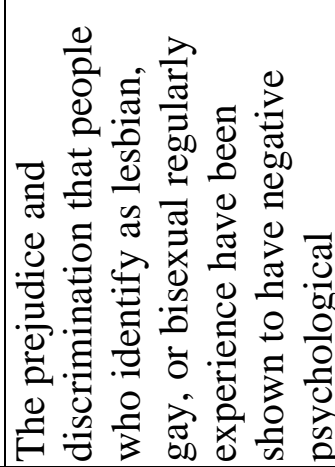 & 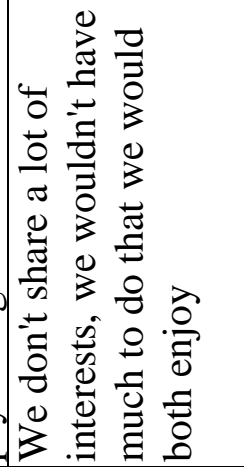 \\
\hline \multirow[t]{4}{*}{ 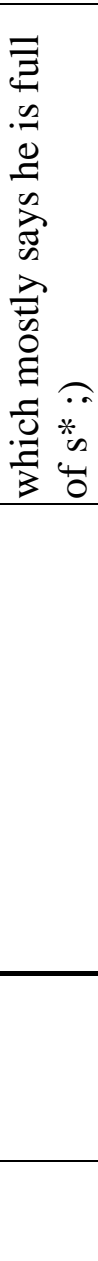 } & 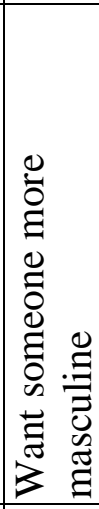 & 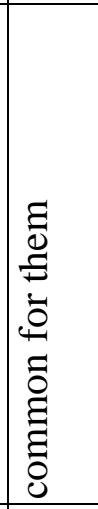 & 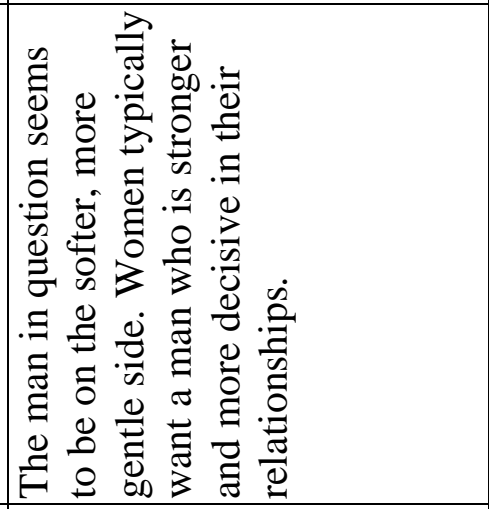 & $\begin{array}{l}\mathscr{0} \\
\frac{0}{0} \\
\frac{\pi}{0} \\
0 \\
0\end{array}$ & 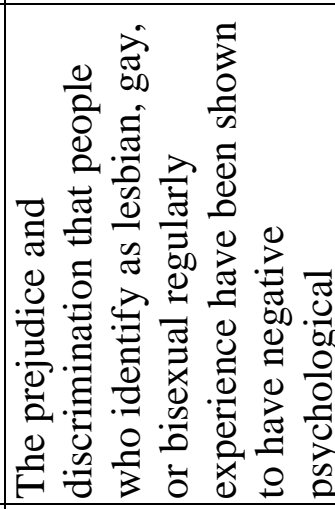 & 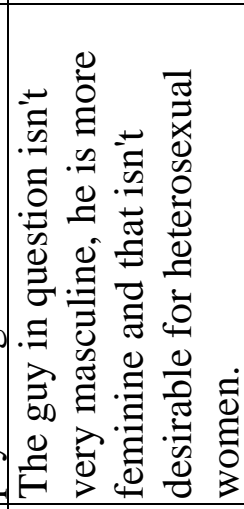 \\
\hline & 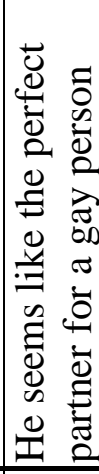 & 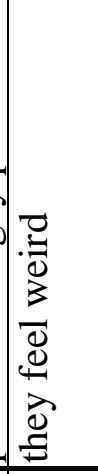 & 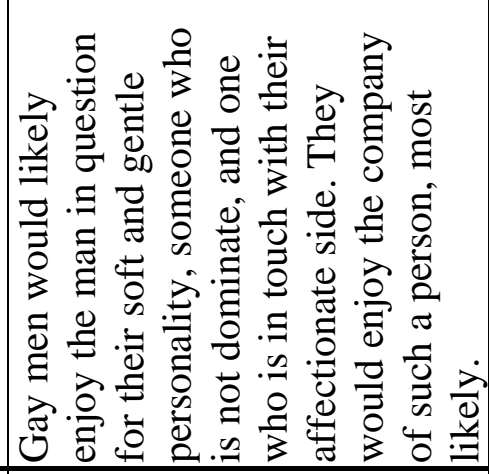 & 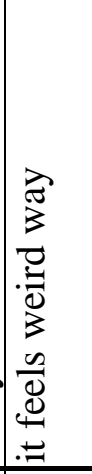 & 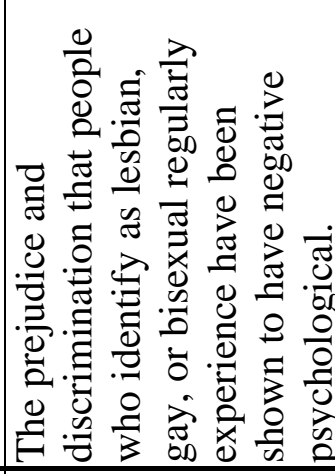 & 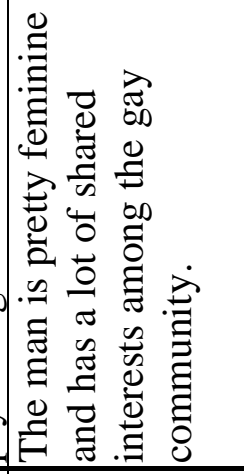 \\
\hline & 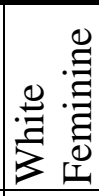 & 章 & : & 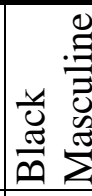 & 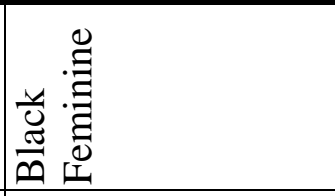 & : \\
\hline & $\stackrel{\infty}{=}$ & 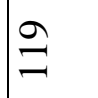 & 이 & $\bar{\beth}$ & ปี & 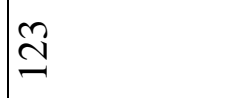 \\
\hline
\end{tabular}




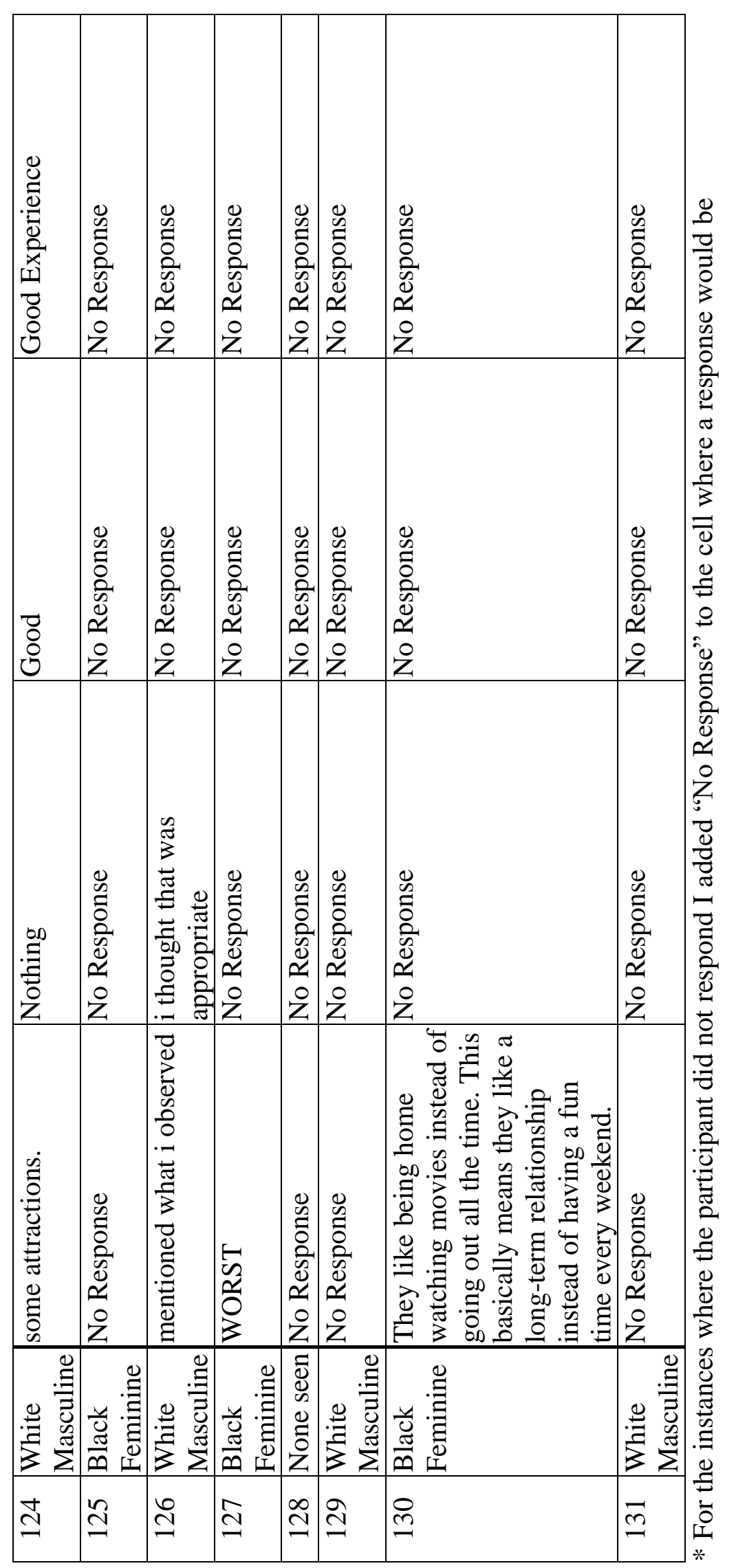


APPENDIX B: VIGNETTES

Vignette B-1. Vignette of a Black man with a masculine profile

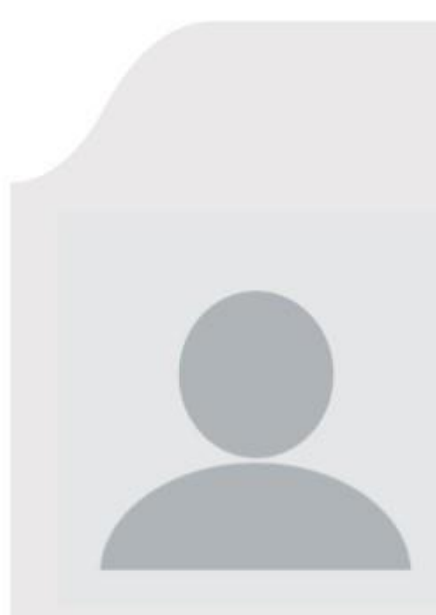

OCCUPATION:

Engineering

HOBBIES:

Sports

Videogames

\section{JOHN SMITH}

\section{RACE: BLACK}

\section{ABOUTME:}

I want to be successful, so I put the work in every day. I have big plans for my future and have the willpower to get it done. I' $m$ also competitive so get ready for someone who will challenge you haha.

\section{TYPICAL FRIDAY NIGHT:}

The best Friday night for me involves going to some local bars. I am an outgoing person, so I love to socialize and be around other people. When I can't go out, then I'll be spending my night gaming on my Playstation.

\section{SIX THINGS I CAN'T LIVE WITHOUT:}

1. Weight lifting

2. Coffee

3. My phone

4. My pets

5. TV

6. Pizza 
Vignette B-2. Vignette of a white man with a masculine profile

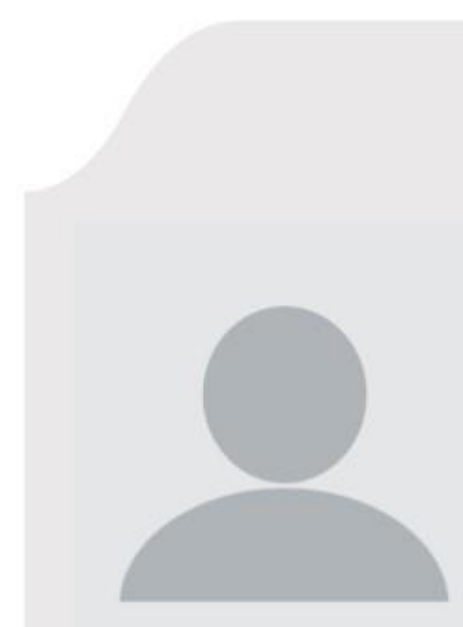

OCCUPATION:

Engineering

HOBBIES:

Sports

Videogames

\section{JOHN SMITH}

\section{RACE: WHITE}

\section{ABOUT ME:}

I want to be successful, so I put the work in every day. I have big plans for my future and have the willpower to get it done. I'm also competitive so get ready for someone who will challenge you haha.

\section{TYPICAL FRIDAY NIGHT:}

The best Friday night for me involves going to some local bars. I am an outgoing person, so I love to socialize and be around other people. When I can't go out, then I'll be spending my night gaming on my PlayStation.

\section{SIX THINGS I CAN'T LIVE} WITHOUT:

1. Weight lifting

2. Coffee

3. My phone

4. My pets

5. TV

6. Pizza 
Vignette B-3. Vignette of a white man with a feminine profile

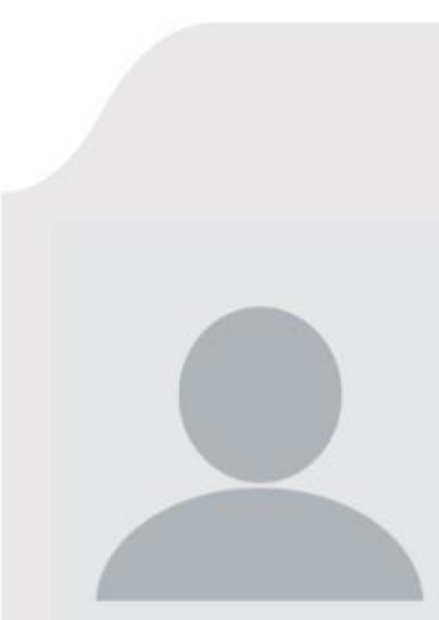

OCCUPATION:

Nursing

HOBBIES:

Cooking

Shopping

\section{JOHN SMITH}

\section{RACE: WHITE}

\section{ABOUT ME:}

I'm a sensitive person and I try to be kind each and every day. I think it's important to be charitable and loving when and where you can in life.

\section{TYPICAL FRIDAY NIGHT:}

The best Friday night for me involves staying at my home, inviting some friends over, and spending time on the couch with a good movie on. When no one is available, or I just need some time alone, then l'll just curl up with a good book.

\section{SIX THINGS I CAN'T LIVE WITHOUT:}

1. Crocheting

2. Coffee

3. My phone

4. My pets

5. TV

6. Pizza 
Vignette B-4. Vignette of a Black man with a feminine profile

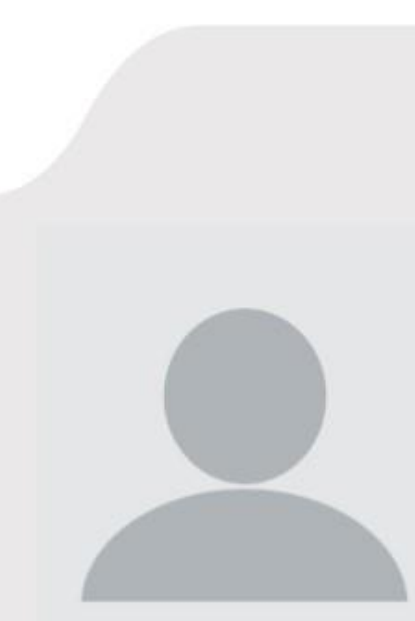

OCCUPATION:

Nursing

HOBBIES:

Cooking

Shopping

\section{JOHN SMITH}

\section{RACE: BLACK}

\section{ABOUT ME:}

I'm a sensitive person and I try to be kind each and every day. I think it's important to be charitable and loving when and where you can in life.

\section{TYPICAL FRIDAY NIGHT:}

The best Friday night for me involves staying at my home, inviting some friends over, and spending time on the couch with a good movie on. When no one is available, or I just need some time alone, then l'll just curl up with a good book.

\section{SIX THINGS I CAN'T LIVE WITHOUT:}

1. Crocheting

2. Coffee

3. My phone

4. My pets

5. TV

6. Pizza 